\title{
Mineral Mapping for Exploration: An Australian Journey of Evolving Spectral Sensing Technologies and Industry Collaboration
}

\author{
Thomas Cudahy \\ Commonwealth Scientific and Industrial Research Organisation (CSIRO) Mineral Resources, \\ 26 Dick Perry Avenue, Kensington, WA 6014, Australia; thomas.cudahy@c3dmm.com; Tel.: +61-407-662-369 \\ Academic Editors: Kevin Tansey, Stephen Grebby and Jesus Martinez-Frias \\ Received: 10 October 2016; Accepted: 16 November 2016; Published: 29 November 2016
}

\begin{abstract}
This paper describes selected results from over a dozen collaborative projects led by Commonwealth Scientific and Industrial Research Organisation (CSIRO) in Australia spanning a 30-year history of developments in satellite, airborne, field and drill core sensing technologies and how these can assist explorers to measure and map valuable mineral information. The exploration case histories are largely from Australian test sites and describe how spectral sensing technologies have progressed from early "niche creation" systems, such as the field PIMA-II (Portable Field Mineral Analyzer) and airborne Geoscan, HyMap ${ }^{\mathrm{TM}}$ and OARS-TIPS (Operational Airborne Remote Sensing - Thermal Infrared Profiling Spectrometer) systems and drill-core HyLogger ${ }^{\mathrm{TM}}$ systems, to the current expanding array of pubic and commercial mineral mapping sensors, including the ASTER (Advanced Spaceborne Thermal Emission and Reflectance Radiometer) satellite system which has acquired imagery spanning the entire Earth's land surface $\left(<83^{\circ}\right.$ latitude). These sensors are delivering voluminous spectral data from different parts of the visible to the thermal infrared (400 to $14,000 \mathrm{~nm}$ ) spectrum at different spectral, radiometric and spatial resolutions. Two critical exploration challenges are central to the case histories, namely: (i) can surface cover, such as vegetation, regolith or transported materials, be characterized and accounted for so that the target geology is accurately revealed; and (ii) does this revealed geology show evidence of alteration footprints to potential economic mineralization. Spectrally measurable minerals important to solving these challenges include white micas, kaolinite and garnets, with measurement of their respective physicochemistries being key. For example, kaolin disorder is useful for mapping transported versus weathered in situ materials, while the chemical substitution in white micas and garnets provide vectors to potential economic mineralization. Importantly, appropriate selection of the optimum sensor/data type for a given geological application depends primarily on the level of detail/accuracy of the mineral information required by the user. A major opportunity is to now harness the many sensor/data types and deliver to users consistent, accurate mineral information products, that is, creation of a number of valuable global mineral product standards. As part of this vision, CSIRO has been developing improved sensor/data calibration processes and information extraction methods that for example, unmix the target mineralogy from green and dry vegetation cover in remote sensing data sets. Emphasis to date has been on generating public spectral-mineral product standards, especially at ASTER's limited but geologically-valuable spectral resolution. The results are showing that scalable, global, three-dimensional (3D) mineral maps are achievable which will only improve our ability to more accurately characterize regolith and geological architecture, increase our understanding of formative processes and assist the discovery of new economic mineral systems.
\end{abstract}

Keywords: mineral mapping; exploration; alteration mineralogy; mineral system; multi-spectral; hyperspectral; remote sensing; geology; satellite; airborne; drill-core 


\section{Introduction}

Minerals are fundamental to the architecture of Earth and its formative geologic processes, including the development of economic resources. Sustainable exploration for these mineral resources is increasingly reliant on new technologies, including sensors operating from satellites, aircraft/drones, field-based and drill-core logging systems that measure reflectance and/or emission spectra across the electromagnetic spectrum between 400 and 12,000 nm (0.4 and $12 \mu \mathrm{m})$. This spectral information is sourced from only the top 1 to $100 \mu \mathrm{m}$ of a given target's surface [1] and requires either a suitable source of light (e.g., the Sun) or given sample's kinetic temperature to generate a spectrum that contains a myriad of spectral features that pertain to its composition. The related opportunity of value to the resources community is often called "mineral mapping" [2]. Mineral mapping technologies have potential significant value for explorers because: (i) it is physics-based, i.e., measurable and reproducible; (ii) it is easily validated through independent, quantitative measurements; (iii) it can provide spatially comprehensive, scalable coverage/data; (iv) it is a non-contact and non-destructive measurement; and (v) many process-diagnostic alteration and weathering minerals have specific spectral signatures.

The spectroscopy of minerals is based on decades of published research [3-20], which have highlighted those wavelength regions where specific minerals and mineral groups possess diagnostic features, including: (i) the Visible and Near-InfraRed (VNIR, 400 to $1000 \mathrm{~nm}$ ) — transition element-bearing oxides / oxydroxides (e.g., hematite and goethite) and minerals with rare earth elements (e.g., apatite and perovskite); (ii) the ShortWave InfraRed (SWIR, 1000 to $2500 \mathrm{~nm}$ )—hydroxyl-bearing dioctahedral silicates (e.g., kaolin, montmorillonite, muscovite, pyrophyllite) and trioctahedral silicates (e.g., talc, chlorite, actinolite-tremolite), carbonates (e.g., calcite, dolomite, magnesite) and sulfates (e.g., alunite, gypsum); and (ii) the Thermal-InfraRed (TIR, 7500 to 12,000 nm) -framework silicates such as quartz and feldspars (e.g., plagioclase $\mathrm{Na}-\mathrm{Ca}$ series of albite to anorthite as well as alkali feldspars such as microcline, orthoclase), pyroxenes (e.g., clinopyroxenes such as diopside and orthopyroxenes such as enstatite), garnets (e.g., Ca-poor Fe-Mn-Al chemical series almandine-spessartine-pyrope versus $\mathrm{Ca}$-rich $\mathrm{Fe}-\mathrm{Al}$ chemical series andradite-grossular), carbonates and silicates. Remote sensing of this diverse spectral-mineral information has been tackled by numerous workers [21-32].

The charter of the Commonwealth Industrial Research Organisation (CSIRO) is to conduct scientific research to assist Australian industry and to further the interests of the Australian community. To that end, CSIRO became involved in mineral mapping research and development in the seventies after the launch of the Earth Resources Technology Satellite 1 (ERTS-1). It was evident that this new technology had the potential to assist resource exploration, especially across the vast, remote and often environmentally/culturally sensitive Australian landscape. CSIRO established a strategy of building projects in collaboration with industry and government agencies, often through (supported by) the Australian Minerals Industry Research Association (AMIRA) [33] or government bodies such as Minerals and Energy Research Industry of Western Australia (MERIWA, now MRIWA) [34] and the National Collaborative Research Infrastructure Strategy National (NCRIS) Auscope [35]. This close association between CSIRO, industry and government has ensured that project outcomes were designed to benefit sponsors though it also sometimes meant that non-sponsors were restricted from gaining (timely) access to project results and that fewer journal papers were submitted for open publication. This is in part the impetus for this paper, especially as the confidentiality periods of many of these projects have since expired.

In addition to those sensors developed by CSIRO, the close connection between CSIRO and the resources sector has often attracted sensor development organizations to provide early access to their sensor data as well. The sensors/data covered in this paper reflect those worked on by the author and include: airborne Geoscan Mk II; field PIMA; airborne MIRACO ${ }_{2}$ LAS; airborne AMS (Airborne Multispectral Scanner); airborne OARS- TIPS; airborne HyMap ${ }^{\text {TM }}$, airborne SEBASS (Spatially Enhanced Broadband Array Spectrograph System), satellite ASTER, satellite Hyperion, satellite Worldview-3 (WV-3), airborne TASI-600 (Thermal Airborne Spectrographic Imager) and drill 
core HyLogger ${ }^{\mathrm{TM}}$. These sensors span not just different platforms but also different wavelength regions, spectral-spatial-radiometric resolutions and calibration procedures.

CSIRO's development/evaluation of these new sensors/data has often focused on two fundamental exploration challenges for the resource industry in Australia, namely: (i) can the nature of the regolith [36] and/or transported cover be characterized and mapped, i.e., does a given area/sample comprise transported materials such that an explorer must drill before sampling or does it comprise in situ materials such that an explorer can sample from the surface; and (ii) is there a mineral alteration footprint present that can be used to vector towards "hidden" ore? Both of these questions are now central to an Australian collaborative strategy between the public and private resources sector to tackle the challenge of mineral exploration through "cover" [37].

This paper presents selected sensor / geological results from a series of CSIRO collaborative projects extending from the late 1980s to the present, keeping within the theme of improving industry's ability to more accurately and efficiently "mineral map" the regolith and alteration footprints. The paper finishes up with a perspective of the current status of mineral mapping technologies and future opportunities and challenges.

\section{Spectral Sensing for Mineral Exploration-A Journey}

\subsection{AMIRA P243-Remote Sensing for Gold in Western Australia Project}

\subsubsection{Background}

The AMIRA P243 project began in the late 1980s during a gold exploration boom that coincided with the arrival of new sensors such as Landsat Thematic Mapper (TM) and SPOT (Systeme Probatoire d'Observation de la Terre) imaging satellites. The main challenge recognized by sponsors and the project team [38] was how these technologies could provide valuable information for gold exploration across deeply weathered environments such as the highly prospective (Au) Archaean Yilgarn Craton [36]. To help answer this question, the project focused on available remote sensing data sets, including NASA's airborne NS001 (Landsat TM simulator) and Thermal Infrared Multi-spectral Scanner (TIMS) as well as Landsat TM and SPOT (Geoscan was evaluated as part of the AMIRA P382 Project-see Section 2.2). The project also built spectral libraries of weathered samples from mineralized and background environments, with many of these samples being characterized for their geochemistry and mineralogy using other analytical methods. The reflectance spectra between 400 and $2500 \mathrm{~nm}$ were measured using a GER (Geophysical Environmental Research) IRIS Mark IV dual-beam spectrometer, which has a $\sim 12 \mathrm{~nm}$ spectra resolution. Samples were measured approximately $60 \mathrm{~cm}$ from the IRIS's optical head with a $1000 \mathrm{~W}$ quartz halogen light (1.5 m distance from sample/reference) providing the illumination. The reference panel was made from compacted polytetrafluoroethylene powder.

\subsubsection{Spectral-Mineral Regolith Characterization}

Processing of the airborne and satellite data using methods such as ratios [24], log-residuals [39], minimum-noise fraction [40] and decorrelation-stretch [41], generated colorful images that yielded greater discrimination information for regolith and geology mapping compared with conventional methods using aerial photography [42]. The complementary roles of the different wavelength regions were also evident though the wide bands of the multi-spectral remote sensing data meant that only broad mineral groups, rather than specific minerals, could be gauged, such as iron oxide content from SPOT and Landsat TM, "clays" from Landsat TM and NS001 and quartz sand from TIMS. In contrast, the field IRIS measurements highlighted how much more mineral information was available at higher spectral resolution [43]. For example, poorly-ordered kaolinite was found to be typical of well-drained soils and lateritic duricrust while well-ordered kaolinite is associated with weathered felsic and mafic saprock and mottled zone ( saprolite) (Figure 1a) [44], consistent with studies of lateritic terrains from West Africa [45]. The IRIS spectral measurements also revealed the development of white 
mica (e.g., muscovite) in saprock/saprolite over gold deposits (Figure 1a). White mica is a common K-metasomatic alteration product in sub-amphibolite facies Archaean ultramafic, mafic and felsic rocks [46]. The persistence of white mica up through the lateritic weathering profile is related to its relative (e.g., compared with chlorite) resistance to weathering. Thus, spectral detection of white mica in weathered ferromagnesian (mafic and ultramafic) rocks is a potential indicator/target for Archaean Au-related K metasomatism ("A" in Figure 1b). The challenge is separating this "alteration-related" white mica in weathered ferromagnesian rocks with "primary" white mica in alkali-rich felsic rocks, both of which can be mixed with kaolinite ("B" $n$ Figure 1b), which also absorbs in the same wavelength $2200 \mathrm{~nm}$ region.
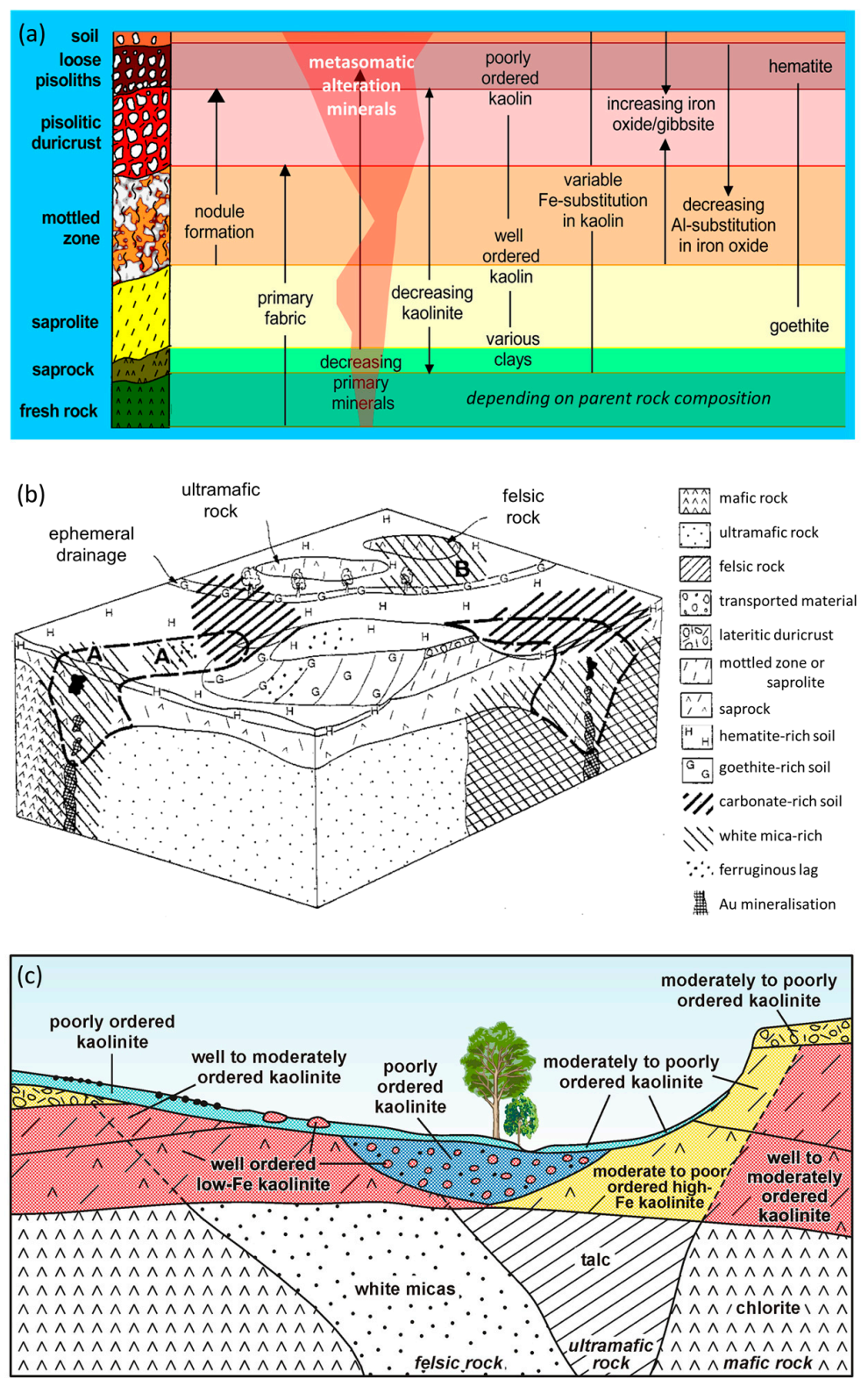

Figure 1. Schematic mineral-regolith models. (a) Cross section of a lateritic profile showing changes in a range of fresh rock and weathering minerals, including a zone of metasomatic alteration that persists from fresh rock through to the surface [44]; (b) Block diagram that includes different types of parent rock as well as erosional dissection through the lateritic profile. Areas of white mica in weathered mafic or ultramafic rocks ("A") are spectral-sensing exploration targets [44]; (c) Dissected lateritic profile over different parent rock types showing diagnostic variations in kaolin physicochemistry [47]. 


\subsubsection{Post P243 Developments}

The complexity of kaolin types and their association with different weathered rock types was not apparent during the P243 project because of the limited SWIR-2 (2000 to $2500 \mathrm{~nm}$ ) spectral resolution of the IRIS field spectrometer $(\sim 12 \mathrm{~nm})$. By 1992 a new field spectrometer developed by CSIRO, called the PIMA-II (Portable Infrared Mineral Analyzer), was in the process of being commercialized by Integrated Spectronics Pty. Ltd. (ISPL). The PIMA-II has a SWIR-2 spectral resolution of $\sim 4 \mathrm{~nm}$ enabling the recognition and measurement of: (i) three outer hydroxyl kaolin absorption bands at 2160, 2175 and $2185 \mathrm{~nm}$, which are of variable intensity depending on the kaolin mineral type and its disorder (crystallinity) [47]; (ii) the kaolin group's inner hydroxyl absorption band at $2205 \mathrm{~nm}$ having a constant $18 \mathrm{~nm}$ width (full width at half height or FWHH); and (iii) a variable, weaker absorption at $\sim 2240 \mathrm{~nm}(\sim 20 \mathrm{~nm} \mathrm{FWHH})$ related to the degree of Fe (and/or Mg) substitution in the kaolin lattice (up to $3 \%$ ) [48,49].

Importantly, the intensity of the kaolin $2240 \mathrm{~nm}$ feature, when linked with a well-developed kaolinite absorption at $2205 \mathrm{~nm}$, can be used as a gauge for parent rock composition [47]. For example, weathered ferromagnesian (intermediate, mafic and ultramafic) rocks have high levels of Fe and/or $\mathrm{Mg}$ substitution in kaolin (i.e., detectable $2240 \mathrm{~nm}$ feature) whereas weathered felsic materials are relatively poor (i.e., little/no development of the $2240 \mathrm{~nm}$ feature) (Figure 1c).

Mixing of white mica with kaolinite in weathered rocks can be spectrally gauged through broadening of the $2200 \mathrm{~nm}$ absorption FWHH [47]. This is because white mica has an average $2200 \mathrm{~nm}$ FWHH of $\sim 30 \mathrm{~nm}$ such that broadening of the $2205 \mathrm{~nm}$ FWHH beyond that expected of kaolin's $>18 \mathrm{~nm}$ can be explained by a mixing with white mica [47].

Recognition of a combined $2240 \mathrm{~nm}$ Fe-kaolin feature with broadening of the kaolin $2205 \mathrm{~nm}$ inner hydroxyl absorption (as well as a $2160 \mathrm{~nm}$ feature) represents potential K-metasomatizm of deeply weathered ferromagnesian rocks and thus an exploration target (Figure 1a,b). Similarly, spectral detection of white mica, together with other primary (or alteration) minerals diagnostic of ferromagnesian rocks (e.g., amphibole, chlorite, talc), is another exploration opportunity (Figure 1a).

Finally, poorly-ordered kaolin is typically developed over weathered ultramafic rocks and transported materials (Figure 1c) [47,50]. That is, spectral measurement of kaolin disorder can be used to assist mapping transported versus weathered in situ materials, which was a major focus for the Kalgoorlie and Rocklea Inlier projects (see Sections 2.9 and 2.12.2, respectively).

\subsection{AMIRA P382 Project-Mineral Mapping with Spectrally Processed Geoscan Mk II Scanner Data}

\subsubsection{Background}

During the 1980s, CSIRO and Carr Boyd Minerals Limited recognized that multi-spectral sensors such as Landsat TM were essentially being designed to map green vegetation and not mineral information required by explorers. To address this problem, the airborne Geoscan systems were developed with the Geoscan Mk II comprising 24 spectral bands across the VNIR-SWIR-TIR. Geoscan represented the first commercial remote sensing system designed specifically for resource exploration [51,52]. By 1990, Geoscan was operating worldwide with success, including the discovery of the Hadleigh Castle gold deposit in Queensland. Some parts of the exploration industry though were keen to receive an independent assessment of this system which led to the establishment of the AMIRA P382 project in 1991. The P382 project focused on two geological test sites, namely Coppin Gorge in Western Australia and Olary in South Australia [53].

The project's final report emphasized the need for improved calibration measures if reliable mineral information is to be routinely generated, especially: (i) 12-bit quantization of the data to negate the need for operator adjustments of the data's dynamic range during acquisition); (ii) blackbody calibration of the TIR module; (iii) routine wavelength calibration; (iv) routine collection of a dark current imagery; and if possible (v) isolate and remove the different forms of systematic instrument noise apparent in all modules [54]. Without these in place, the project team was required to implement 
a series of noise removal and calibration processes before applying a variation of Log Residuals [39], called here KWIK residuals, to generate apparent reflectance VNIR-SWIR imagery. KWIK residuals is a method based on normalization with respect to pixel and band means and requires a sensible choice of region-of-interest (ROI) for estimating a likely scene estimate for a "flat" spectrum, which in this study was the whole Geoscan image to avoid a single material dominating the shape of all KWIK residual spectra. A comparable calibration process was not available for the TIR module such that a decorrelation-stretch method [41] was applied to the noise-cleaned data to enhance spectral-emissivity contrast, albeit with significant uncorrected kinetic temperature (as well as instrument effects) remaining, evident by topographic variations (Figure $2 b$ ).

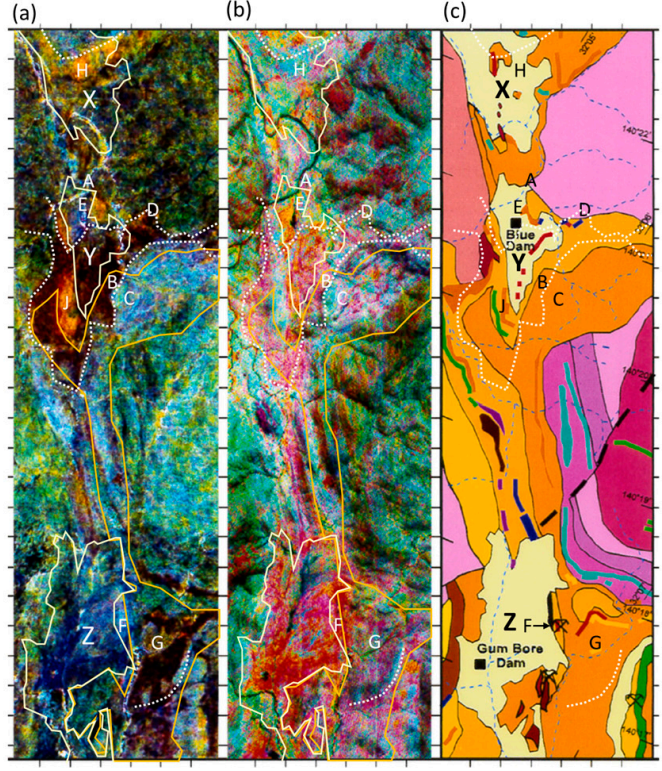

RGB KWIK 14:15:18 RGB D-stretch 19:21:23 Published 50K geology $(2180: 2224: 2358 \mathrm{~nm}) \quad(8600: 9660: 10710 \mathrm{~nm})$
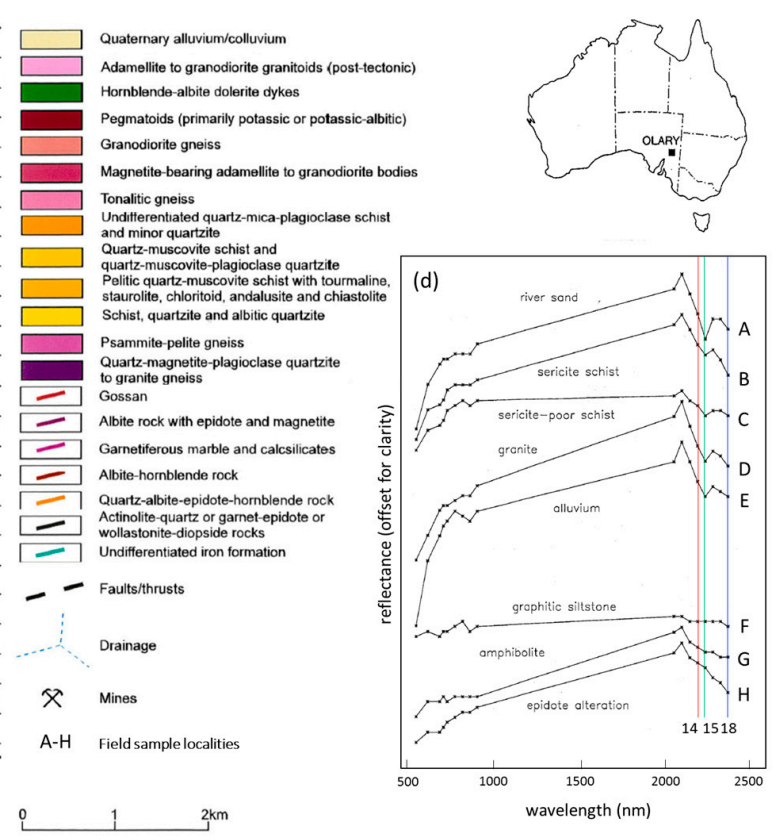

Figure 2. Airborne Geoscan Mk II results ( 1992) for Olary, South Australia (scene center approximately $-32.0981^{\circ}$ latitude $140.3228^{\circ}$ longitude). (a) KWIK residual RGB color composite of SWIR bands 14 (2180 nm): 15 (2224 nm): 18 (2358 nm); (b) Inverted de-correlation stretch RGB color composite of TIR bands 19 (8600 nm): 21 (9660 nm): 23 (10,710 nm); (c) Published 1:50,000 scale geology plus legend; (d) Selected Geoscan Mk II KWIK residual pixel-spectra from field sites A-H.

\subsubsection{Updating Geology-Regolith Maps}

If the data are accurately reduced to reflectance, then a pixel-normalization method such as KWIK residuals will generate images that appear flat, lacking topographic (sun-illumination) information. The Olary results (Figure 2a) show this to be the case, especially when compared with the uncalibrated decorrelation-stretch TIR image (Figure $2 b$ ) confirming that the pre-processing was effective.

The KIWK residual color composite image of Geoscan bands 14, 15 and 18 (Figure 2a) shows that three areas of published Quaternary alluvium/colluvium (Figure 2c) have different spectral-mineral signatures, with area: $X$ being yellow; $Y$ being red; and $Z$ being blue. From a mineral spectroscopy perspective, these three colors indicate that: area $X$ is a tri-octahedral silicate mineral (relative absorption @ $2358 \mathrm{~nm}$ ) such as epidote and/or amphibole; Y is white mica rich (relative absorption @ $2224 \mathrm{~nm}$ ); and $\mathrm{Z}$ is kaolin rich (relative absorption @ 2180 and $2224 \mathrm{~nm}$ ).

A selection of KIWK residual pixel-spectra (A to $\mathrm{H}$ in Figure 2a,b,d) show recognizable mineral signatures consistent with this spectral-mineral interpretation. For example, pixel spectra from red areas near $Y$ (Figure 2a) of alluvium/colluvium and neighboring mapped granite and schist/quartzite (A, B and D respectively in Figure 2c,d) show relatively intense absorption at $2224 \mathrm{~nm}$ (band 15) and to 
a lesser degree at $2358 \mathrm{~nm}$ (band 18) consistent with white mica's primary and secondary absorptions at $\sim 2200$ and $2350 \mathrm{~nm}$, respectively. In contrast, pixel spectra from blue/cyan areas near Z (Figure 2a) over alluvium $(Z)$ and schist/quartzite (C and J respectively, Figure 2c,d) show relatively weaker absorption at 2224 and $2358 \mathrm{~nm}$ but stronger absorption at $2160 \mathrm{~nm}$ consistent with the presence of kaolin.

Even though the Geoscan KWIK residual pixel spectra do not show clear evidence of a trioctahedral silicate absorption band in the 2300 to $2330 \mathrm{~nm}$ region (artefact either of the KWIK residual method and/or a lack of a Geoscan spectral band $>2354 \mathrm{~nm}$ ) related to amphibole and/or epidote in the published geological mapping (e.g., quartz-albite-epidote-hornblende rock in Figure 2c), the yellow color in Figure 2a is consistent with this mineralogy. This "yellow" trioctahedral silicate signature (Figure 2a) is well developed over mapped alluvium-colluvium at X (Figure 2a,c). Field investigation showed that this area comprised an extensive pediment of epidote rock float that terminated mid-slope (white dotted line near $\mathrm{H}$ ) indicating that the basement geology is close/at surface. That is, the published map of the boundaries of alluvium/colluvium, as well as the provenance of this alluvium/colluvium can be updated using the remotely sensed mineral information. Furthermore, recognition of epidote and white mica cross-cutting stratigraphy and persisting through transported materials are potentially important alteration indicators for explorers.

\subsubsection{Project Postscript}

Geoscan's multi-spectral bands enabled mapping of "broad" mineral information, such as kaolin versus muscovite versus epidote/amphibole-information that is not available from Landsat TM. However, measuring and mapping more specific mineral information requires many more spectral bands that are well calibrated and with high signal-to-noise (SNR) (see "hyperspectral" systems such as HyMap ${ }^{\mathrm{TM}}$ in Section 2.9). Nevertheless, the integrated VNIR-SWIR-TIR design of Geoscan is a powerful one for explorers as it delivers a wide range of mineral group information, including: (i) propylitic (minerals such as chlorite, amphibole, epidote which have absorption $2300 \mathrm{~nm}$ region); (ii) phyllic (white mica with relatively symmetric absorption $2200 \mathrm{~nm}$ ); (iii) advanced argillic (kaolinite, dickite, alunite and pyrophyllite with absorption $2165 \mathrm{~nm}$ ); (iv) silicic (quartz/chalcedony with features at $8625 \mathrm{~nm}$ ); (v) skarn (garnet with features in the 10,800 nm region); (vi) carbonate (calcite, dolomite with features at 11,200 $\mathrm{nm}$ and $2300 \mathrm{~nm}$ regions); (vii) iron oxides and/or gossans (hematite, goethite and related hydrated forms with features in 550-1500 nm region); and (viii) iron oxidation state (ferric versus ferrous silicates (actinolite, chlorite) and carbonates (ankerite, siderite) with broad absorption in the 1000-1600 nm region. A similar multi-spectral, integrated VNIR-SWIR-TIR configuration to that of Geoscan was later used for the satellite ASTER system [55], which has since become the standard remote sensing tool for the resources industry.

\subsection{MIRACO ${ }_{2}$ LAS Project-Airborne, Active Hyperspectral TIR Profiling}

\subsubsection{Background}

CSIRO's airborne MIRACO 2 LAS project began in the mid-1980s and was unusual because it was strategically funded by CSIRO with no industry support until the first geological trials in 1992. The original aim of the project was to establish whether an airborne active $\mathrm{CO}_{2}$ laser, rapidly scanning across $\sim 100$ wavelengths between 9200 and 11,200 nm (i.e., within the TIR) in line-profile mode (i.e., not imaging) and from a flying height of $\sim 400 \mathrm{~m}$, could provide sufficient SNR to deliver measurable silicate mineral (e.g., quartz, feldspar, garnet, pyroxene) spectral signatures. At that time, it was a challenge to achieve sufficient SNR from a remote, passive, hyperspectral TIR system, combined with the inherent problem of down-welling radiance which dampens mineral emissivity features as sky temperature approaches the land surface temperature. An active system negates these effects.

The design and operation of MIRACO ${ }_{2}$ LAS is described by [56] while MIRACO $\mathrm{MAS}_{2}$ data validation, reduction methodology and geological results are provided by [57]. The first geological trails of the MIRACO ${ }_{2}$ LAS system were in collaboration with the Japanese government agency ERSDAC 
(Earth Remote Sensing and Data Analysis Centre, later called Japan Space Systems) and included test sites in the Flinders Ranges of South Australia (e.g., Mount Fitton) and Broken Hill in New South Wales (Figure 3) [57]. Minerals targeted at these test sites included species of carbonates (dolomite and magnesite), garnets (almandine and spessartine) and feldspars (albite and microcline). Pyroxenes were also aimed for but not available/evident at these areas (see Section 2.4).
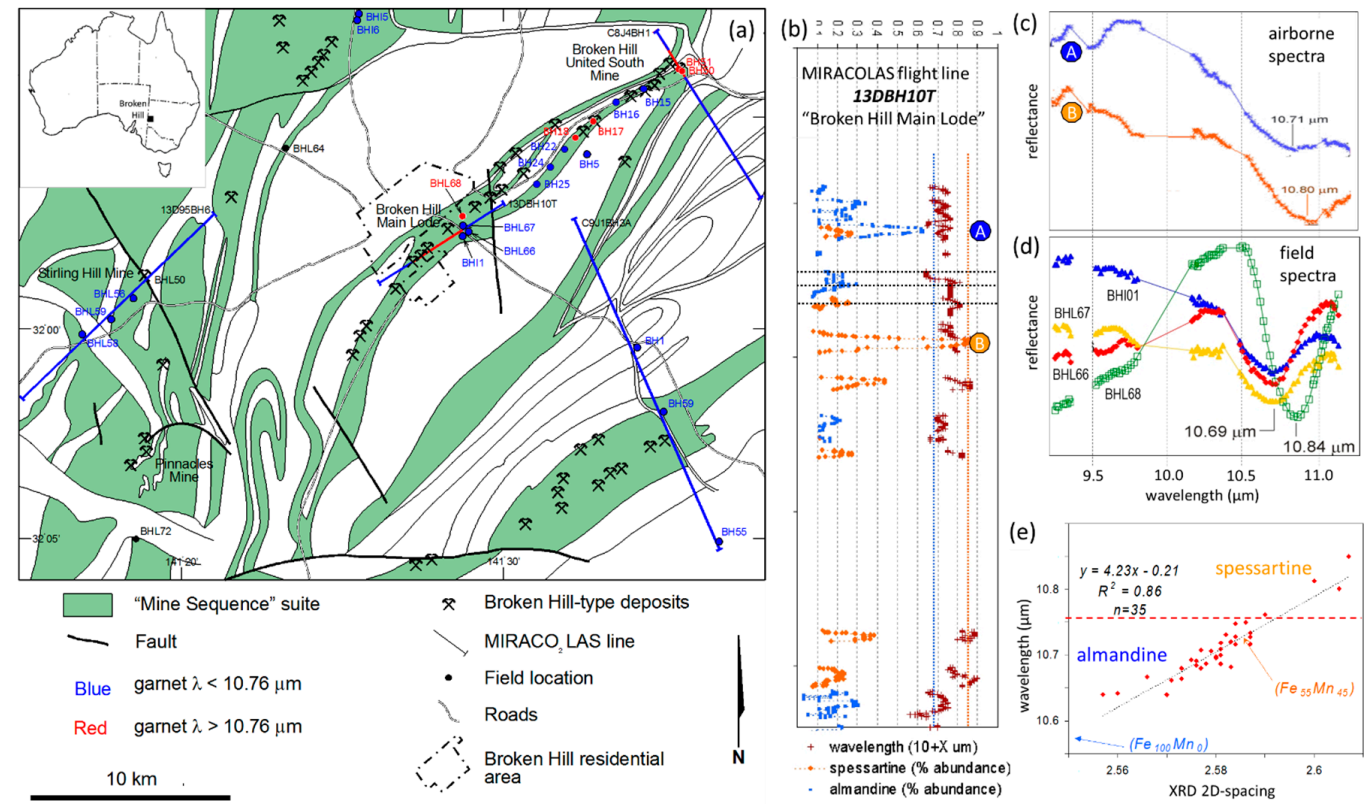

Figure 3. Airborne MIRACO 2 LAS results ( 1992) for the Broken Hill area, New South Wales, Australia. (a) Map of the distribution of Broken Hill style base metal deposits and their Mine Sequence Suite host rocks (green) [57], together with field sample locations and the tracks of airborne MIRACO ${ }_{2}$ LAS surveys which have both been color-coded with respect to garnet TIR reflectance trough wavelength. Scene center is approximately $-31.9669^{\circ}$ latitude $141.44134^{\circ}$ longitude; (b) Segment of MIRACO ${ }_{2}$ LAS flight-line "13DBH10T" from over the Broken Hill Main lode open pit and surrounding areas and processed to show the "unmixed" proportion of almandine (blue) and spessartine (orange) garnets as well as the wavelength position of the garnet reflectance trough at approximately $\sim 10,700 \mathrm{~nm}$ (10.7 $\mu \mathrm{m}$; brown); (c) MIRACO ${ }_{2}$ LAS pixel spectra of almandine-rich (A; reflectance trough at 10,700 $\mathrm{nm}$ $(10.71 \mu \mathrm{m}))$ and spessartine-rich (B; emissivity peak at 10,800 $\mathrm{nm}(10.80 \mu \mathrm{m})$ areas shown in $(\mathbf{b}))$; (d) Laboratory $\mathrm{CO}_{2}$ laser spectra of garnet-bearing field surface samples-field localities shown in (a); (e) Scatter-gram of the positions of the laboratory X-ray Diffraction d-spacing peak at 2.58 Angstrom units $\left(10^{-8} \mathrm{~cm}\right)$ (garnet $420 \mathrm{hkl}$ peak) and laboratory $\mathrm{CO}_{2}$ laser reflectance trough at 10,700 $\mathrm{nm}(10.7 \mu \mathrm{m})$.

The results described here focus on the hyperspectral TIR measurement and mapping of the Fe-Mn chemistry of Ca-poor garnets (almandine to spessartine) in the Broken Hill area (Figure 3). These garnets developed during high-grade metamorphism (andalusite to granulite facies) with most being Fe-rich (almandine). However, garnet composition becomes Mn-rich (spessartine) near strata-bound $\mathrm{Pb}-\mathrm{Zn}-\mathrm{Ag}$ mineralization, especially in the Mine Sequence suite that comprises quartz-feldspathic gneiss, quartz-gahnite and garnet-quartz rocks [58]. A more detailed account of the Broken Hill geology is given in Section 2.11.1.

\subsubsection{Garnet Chemistry Alteration Footprints}

Selected laboratory $\mathrm{CO}_{2}$ laser TIR spectra of garnet-bearing samples from across the Broken Hill block (Figure 3d) show variations in wavelength of the reflectance minimum near 10,700 $\mathrm{nm}$ that correlates with the position of the X-ray Diffraction (XRD) d-spacing near $\sim 2.58$ Angstrom units $\left(10^{-8} \mathrm{~cm}\right)$ for the garnet $420 \mathrm{hkl}$ peak (Figure 3e). There is an approximate $200 \mathrm{~nm}$ spectral shift $(10,600$ 
to $10,800 \mathrm{~nm}$ ) between the almandine and spessartine endmembers. A change in garnet $\mathrm{Fe} /(\mathrm{Fe}+\mathrm{Al})$ number (Fe number) of $<0.1$ corresponds to a $\sim 20 \mathrm{~nm}$ wavelength shift in the TIR absorption minimum, which in theory should be detectable given the spectral resolution of $\mathrm{MIRACO}_{2} \mathrm{LAS}$.

Two examples of MIRACO $_{2}$ LAS pixel spectra are presented in Figure 3c, which clearly show the broad garnet reflectance trough between 10,500 and 11,200 nm. These two spectra come from flight-line 13DBH10T over the main Broken Hill mine open pits and dumps (A and B in Figure 3b). Using Figure $3 e$, the wavelength positions at 10,700 (" $\left.\mathrm{A}^{\prime \prime}\right)$ and 10,800 ("B") nm of these two airborne pixel spectra equate to mid-level (Fe number $\sim 0.5$, i.e., almandine-spessartine) and Mn-rich (Fe number $\sim 0.9$, i.e., spessartine) compositions, respectively.

Tracking the MIRACO ${ }_{2}$ LAS wavelength of this garnet reflectance minimum for 13DBH10T using the derivative of a fitted fourth-order polynomial (brown trace in in Figure $3 b$ ) shows variation in garnet wavelength between 10,660 $\mathrm{nm}$ (Fe number $\sim 0.1$, i.e., near pure almandine) to 10,870 $\mathrm{nm}$ (Fe number $\sim 1.0$, i.e., near pure spessartine). Partial unmixing [59] of 13DBH10T to estimate the relative proportions selected/interpreted almandine (blue) versus spessartine (orange) spectral endmembers (A and B in Figure $3 b, c)$ shows a broadly similar pattern to that of the fourth-order fitted polynomial wavelength (brown-Figure 3b), though in detail there are differences, for example positions highlighted by black dotted horizontal lines (Figure 3b). These differences can in part can be explained by the effect of spectral depth (intensity) rather than wavelength driving the estimated partial unmixing abundances.

The wavelength position of the garnet reflectance trough near 10,700 $\mathrm{nm}$ for both the airborne MIRACO $\mathrm{C}_{2}$ LAS and field sample (measured using a MicroFTIR ${ }^{\mathrm{TM}}$ spectrometer) TIR data were separated into two types, namely: (i) almandine-rich where $\lambda<10,760 \mathrm{~nm}$ (blue); and (ii) spessartine-rich where $\lambda>10,760$ (red). The results (Figure 3a) identify three zones of spessartine-rich garnet, all of which are located within the mine sequence rocks (quartz-gahnite and garnet-quartz rocks), with two associated with known mineralization at the Broken Hill Main Lode and the others at Broken Hill United South (Figure 3a). There is also an apparent cross-cutting pattern within a laterally continuous, thin $(\sim 2 \mathrm{~m}$ wide) unit of garnet-sandstone/quartz-gahnite rocks that was traced in the field for over $10 \mathrm{~km}$ from the northern edge of the Broken Hill Main Lode workings to the Broken Hill United South Mine in the north-northeast (Figure 3a). The third area is located midway between these areas, i.e., a 4-5 km wide spacing, which is consistent with the pattern of seafloor convective cells above shallow hot intrusions [60] where $\mathrm{Mn}$ is concentrated close to the hydrothermal discharge sites and Fe is more distal [61]. That is, a tool that can map stratigraphically cross-cutting (gradients) garnet compositions could assist exploration for Broken Hill style base metal mineralization.

\subsubsection{Project Postscript}

Technology developments by the late 1990s, meant that MIRACO 2 LAS was superseded by high SNR airborne passive hyperspectral TIR systems, such as TIPS and SEBASS (Sections 2.4 and 2.8).

\subsection{Airborne Hyperspectral VNIR-SWIR-TIR Profiling Integrated with Geophysics}

\subsubsection{Background}

This collaborative industry project between CSIRO and World Geoscience Corporation (Perth, Australia) (later Fugro Airborne Services) spanned the mid-1990s to early 2000s and had the aim of developing an operational airborne system that integrated simultaneous acquisition of line-profiling VNIR-SWIR-TIR mineral mapping with gamma ray spectrometry and magnetics [62,63]. The rationale being that for a small additional cost, customers would receive not just the standard geophysics data but also a full suite of hyperspectral mineral mapping products. One of these hyperspectral line-profile sensors was TIPS, which was a Fourier transform TIR (FTIR) system. Here we focus on TIPS data collected in 2001 from the Munni Munni test site in Western Australia (Figure 4) where there is a well-exposed, differentiated ultramafic body with surface exposure of the clino-pyroxene mineral, diopside. Importantly, diopside at Munni Munni changes its chemical composition (Mg\# number; 
$\mathrm{Mg} /(\mathrm{Mg}+\mathrm{Fe}))$, at the top of the differentiated ultramafic complex where lower diopside $\mathrm{Mg} \#$ numbers are associated with platinum group element (PGE) mineralization [64].
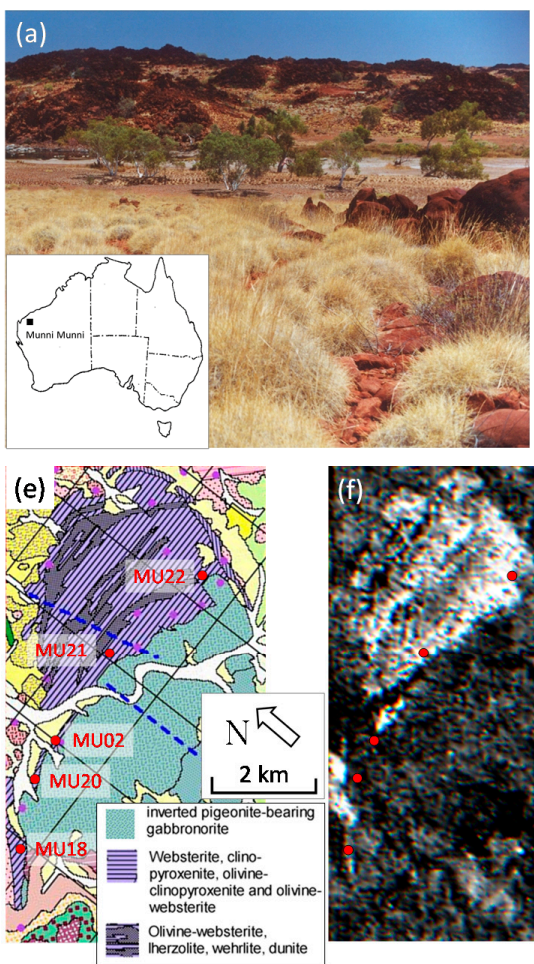
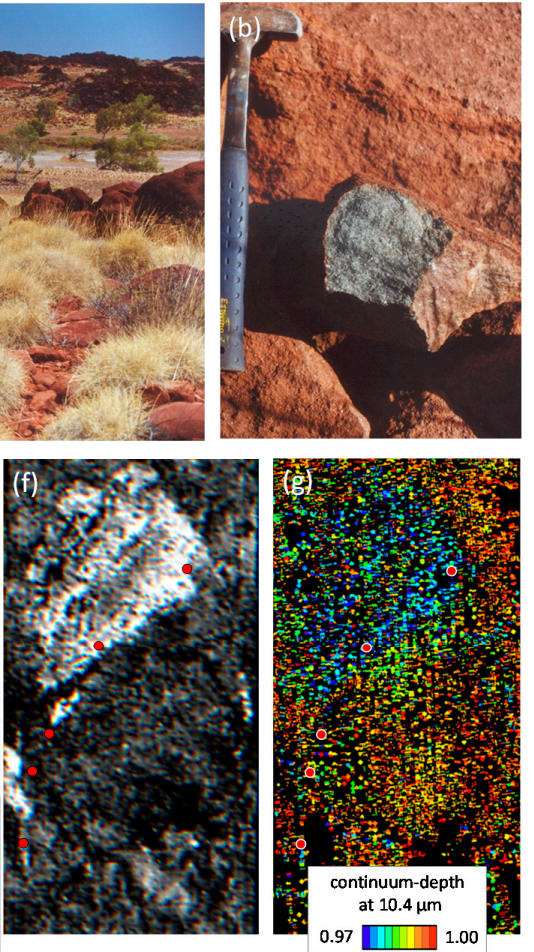

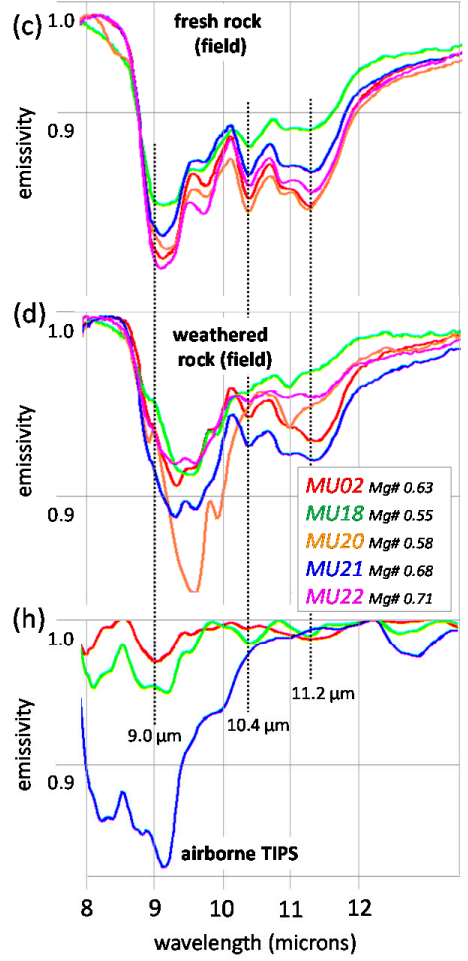

Figure 4. Airborne TIPS results from Munni Munni, Pilbara Craton, Western Australia. (a) Field photograph of websterite (foreground) and gabbro (background) outcrops. Note the extensive cover of Spinifex grass; (b) Close-up view of both natural weathered rock surfaces and a broken surface of diopside-rich websterite (locality MU21); (c) Field "MicroFTIR" emissivity spectra of diopside-bearing fresh rock samples. Field localities shown in (e); (d) Field "MicroFTIR" emissivity spectra of diopside-bearing weathered rock surfaces. Field localities shown in (e); (e) Published 100K geology of the Munni Munni area together with the locations of selected field samples of diopside-rich websterite. Scene center approximately $-21.1236^{\circ}$ latitude $116.8420^{\circ}$ longitude; (f) Interpolated, airborne TIPS processed partial unmixing "diopside" image ( $10 \mathrm{~m}$ pixel) generated from the red spectrum in (h); (g) Interpolated airborne TIPS 10,400 nm $(10.4 \mu \mathrm{m})$ continuum-depth image (blue in large depth); (h) Airborne TIPS pixel spectra selected and showing the diopside related emissivity lows at $\sim 10.4 \mu \mathrm{m}$ for the red and green curves. Blue spectrum is of a quartz-rich pixel.

\subsubsection{Pyroxene Mapping in Ultramafic Rocks}

The field TIR emissivity spectra of broken (fresh) surfaces of diopside-bearing ultramafic rocks from Munni Munni (Figure 4b,c,e) show a consistent suite of emissivity troughs, each 100 to $400 \mathrm{~nm}$ wide, at $9000,10,400$ and 11,200 nm diagnostic of diopside. The weathered skins of these rocks (Figure $4 \mathrm{~b}$ ) reduces the intensity of these spectral troughs, especially the feature near $9000 \mathrm{~nm}(9.0 \mu \mathrm{m})$ which overlaps clay spectral bands between 9000 and 10,000 $\mathrm{nm}$. Nevertheless, the diopside features at 10,400 and 11,200 nm remain detectable (Figure 4d). The assayed Mg\# number for these field samples (Figure $4 \mathrm{~d}$ ) range from 0.55 to 0.71 , with the lower Mg\# numbers potentially associated with PGE mineralization, i.e., samples MU02, MU18 and MU20. However, there is no apparent shift in the wavelength position of the diopside TIR spectral features with respect to a change in Mg\# number. Nor was there any other evidence in the $>50$ field and drill core samples examined of a measurable TIR spectral property related to Mg\# number [65]. Thus, unlike garnets, the opportunity for spectral measurement of pyroxene (diopside) chemical solid solution is a challenge. 
Nevertheless, remote TIR mapping of diopside is itself useful for characterizing differentiated mafic-ultramafic bodies potentially associated with PGE and/or Ni-sulfide mineralization. To test this opportunity, airborne TIPS radiance data from Munni Munni were processed [66] to emissivity. Examples of processed pixel emissivity spectra (Figure 4h) show the diagnostic diopside features at 10,400 and 11,200 $\mathrm{nm}(10.4$ and $11.2 \mu \mathrm{m})$. One of these (red) was then used as the endmember for partial unmixing [59] which yielded the map in Figure 4f. High amounts (brighter tones) of diopside closely follows the published map of diopside-bearing pyroxenite (Figure 4e). Furthermore, layering within this differentiated ultramafic unit is mapped with this TIR spectral endmember. However, this TIPS endmember also shows features at 8300 and $9100 \mathrm{~nm}$ which are likely to be caused by quartz (Figure 4h), which is pervasively developed in soils (aeolian in origin). That is, the "unmixed" map (Figure 4f) could simply be expressing a negative "quartz effect" because of its relative low abundance (in soils only) over the ultramafic rocks. To negate this possibility, the depth (continuum-removed) of the diagnostic diopside 10,400 $\mathrm{nm}$ feature was calculated (Figure $4 \mathrm{~g}$ ), which also defines the limits of the pyroxenite (Figure 4e) albeit with a greater level of noise compared with the unmixed endmember product (Figure 4f) though arguably with a higher degree of confidence for mapping diopside.

\subsubsection{Project Postscript}

Even though there were a series of successful trails of the geophysically-integrated hyperspectral VNIR-SWIR-TIR line-profiling systems around Australia, this technical success did not translate into commercial global operations by Fugro Airborne Services. The activity did however help establish the technological foundation for CSIRO's drill-core Hylogger ${ }^{\mathrm{TM}}$ systems [67].

\subsection{AMIRA P435 Project_Mineral Mapping with Field Spectrometry}

\subsubsection{Background}

The P435 project (1994-1997) was supported by 15 mining-exploration companies and two Australian Federal/State government geoscience agencies with the aim of developing the exploration potential of the PIMA-II field spectrometer. This involved: (i) building and better understanding the spectroscopy of key alteration/regolith minerals; (ii) generating detailed case histories from a range of deposit and alteration styles from around the world; (iii) improving spectral interpretation methods and related software; and (iv) technology training through workshops and reports. Fifteen Australian and Pacific Rim deposits were studied spanning Archaean and Proterozoic $\mathrm{Au}$ and $\mathrm{Cu} / \mathrm{Au}$, porphyry-epithermal $\mathrm{Cu} / \mathrm{Au}$ and base metal systems. There were also specific studies on white micas, kaolinite, chlorite and the impacts of water. The project delivered to sponsors thirty technical reports and four field and/or laboratory workshops.

The example shown here is from the Birthday South lode (Figure 5) within the Kalgoorlie Superpit [68] which examined 400 samples from five diamond drill-holes (DDHs) and 165 blast hole drill samples from the mine bench at the $-230 \mathrm{~m}$ level. All rock samples were from fresh, metasomatically altered dolerite with spectral measurements taken from both the wall rock and veins. The spatial density of sampling was designed to enable generation of a three-dimensional (3D) representation of the alteration mineralogy. The main focus here is on white mica, chlorite and opaque mineral (pyrite) properties from the $-230 \mathrm{~m}$ bench only.

\subsubsection{Proximal Mine White Mica Alteration Footprint-Fresh Rock}

The $150 \mathrm{~m}$ wide ( $-230 \mathrm{~m}$ RL) Birthday South bench sampling intersected a zone of high-grade Au mineralization (Figure 5a), which is broadly related spatially/statistically to sulfur (S; Figure 5b,c). The $S$ is chiefly contained in pyrite, which has the spectral effect of shifting the peak reflectance @ $1500 \mathrm{~nm}$ to both lower reflectance (Figure 5d) and shorter wavelength (Figure 5f). The reduction in a given sample's reflectance by an "opaque" phase such as pyrite can also effect the spectrally apparent content ( absorption depth) of other mixed "transparent" minerals [16], by effectively reducing the 
penetration (path length) of the volume scattered photons. XRD analyses of the Birthday South samples, showed that increasing pyrite content is accompanied by increasing white mica content and decreasing chlorite content (Figure 5g), however the PIMA results show that the pyrite-rich samples have relatively low $2200 \mathrm{~nm}$ absorption depths (Figure $2 \mathrm{~b}, \mathrm{e}$ ).

This non-linear spectral mixing behavior does not extend to the wavelength position of $2200 \mathrm{~nm}$ absorption which shows a linear relationship with laboratory electron microprobe analyses of white mica Tschermak substitution (Figure 5i) $\left[(\mathrm{Al} \leftrightarrow \mathrm{Si})_{\text {tet }}=\left(\mathrm{Al} \leftrightarrow\left\{\mathrm{Fe}^{2+,} \mathrm{Mg} \text {, site vacancy }\right\}\right)_{\text {oct }}\right][69,70]$, which is sensitive to the physicochemical conditions of white mica formation. Here at Birthday South, white mica is a metasomatic alteration product in ferromagnesian (dolerite) host rocks with an increase in its Tschermak substitution related to an increase in alteration intensity/proximity and hence gold mineralization. That is, the white mica becomes Si-rich (Al-poor) with proximity to gold mineralization, with its footprint extending for at least the entire width of the bench (i.e., $150 \mathrm{~m}$ ) compared with the $50 \mathrm{~m}$ wide Au zone.
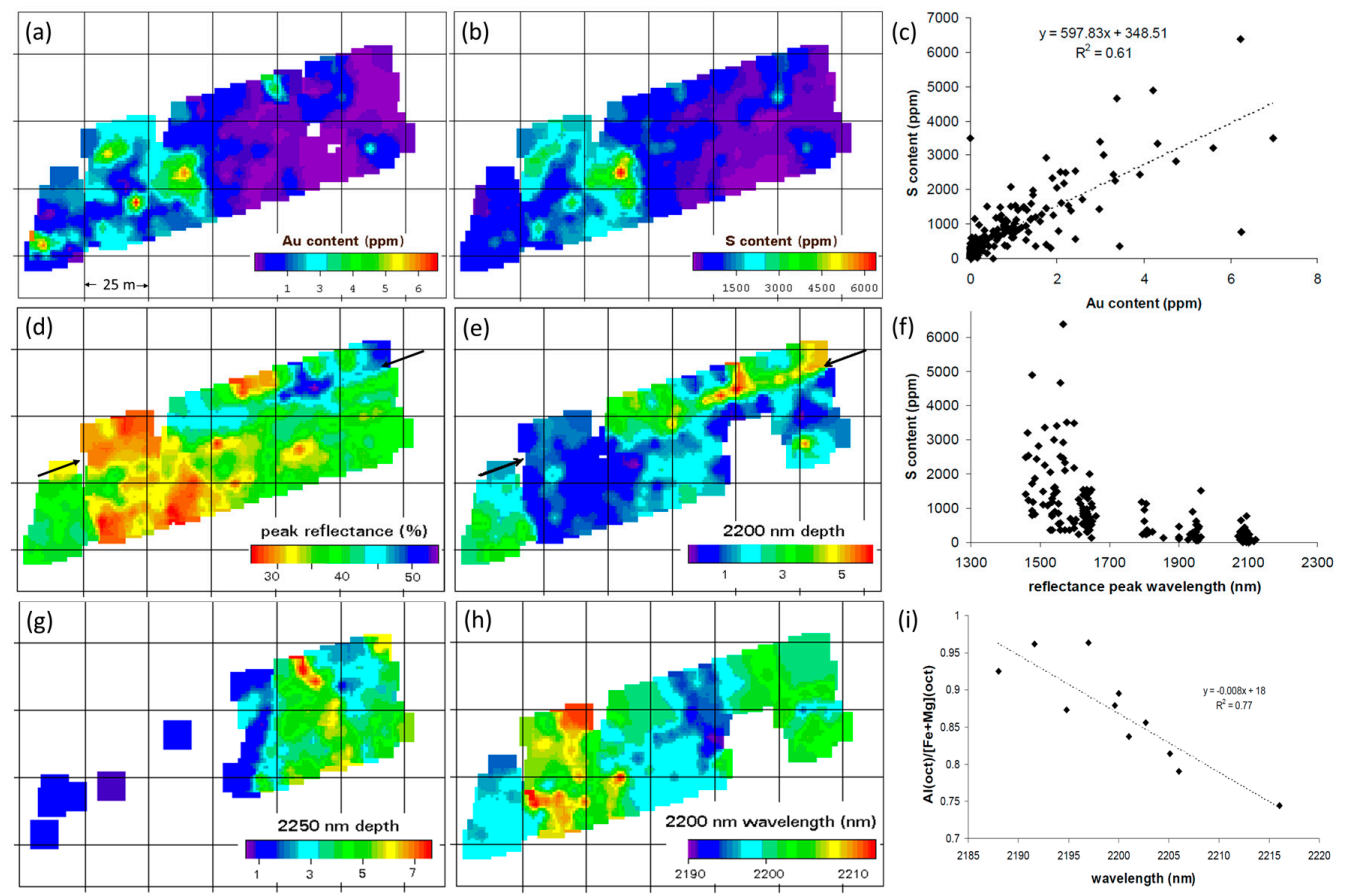

Figure 5. Blast-hole pulp (166 samples, $10 \mathrm{~m}$ depth composite) results ( 1996) for the $-230 \mathrm{~m}$ bench of Birthday South, Superpit, Kalgoorlie, Western Australia. Approximate position $-30.7715^{\circ}$ latitude $121.5021^{\circ}$ longitude. (a) Interpolated mine bench map of Au content (ppm); (b) Interpolated mine bench map of S content (ppm); (c) Scatter-gram of Au versus S contents; (d) Interpolated mine bench map of PIMA maximum reflectance value (\%) with lower albedo yielding warmer tones; (e) Interpolated mine bench map of PIMA $2200 \mathrm{~nm}$ absorption continuum depth; (f) Scatter-gram of the wavelength position of the PIMA peak reflectance versus the S content; (g) Interpolated mine bench map of the depth of the continuum-removed $2250 \mathrm{~nm}$ absorption ( chlorite mineral content); (h) Interpolated mine bench map of the wavelength of the continuum-removed $2200 \mathrm{~nm}$ absorption ( white mica Tschermak substitution); (i) Scatter-gram of the wavelength of the $2200 \mathrm{~nm}$ absorption versus electron-microprobe analyses of the white mica octahedral sheet $\mathrm{Al}$, Fe and $\mathrm{Mg}$ cations $\left(\mathrm{Al}_{\mathrm{oct}} /\left[\mathrm{Fe}_{\text {oct }}+\mathrm{Mg}\right.\right.$ oct $]$ ) for 13 Birthday South samples showing effects of coupled Tschermak substitution.

\subsubsection{Project Postscript}

Remote detection of $<5 \mathrm{~nm}$ wavelength changes of the $2200 \mathrm{~nm}$ absorption observed at Birthday South requires a spectral resolution of $<20 \mathrm{~nm}$, given a $30 \mathrm{~nm}$ white mica absorption FWHH. Thus, multi-spectral systems with SWIR-2 spectral resolution of $>40 \mathrm{~nm}$ (i.e., Geoscan and ASTER) are not 
suited for accurate measurement of white mica Tschermak substitution (see instead hyperspectral systems below, e.g., Section 2.4).

\subsection{Airborne Hyperspectral Imaging of the Kalgoorlie Superpit}

\subsubsection{Background}

Like the PIMA-II, the 96 VNIR-SWIR channel Airborne Multi-spectral Scanner (AMS) with a SWIR-2 spectral resolution $\sim 17 \mathrm{~nm}$, was developed by ISPL. The AMS was built in mid-1990s for De Beers to service their global diamond exploration program for which it was a technical success [71]. In 1998, De Beers provided CSIRO with the opportunity to collect AMS data over the $>4 \mathrm{~km}^{2}$ area of the Kalgoorlie Superpit open pit mine to follow up the P435 Birthday South results (location shown by white rectangle in Figure 6). No on-board, geolocation information was available for these early AMS data, which combined with the high topographic-relief of the open pit mine, caused spatial mapping errors in these early derived mineral maps (Figure 6).
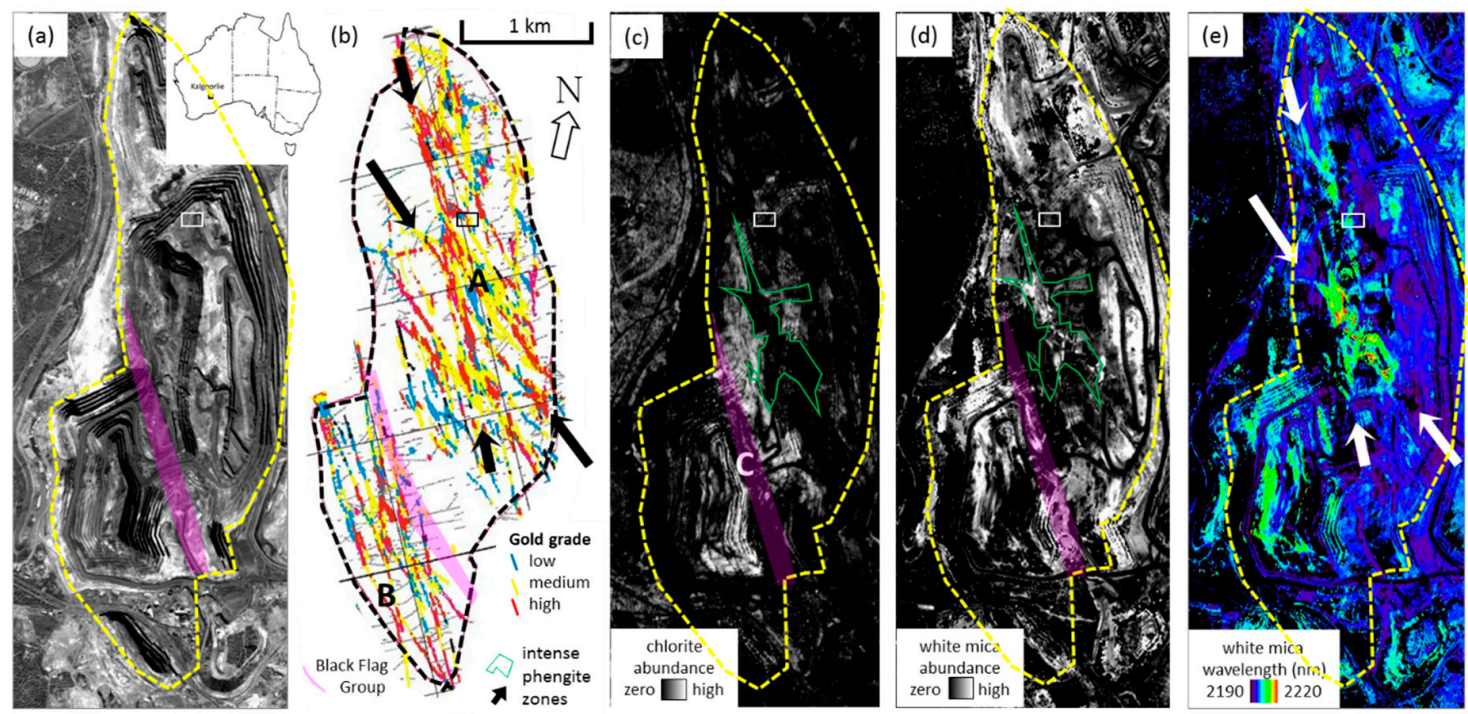

Figure 6. Airborne AMS 1998 mineral mapping results for the Superpit, Kalgoorlie, Western Australia. Approximate position $-30.7715^{\circ}$ latitude $121.5021^{\circ}$ longitude. (a) AMS visible albedo image of the Superpit together with an overlay of the Black Flag Group (magenta), which in theory spans the Golden Mile Fault; (b) Map of gold grade modelled from blast hole drill analyses for the approximate date of the AMS survey (courtesy of Kalgoorlie Consolidated Gold Mines, Australia. Major linear zones of Au highlighted by black arrows; (c) Processed AMS image of the continuum-depth of the $2260 \mathrm{~nm}$ absorption ( chlorite content). Green polygon of long wavelength $2200 \mathrm{~nm}$ feature (e) shown for cross-reference; (d) Processed AMS image of the continuum-depth of the $2200 \mathrm{~nm}$ absorption (includes white mica). Green polygon of long wavelength $2200 \mathrm{~nm}$ feature (e) shown for cross-reference. (e) Processed AMS image of the wavelength minimum of the continuum-removed $2200 \mathrm{~nm}$ absorption ( $\sim$ white mica Tschermak substitution but kaolin has not been masked/unmixed). Examples of major linear zones of phengite are highlighted by white arrows.

\subsubsection{Remote Sensing White Mica Alteration Footprints—Fresh Rock}

Figure 6a shows the 1998 AMS albedo image of the Kalgoorlie Superpit superimposed with the zone of published Black Flag Group (magenta), which comprises carbonaceous sediments (carbon black is also an opaque phase in the VNIR-SWIR), together with the Golden Mile Fault (possible mineralizing fluid pathway). A summary of the Superpit 1998 Au grades [72] (Figure 6b) shows a number of trends/zones, including NW-SE and NNW-SSE sets (e.g., black arrows). From these Au data, the Black Flag Group (magenta) separates the Superpit into NNE and SSW zones (A and B, 
Figure $6 \mathrm{~b}$, respectively). From the AMS data, these zones are separated by a broad chlorite-rich zone (C in Figure 6c), which was measured using the continuum-depth of the $2260 \mathrm{~nm}$ absorption which was also used in PIMA-II Birthday South processing (Figure 5g). This apparent chlorite is typically developed in areas poor in $2200 \mathrm{~nm}$ absorbing minerals (white mica and/or kaolin), estimated using the continuum-depth of the $2200 \mathrm{~nm}$ absorption.

The mineral mapping products generated in 1998 (Figure 6) did not mask/ unmix complicating effects such as kaolin from white mica, which share a $2200 \mathrm{~nm}$ absorption, albeit with different FWHHs. Kaolin can be recognized in the 1998 AMS Superpit products along the open pit walls where weathered rock is exposed generating large $2200 \mathrm{~nm}$ absorption depths (Figure 6d) with short wavelengths (Figure 6e), calculated using the first derivative of a fitted fourth-order polynomial to the wavelength segment between 2120 and $2240 \mathrm{~nm}$. This interpreted kaolin is prevalent on the eastern side of the open pit though on the SW pit wall there is also longer wavelength 2200 absorption extending to the surface. This suggests that white mica has persisted through the regolith profile to the surface, which highlights a remote sensing exploration opportunity (see M370 project in Section 2.9). The $2200 \mathrm{~nm}$ absorption at the base of the open pit where chlorite is also in found fresh rock, is interpreted as white mica only. The fresh rock pattern of the white mica $2200 \mathrm{~nm}$ absorption wavelength (Figure 6e), shows linear zones of phengite similar to the Au grades (Figure 6b) and extending for up to $3 \mathrm{~km}$ (arrowed) across mine benches, mine faces, haul roads and into the upper weathered parts of the open pit mine.

Several conclusions can be made from this study: namely: (i) Au mineralization in the Superpit is proximally associated with abundant long-wavelength (phengitic) white mica in mafic rock, which extends for kilometers and persists up through the regolith profile (Figure 1a), i.e., is a good target mineral for Au exploration in weathered environments; (ii) chlorite is more distal and not evident in the overlying regolith (Figure 6c), i.e., not a good target mineral for exploration but if present indicates relatively fresh rock; (iii) the tops of exposed mine benches can be used to generate an accurate map of the alteration zonation, despite the various types of surface disturbance caused by mining such as haul roads, which when present are easily recognizable and thus discounted/masked; and (iv) combined with the Birthday South results (above), there is a scalable, fractal nature to the spectrally-mappable mineral alteration gradients.

\subsubsection{Project Postscript}

Additional airborne hyperspectral surveys were collected over the Superpit in later years also revealing similar white mica-chlorite-kaolinite patterns though with some changes in geometry as open pit mining proceeded deeper. That is, there is an opportunity to begin generating 3D mineral maps of active open pit mines from remote sensing imagery, which could be used in combination with drill core and/or mine-face scanning data to more accurately predict the geometry of the deposit at depth (See Rocklea Inlier in Section 2.12.2).

\subsection{MERIWA M322 Project—Panorama VMS System}

\subsubsection{Background}

In 1998, ISPL was ready to begin commercial operations using their 124-channel airborne hyperspectral VNIR-SWIR imaging system called HyMap ${ }^{\mathrm{TM}}$ [73] through its sister company HyVista Corporation (HVC). Early public geological trails of HyMap ${ }^{\mathrm{TM}}$ were in collaboration with CSIRO at the Panorama Archaean volcanic massive sulfide (VMS) system in the remote Pilbara of Western Australia (Figure 7). This collaborative project also involved MERIWA, ERSDAC and two mining companies [74]. Panorama was selected for geological testing of the HyMap ${ }^{\mathrm{TM}}$ system because recently published mapping [75] had showed a $\sim 40 \mathrm{~km}$ pattern of $3.42 \mathrm{Ga}$ volcanic massive sulfide hydrothermal alteration exposed in cross section. However, there were concerns raised by geoscientists working in this area that they expected little to come from the HyMap ${ }^{\mathrm{TM}}$ survey because: (i) the proximal propylitic alteration, characterized by chlorite, was poorly expressed at the surface as a result of weathering; (ii) PIMA-II 
studies had found no clear regional pattern in the white mica Tschermak substitution [76,77]; and (iii) the region is often covered by spinifex grass and other vegetation.
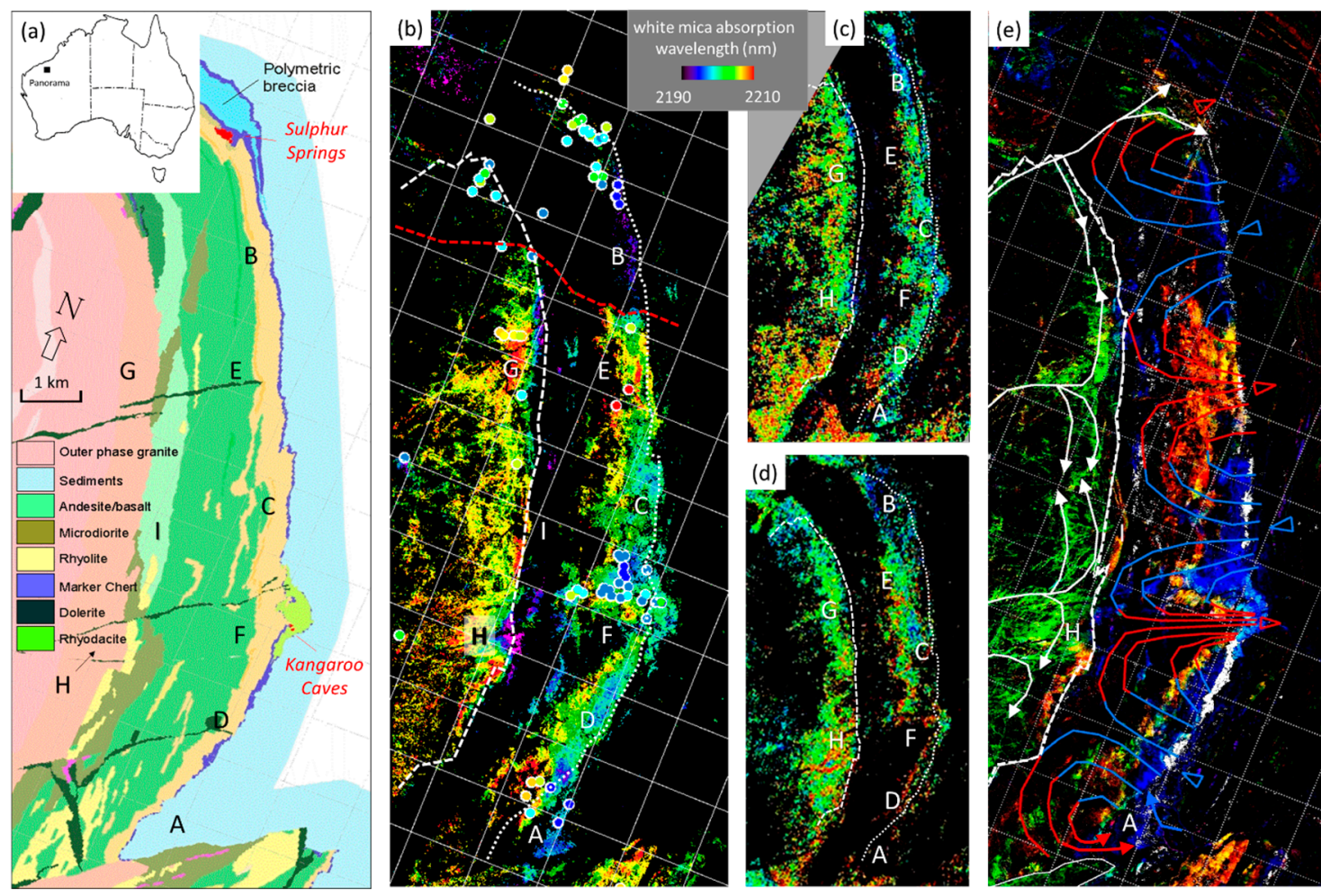

Figure 7. Airborne and satellite mineral mapping results for the Archaean Panorama volcanic massive sulfide, Pilbara, Western Australia. Scene center approximately $-21.1980^{\circ}$ latitude $119.2216^{\circ}$ longitude. (a) Published geology [75]; (b) Airborne HyMap ${ }^{\mathrm{TM}}$ (from 1998) image of white mica composition based on the wavelength minimum of the continuum-removed $2200 \mathrm{~nm}$ absorption ( Tschermak substitution). Similarly processed field data are embedded. Upper and lower boundaries of the volcanic pile are shown; (c) Satellite Hyperion (from 2001) of white mica composition based on the wavelength minimum (first derivative of a fourth-order polynomial fit) of the continuum-removed $2200 \mathrm{~nm}$ absorption ( Tschermak substitution); (d) Satellite ASTER image (from 2001) of Al-clay composition based on the index $B_{5} / B_{7}$ and masked using $\left(\mathrm{B}_{5}+\mathrm{B}_{7}\right) \mathrm{B} 6>2$; (e) Airborne HyMap ${ }^{\mathrm{TM}}$ image based on partial unmixing (RGB) of three white mica rich image endmembers overlaid with a threshold partially unmixed chert endmember product (white) and interpreted magmatic (white) seawater (blue to red) fluid flow lines.

HVC delivered the Panorama HyMap ${ }^{\mathrm{TM}}$ radiance@sensor data to CSIRO within two weeks of the airborne survey in late 1998. Within four hours after receiving these data, the complete architecture of the Panorama seawater and magmatic related hydrothermal convection cells, including all the known discharge sites as well as new ones (= targets for base metal mineralization), were revealed in a white mica composition gauged using a log residual [39] color composite of the three bands spanning the white mica $2200 \mathrm{~nm}$ absorption [74]. The results presented here focus on subsequent more detailed processing methods (e.g., spectral parameterization and partial unmixing) for mapping of the architecture of the VMS hydrothermal system. Only two of the original four 1998 Panorama HyMap ${ }^{\text {TM }}$ survey flight-lines are examined, with these two spanning the Sulphur Springs and Kangaroo Caves VMS base metal deposits and the footwall extrusive and intrusive rocks (Figure 7a,b,e). Reducing/removing the complicating effect of kaolin on the white mica $2200 \mathrm{~nm}$ absorption information was also important (see airborne hyperspectral Superpit study in Section 2.6). 


\subsubsection{VMS Alteration Architecture Using White Mica Information}

The first method for extracting white mica information from the HyMap ${ }^{\mathrm{TM}}$ reflectance data involved a step-wise, multi-parameter plus masking approach, later called multi-feature extraction method or MFEM [78]. This involved calculating the wavelength of the white mica absorption near $2200 \mathrm{~nm}$ using the first derivative a fourth-order polynomial fitted between 2120 and $2240 \mathrm{~nm}$, which was then masked: (i) to remove pixels with detectable dry vegetation using a cellulose absorption feature near $2100 \mathrm{~nm}$; (ii) to remove pixels with detectable green vegetation cover using an Normalized-Difference-Vegetation-Index (NDVI) [79]; (iii) to remove pixels with detectable kaolin using the presence of $2160 \mathrm{~nm}$ absorption; and (iv) to include pixels with a detectable white mica absorption at $\sim 2350 \mathrm{~nm}$. Importantly, the MFEM method allows statistical comparison of the remote sensing white mica information with similarly processed field PIMA-II spectral data as well as other quantitative sample data such as laboratory electron-microprobe geochemical analyses of white mica Tschermak substitution.

The MFEM processed HyMap ${ }^{\mathrm{TM}}$ and PIMA-II results (color coded in Figure $7 \mathrm{~b}$ ) show similar patterns in white mica $2200 \mathrm{~nm}$ wavelength that cross-cut the published geology (e.g., A-B-C-D in Figure 7a) providing evidence for superimposed metasomatic alteration. This distribution of white mica terminates at the stratigraphic top of the volcanic pile below younger turbiditic sediments (white dotted line $=$ "marker chert" in Figure 7a), except in the south (A in Figure 7b). Both VMS sites at Sulphur Springs and Kangaroo Caves (Figure 7a) are located in the volcanic rocks at this seafloor interface, where discharging fluids would have experienced large changes in physicochemical gradients inducing metal precipitation. These particular discharge sites are characterized by moderate to long (green to yellow) wavelength (Si-rich, Al-poor) white mica, i.e., moderate to high levels of Tschermak substitution. Sulphur Springs has fewer mapped pixels because of a blanket of spinifex grass cover at the time of the airborne campaign. This cover was largely burnt (removed) in the area south of Sulphur Springs (red dashed line in Figure 7b) not long before the 1998 HyMap $^{\text {TM }}$ survey.

Between the Sulphur Springs and Kangaroo Caves VMS sites, the HyMap ${ }^{\mathrm{TM}}$ results show another two-kilometer-wide zone of long-wavelength (yellow-red) white mica not previously recognized as a VMS discharge site [75]. This new zone shares similar characteristics with Kangaroo Caves including: (i) white mica alteration extending deep $(\sim 1 \mathrm{~km})$ into intermediate and mafic rocks stratigraphically below (i.e., a metasomatic alteration effect); (ii) a lack of white mica in the bottom half of the volcanic pile; (iii) localized ( 1000 $\mathrm{m}$ wide and $200 \mathrm{~m}$ thick), very short-wavelength (magenta) white mica at the contact with (white dashed line) and extending into the underlying granite; and (iv) very long-wavelength (red) white mica deeper (500-1000 m) within the granite ( $\mathrm{G}$ and $\mathrm{H}$, Figure $7 \mathrm{~b}$ ) and linked with deeper sub-vertical zone/s. The implication is that this new zone represents a potential VMS exploration target.

Across the study area, the HyMap ${ }^{\mathrm{TM}}$ results show that the composition of the white mica crosscuts stratigraphically-conformable rhyolitic, andesitic and basaltic extrusive rocks, with shorter wavelength white mica zones ( 2 km wide) positioned at B, C and D and longer wavelength white mica zones ( $\sim 2 \mathrm{~km}$ wide) at $\mathrm{E}$ (Sulphur Springs), F (Kangaroo Caves) and SW of D (Figure 7b). This four-kilometer cyclic pattern over an approximately two-kilometer thick volcanic pile is consistent with modelling of VMS hydrothermal convective cells [60].

Note that the HyMap ${ }^{\mathrm{TM}}$ results also show short-wavelength white mica developed in the overlying sediments near " $\mathrm{A}$ ", which suggests that this part of an apparent northward-prograding turbidite fan was deposited during the hydrothermal event. The large gradient in white mica composition across this sediment pile possibly reflecting changing fluid flow conditions as the underlying discharge became increasingly buried.

The second approach for extracting white mica information from the HyMap ${ }^{\mathrm{TM}}$ reflectance data used a CSIRO partial unmixing method [59]. Three white mica endmembers were used to generate a composite white mica mineral map (Figure 7e), including: (i) a long-wavelength signature taken from the volcanic rocks (red); (ii) a short-wavelength signature also taken from the volcanic rocks (blue); and 
(iii) a medium wavelength signature taken from the granite (green), which has relatively high water content (gauged using the intensity of the reflectance shoulders leading into the 1900 and $2700 \mathrm{~nm}$ water bands). A fourth HyMap ${ }^{\mathrm{TM}}$ spectral endmember is also included in Figure 7e, namely one taken from the marker chert (white), which was added as a "mask-in above a threshold" product (solid white). Importantly, both the mapped thickness and extent of this HyMap ${ }^{\mathrm{TM}}$ marker chert endmember closely matches the published geology (Figure 7a), including its thicker southern termination below the white mica altered turbidites (" $\mathrm{A}$ "), i.e., further evidence for coeval sedimentation and VMS activity in this area.

Compared with the MFEM results (Figure 7b), partial unmixing of the HyMap ${ }^{\mathrm{TM}}$ imagery (Figure 7e) shows clearer discrimination of the white mica alteration zonation both within the volcanic rocks and the underlying granite but does not show the changes in white mica absorption wavelength within a given rock type, such as $\mathrm{A}$ and $\mathrm{D}$ in rhyolite and $\mathrm{G}$ and $\mathrm{H}$ in granite (Figure $7 \mathrm{~b}, \mathrm{e}$ ). The three image spectral endmembers used in the partial unmixing (Figure 7e) include one selected from a recharge site (short wavelength-blue tones in Figure 7e) in the volcanic rocks, another from a discharge site (long wavelength-red tones in Figure 7e) also in the volcanic rocks and the last from within the granite (mid wavelength-green tones in Figure 7e). That is, the overall spectral-mineral character of the rock rather than white mica Tschermak substitution is being discriminated. Field validation found that the granite-derived spectral endmember has a mid-wavelength $2200 \mathrm{~nm}$ feature and that it is relatively rich in water [74], i.e., deeper shoulders to the water band at $1900 \mathrm{~nm}$. Within the volcanic pile the unmixed product also shows error, for example near " $\mathrm{I}$ " in Figure 7b, where the unmixed product showed white mica but the MFEM product and field mapping showed that no white mica was present. This emphasizes the challenges in using statistical methods accurately with important user decisions regards: (i) selection of the optimum input wavelength regions; (ii) the selection and interpretation of optimum endmembers; (iii) setting optimum thresholds; and (iv) the appropriate use of masks such as "infeasibility" scores [59].

Nevertheless, both the MFEM and partial unmixing methods reveal useful geological information about the architecture and genesis of the Panorama VMS system-information that could assist an explorer in defining targets. This includes for example, recognition of a VMS-related "cracking front" ( $\sim 350{ }^{\circ} \mathrm{C}$ isotherm) which separates chemically-distinct but thermally-linked volcanic and magmatic fluid convective systems (Figure 7e). The boundary can be recognized by fractured-constrained white mica below the cracking front ( granite-volcanic contact—white dashed line Figure $7 \mathrm{~b}, \mathrm{e}$ ) and pervasive white mica above. This contrast in white mica behavior is driven by the descending thermal aureole and related thermal contraction and change in fluid/rock pressures. The mineral mapping data also show contrasting patterns in white mica composition with above the cracking front comprising pronounced lateral variations in Tschermak substitution related to evolved convective cells whereas below there is little variation and there are deep roots in white mica development below the discharge sites in the overlying volcanic rocks.

Thus, the hyperspectral imagery enables mapping of two independent but thermally-connected, convective hydrothermal systems, namely: (i) a magmatic system; and (ii) a seawater system. Possible fluid flow vectors are interpreted for both of these systems (Figure 7e) with seawater recharge sites identified (blue triangles). Higher levels of $\mathrm{Na}$ in these short-wavelength white micas were found through electron-microprobe analyses of associated field sample [74]. Seawater convective cell discharge sites are marked by red triangles. Also apparent is a magmatic white mica signature (green) in the Sulphur Springs area (Figure 7e), which is evidence for magmatic fluids breaching the cracking front and migrating up into the zone of seawater convection, an interpretation later supported by isotope studies [80].

\subsubsection{Project Postscript}

Like Mount Fitton in South Australia, which was recognized and adopted as a useful geological test site for evaluating new sensors [32,62,81,82], the success of the Panorama HyMap ${ }^{\mathrm{TM}}$ study [83-85] also attracted further interest in testing other sensors including airborne ARGUS $[63,86]$ and the 
satellite-borne Hyperion $[87,88]$ and ASTER imaging sensors. The ability of these satellite systems for mapping the VMS related pattern white mica compositional information is presented in Figure 7c,d. The Hyperion was processed using a first derivative of a fitted fourth-order polynomial similar to the HyMap $^{\mathrm{TM}}$ processing (Figure $7 \mathrm{~b}$ ) whereas processing the lower SWIR spectral resolution ASTER data required use of a ratio of ASTER bands $B_{5} / B_{7}$ masked to include only those pixels that generate an Al-clay absorption at $2200 \mathrm{~nm}$ using a ratio of $\left(\mathrm{B}_{5}+\mathrm{B}_{7}\right) / \mathrm{B}_{6}$. Taking into consideration the differences in spatial, spectral and radiometric resolutions between these three sensors, there is similarity in the pattern of white mica composition that shows the lithology-crosscutting recharge sites (e.g., " $\mathrm{B}$ " and " $\mathrm{C}$ ") and discharge sites (e.g., " $\mathrm{E}$ " and " $\mathrm{F}$ ") within the volcanic pile as well as the mica alteration in the granite apparent in their respective products. Thus, these satellite systems can also be used by explorers to map possible hydrothermal white mica information associated with VMS systems in at least relatively well exposed geology.

The Panorama HyMap ${ }^{\mathrm{TM}}$ study was also the catalyst for the government geoscience agencies across Australia to begin thinking about the opportunities of collecting regional remote sensing data as part of their standard collection of public geophysical, geochemical and geological precompetitive geoscience data. However, this was tempered by their concerns regarding regolith (and vegetation) cover on a signal measured from only the top $100 \mu \mathrm{m}$ of the surface, which was (is) a prevailing view that remote sensing would only be valuable in well-exposed areas such as Panorama and not the rest of Australia where "seeing through" vegetation, regolith and transported cover is imperative for successful exploration. Tackling this "cover" challenge was the impetus for the Kalgoorlie MERIWA M370 project (see Section 2.9).

Finally, the vegetation-mineral mixing problem highlighted at Panorama (Figure $7 \mathrm{~b}$ ) has since been tackled using a variety of techniques $[85,89]$ and now implemented in the generation of seamless 3D mineral mapping products from drill core, surface and remote sensing data (See 3D Mineral Mapping project in Section 2.12).

\subsection{SEBASS Airborne Passive Hyperspectral TIR Imaging_Yerington Nevada Porphyry-Skarn System}

\subsubsection{Background}

In early 1999, CSIRO was approached by Aerospace Corporation to assist with geological trials of their airborne, liquid helium cooled, mid-infrared (MIR; 3000-5000 nm) and TIR hyperspectral imaging system called SEBASS [90]. Both of the SEBASSS MIR and TIR wavelength modules comprise 128 by 128-pixel detector arrays with the TIR module (also called long-wave infrared or LWIR) spanning the wavelength region between 7500 and $13,600 \mu \mathrm{m}$. The ensuing collaborative airborne campaign in September 1999 included the Yerington (Nevada) porphyry-epithermal-skarn system (Figure 8a), which was chosen because: (i) it comprised a well-exposed cross section through a porphyry-skarn-epithermal alteration mineral system with related chemical variations in garnets and feldspars [91,92]; and (ii) it had a history as a remote sensing geological test site [93,94]. CSIRO established an industry collaboration project which involved Aerospace Corporation as well as a number of mining companies, ERSDAC (Japan) and HVC and examined not just SEBASS but also the complementary role of the TIR with VNIR-SWIR using hyperspectral HyMap and (high altitude) AVIRIS data. Key TIR results showed that the compositions of both plagioclase feldspar $\mathrm{Na}-\mathrm{Ca}$ chemistry [95] and the $\mathrm{Fe}-\mathrm{Al}$ chemistry of Ca-rich series of garnets (grandites) could be measured and mapped [96,97]. Here we focus on garnet chemistry mapping and its role in defining alteration footprints.

\subsubsection{Garnet-Skarn Fe-Al Composition}

Three SEBASS flight-lines intersecting the skarn system at Yerington (Figure 8f) were pre-processed to generate apparent emissivity [96]. Selected SEBASS emissivity pixel spectra (Figure 8b) match associated field MicroFTIR ${ }^{\mathrm{TM}}$ emissivity spectra (Figure 8c), both of which showing diagnostic spectral 
features of garnets with different Fe-Al compositions (Figure 8d,e). However, the apparent emissivity contrast of the airborne spectral features ( 0.9 to 1.0) is much less compared to that of the field spectra ( $\sim .4$ to 1.0$)$, presumably because of uncorrected down-welling radiance effecting the airborne signatures. Nevertheless, the spectral shape is itself sufficient for mapping the garnet composition, such as the wavelength position of the garnet emissivity peak near 11,400 $\mathrm{nm}$. Comparisons of this peak wavelength position versus: (i) the XRD d-spacing for the garnet $420 \mathrm{hkl}$ peak (Figure 8d); and (ii) electron-microprobe analyses of the $\mathrm{Fe}$ and $\mathrm{Al}$ contents of garnet grains (Figure 8e), show significant correlations. That is increasing wavelength of the garnet $11,400 \mathrm{~nm}$ emissivity peak is proportional to the $\mathrm{Fe} /((\mathrm{Fe}+\mathrm{Al})$ content of the almandine-grossular solid solution series.

The wavelength position of $11,400 \mathrm{~nm}$ garnet peak ( garnet Fe-Al composition) in the SEBASS apparent emissivity data was measured using the first derivative of a fitted fourth-order polynomial between 11,000 and 12,000 $\mathrm{nm}$ (note that carbonates also have a narrow trough at these wavelengths-i.e., potential mixing problem), which was then masked to include only those pixels with a 11,400 nm peak. The resultant garnet $\mathrm{Fe}-\mathrm{Al}$ composition map (Figure 8a) is validated using: (i) field sample emissivity data (color coded dots in Figure 8a), which were processed the same way as the SEBASS data; and (ii) a published garnet composition map (Figure 8f) [98], which was generated using laboratory electron-microprobe analyses of an extensive suite of field samples [91]. Importantly all three datasets show that Fe-rich garnet (almandine) is centered over $\mathrm{Cu}$ mineralization at Casting Copper and Douglas Hill mines whereas Al-rich garnet ( grossular) is distal (1-4 km away) from $\mathrm{Cu}$ mineralization.
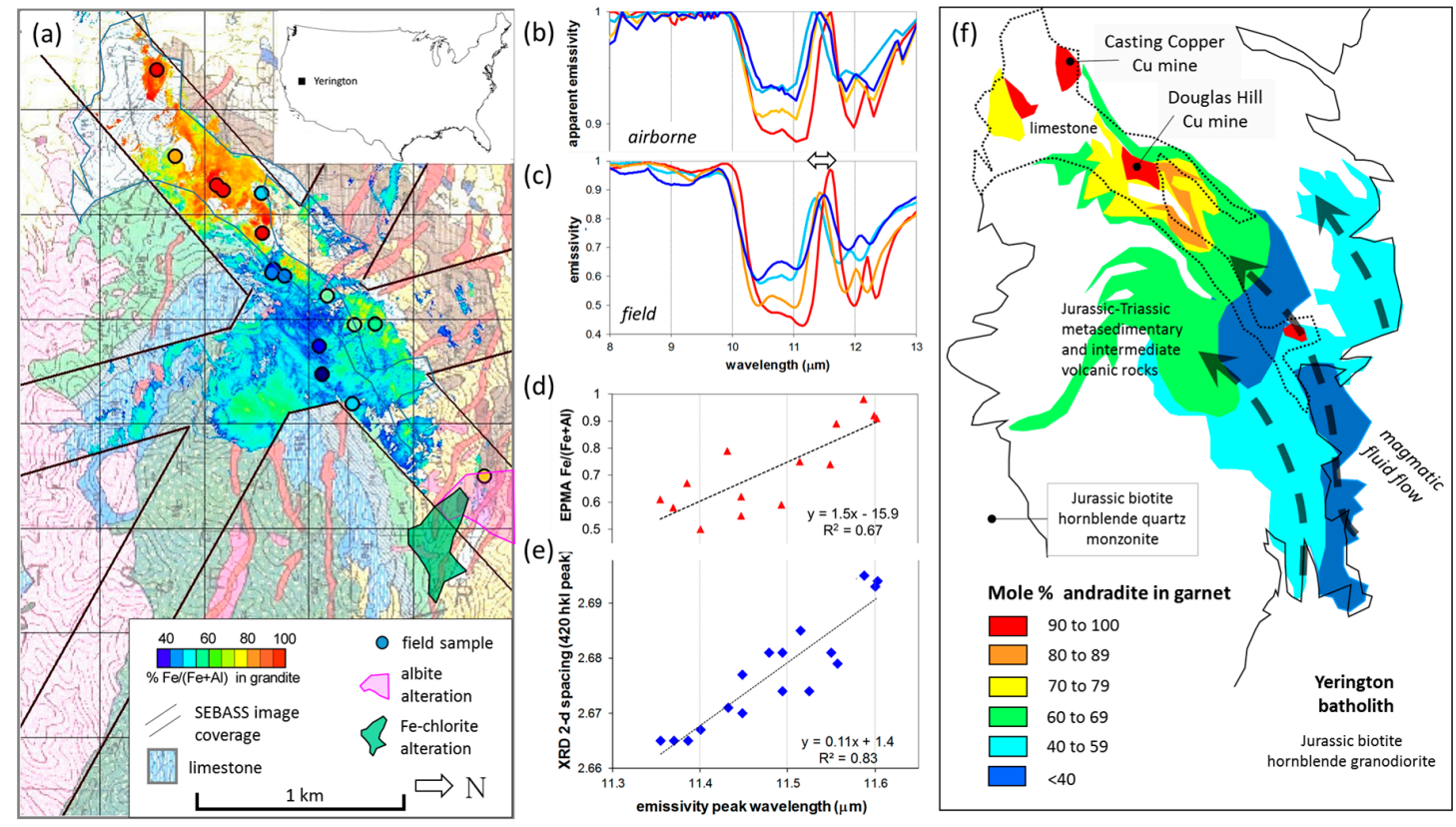

Figure 8. Garnet composition results for the Yerington copper porphyry-skarn system, Nevada, USA. Approximate scene center $-38.9544^{\circ}$ latitude $-119.2669^{\circ}$ longitude. (a) Airborne SEBASS TIR image of garnet $\mathrm{Fe}-\mathrm{Al}$ chemistry based on the wavelength of the $10,600 \mathrm{~nm}$ emissivity peak. Similarly processed field validation data; (b) Selected SEBASS pixel spectra showing evidence of Ca-rich garnets (grandite); (c) Selected field MicroFTIR ${ }^{\mathrm{TM}}$ spectra of grandite-rich rocks from (a); (d) Scatter-grams of laboratory electron-microprobe ( $\mathrm{Fe}-\mathrm{Al}$ ) analyses and (e) XRD 2D spacing of the garnet $420 \mathrm{hkl}$ peak versus the MicroFTIR $10.6 \mu \mathrm{m}$ peak wavelength position of field samples ranging in composition from andradite to grossular garnets sampled from (a); (f) Map of the andradite component (Fe) of the garnet composition based on published electron-microprobe analyses of field samples [98].

These results shown that remote hyperspectral TIR sensing can be used as an exploration tool for measuring and mapping garnet $\mathrm{Fe}-\mathrm{Al}$ compositional gradients and potentially the physicochemical 
evolution and pathways of related mineralizing fluids from a porphyry-magmatic source rocks (e.g., interpreted black dashed lines-Figure 8f). At Yerington, this fluid pathway is further revealed using both: (i) TIR derived plagioclase Na-Ca chemistry that delineates a zone of albite (pink polygon in Figure 8a) [96]; and (ii) SWIR-2 derived chlorite Mg\# number (green polygon in Figure 8a). That is, the combined spectral mineral information indicates that the hydrothermal mineralizing fluids were relatively rich $\mathrm{Fe}, \mathrm{Na}, \mathrm{Si}$ and $\mathrm{Al}$ as well as $\mathrm{Cu}$ and that these were focused along fluid paths and sourced from the neighboring Yerington batholith (Figure 8c).

\subsubsection{Project Postscript}

There have been airborne trials of other TIR systems at Yerington, including ITRES's 32 channel airborne TASI-600 imaging system. CSIRO's evaluation of this system is found in the Supplementary Document 1 which shows that Fe-Al garnet composition is also measurable with TASI-600, even though this system has a spectral resolution $(\sim 100 \mathrm{~nm})$ less than half that of SEBASS and without the system being cooled in liquid helium.

A CSIRO TIR study [99] of garnet skarn associated with at the Candelaria Iron Oxide Copper Gold (IOCG) deposit in Chile showed a similar pattern in field sample Fe-Al garnet compositions. However, even though the garnet skarn was detectable using ASTER's TIR bands $\left(\mathrm{B}_{12} / \mathrm{B}_{13}\right)$, its limited spectral resolution $(\sim 500 \mathrm{~nm})$ is insufficient for measurement of garnet Fe-Al information.

\subsection{MERIWA M370_Regolith, Geology and Alteration Mineral Maps from New Generation Airborne and Satellite Remote Sensing Technologies}

\subsubsection{Background}

This collaborative project aimed to assess whether remote mineral mapping technologies, such as the airborne HyMap system, can provide new and valuable information for exploration in a covered environment where deep regolith and transported materials are common challenges. The Kalgoorlie area was chosen for this task both because of its extensive cover that obscures underlying fresh rock and the high exploration interest of this region based on its rich history of gold endowment. Prior to the project start, there was considerable skepticism from the resource community that remote mineral mapping of this region would provide any value.

In 2004 and with the support of MERIWA, the Geological Survey of Western Australia (GSWA), the Cooperative Research Centre for Landscape Evolution and Mineral Exploration (CRC-LEME), HVC and industry, the collaborative M370 project began with the main aims of: (i) collecting airborne hyperspectral VNIR-SWIR data at $5 \mathrm{~m}$ pixel resolution over an entire 1:100,000 scale standard map-sheet (Kalgoorlie-Kanowna special map-sheet; Figure 9; area of $2500 \mathrm{~km}^{2}$ ), (ii) generating a derived suite of validated mineral products suitable for mapping transported versus in situ weathered materials and fresh rock metasomatic alteration footprints; and (iii) testing whether this information provides any useful information for characterization of the regolith cover and mapping any evidence of alteration footprints through this cover. This need for better tools to improve the characterization of the regolith and to detect any alteration footprints is now central to Australia's UNCOVER initiative [37].

The Kalgoorlie-Kanowna 1:100,000 scale map-sheet was also selected because a new digital regolith map was being generated for this area by the GSWA and thus could prove useful for comparison. Similarly, an exploration-mining company had been conducting extensive drilling across this area for which they were measuring PIMA-II spectra of the bottom-of-hole "fresh rock" samples to extract white mica $2200 \mathrm{~nm}$ wavelength information to help define local-regional metasomatic alteration patterns. The same company had discounted any value in obtaining this information from higher up in the regolith profile, especially from remote sensing systems.

Twenty-six flight-lines of HyMap ${ }^{\mathrm{TM}}$ imagery were collected in May 2004 over the Kalgoorlie-Kanowna 1:100,000 scale map-sheet, some under poor weather conditions, including extensive thin (stratus) cloud and wet ground, which were unavoidable during the contracted airborne 
survey period. The processing methods, validation of mineral products and geological case histories generated from these data are described in the M370 final report [100]. Three geological issues are examined here, namely: (i) the mapping of transported versus weathered in situ materials; (ii) the persistence of white mica information through the weathered profile; and (iii) the exploration significance of surface white mica patterns.
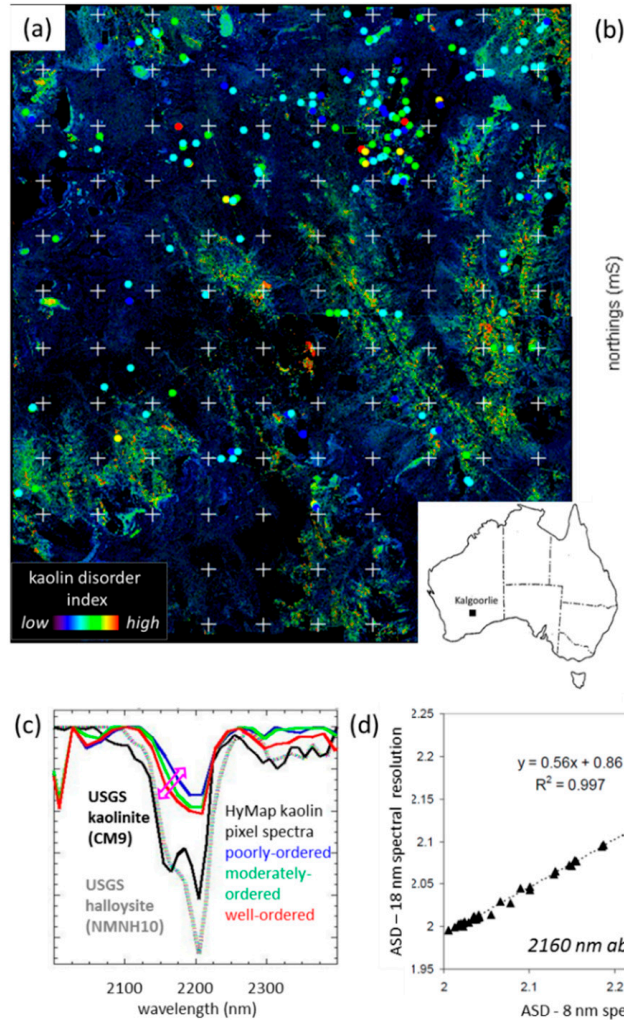
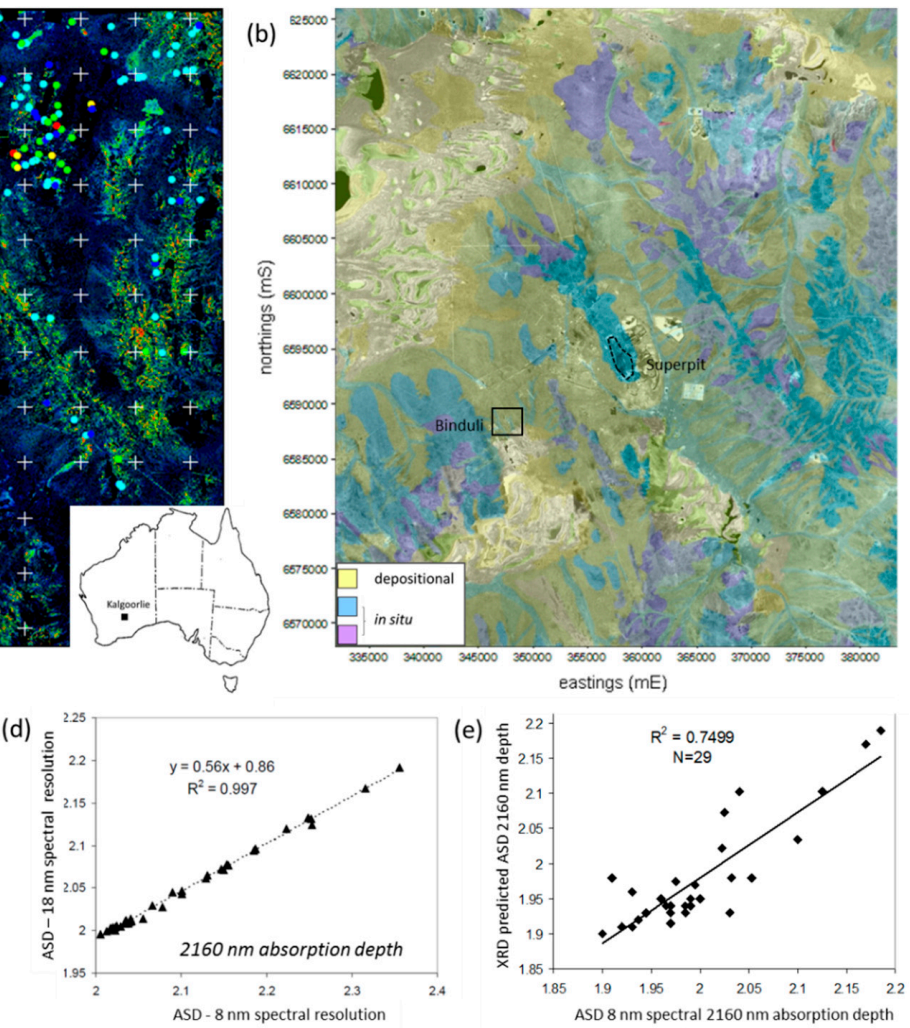

Figure 9. Regolith mineralogy of the Kalgoorlie region, Western Australia, spanning a $2500 \mathrm{~km}^{2}$ area (26 airborne flight-lines @ $5 \mathrm{~m}$ pixel resolution) centered over Kalgoorlie city [100]. (a) Airborne HyMap $^{\mathrm{TM}}$ ( 2005) image of kaolin disorder based on the relative continuum-depths of the $2160 \mathrm{~nm}$ and $2200 \mathrm{~nm}$ absorption (well-ordered kaolin is a warmer color) masked to include only those pixels that show these kaolin features together with similarly processed field sample spectral data (colored dots); (b) Published regolith map showing only depositional (transported) versus in situ units together with the locations of the Superpit (Figure 6) and Binduli (Figure 10); (c) Selected airborne HyMap ${ }^{\mathrm{TM}}$ pixel and the United States Geological Survey (USGS) mineral library spectra of samples rich in kaolin of different disorder (crystallinity); (d) Scatter-gram of ASD spectra of kaolin-rich field samples comparing the depth of the $2160 \mathrm{~nm}$ depth measured at $8 \mathrm{~nm}$ versus at $18 \mathrm{~nm}$ spectral resolution; (e) Field sample data comparing the continuum-depth of the $2160 \mathrm{~nm}$ absorption versus laboratory XRD data processed using Partial Least Squares (PLS) to predict this same spectral feature.

\subsubsection{Mapping Transported Versus In Situ Materials}

Using a regolith spectral-mineral model (Figure 1c), transported materials can in theory be recognized by the development of poorly-ordered kaolin whereas weathered in situ felsic, intermediate and mafic rocks can be recognized by well-ordered kaolin. This change in kaolin disorder was measured spectrally in the SWIR-2 using the relative intensity of the 2160 and 2205 nm kaolin absorptions (see USGS SWIR-2 spectra of halloysite (= poorly-ordered) versus kaolinite (= well-ordered) in Figure 9c) [47]. Even though the narrow widths of these absorptions (FWHH $<20 \mathrm{~nm}$ ) [47] are close to the SWIR-2 spectral resolution of HyMap ${ }^{\mathrm{TM}}$, continuum-removed HyMap pixel spectra (Figure 9c) show variation in the left-handed asymmetry of the $2200 \mathrm{~nm}$ absorption (pink arrow). 
The possibility for HyMap ${ }^{\mathrm{TM}}$ to measure the relative intensity of the $2160 \mathrm{~nm}$ feature was further assessed using field spectra collected with an Analytical Spectral Devices (ASD) Fieldspec Pro of kaolin-rich samples with variable kaolin disorder, which were processed and compared at $\sim 8 \mathrm{~nm}$ versus HyMap's $18 \mathrm{~nm}$ spectral resolutions. The results (Figure 9d) show high correlation as does the depth of the $2160 \mathrm{~nm}$ absorption versus XRD measurement of kaolin disorder (Figure 9e) [47,100]. That is, HyMap data can in theory be used to gauge kaolin disorder.

The use of remote hyperspectral measurement of kaolin disorder for mapping transported versus in situ materials was tested using HyMap ${ }^{\mathrm{TM}}$ for the Kalgoorlie-Kanowna 1:100,000 special map-sheet (Figure 9a). Importantly, the 1:100,000 scale map-sheet of HyMap ${ }^{\mathrm{TM}}$ derived kaolin disorder (Figure 9a) is seamless not showing evidence for flight-line boundaries despite some of the data being collected under less than ideal conditions [100]. The validation of this map involved convolving laboratory ASD spectra measured from 200 field samples to simulate the HyMap ${ }^{\mathrm{TM}}$ band-pass responses before information extraction using the MFEM method. The results (colored dots in Figure 9a) show similar spatial information with the processed airborne HyMap ${ }^{\mathrm{TM}}$ data. Combined, these results show the effectiveness of the MFEM method for rapid, accurate, transferable processing of remote sensing data. The accuracy of the HyMap ${ }^{\mathrm{TM}}$ kaolin product also means that remote hyperspectral SWIR-2 mapping technologies can be used to accurately map transported versus weathered in situ regolith materials over felsic-mafic rocks.

Using Figure 1, poorly-ordered kaolin (cooler colors) should theoretically map transported materials whereas well-ordered kaolin (warmer colors) should map weathered in situ materials. Comparison of this "measured" map versus the published digital regolith map [101], which was generated using standard field mapping and photo interpretation methods and simplified here to show only transported (yellow) versus in situ (blue and mauve) materials (Figure 9b) only, reveals high spatial similarity between the two products.

Note though from Figure 1 that more than just kaolin disorder can be used to help map the regolith. Access to even greater spectral resolution $(<10 \mathrm{~nm}$ in SWIR-2) remote sensing data will enable even more detailed mineral-geological information. For example, mapping the nature of weathered parent rock composition maybe possible through measurement of the $2240 \mathrm{~nm}$ Fe-kaolin feature (Figure 1c), which is not well resolved at HyMap's $18 \mathrm{~nm}$ spectral resolution (Figure 9c).

\subsubsection{Persistence of Primary Minerals through the Regolith}

The possible persistence of fresh rock alteration minerals, such as white mica, upward through the regolith profile to the surface (Figure 1) was tested for an area called Binduli (Figure 9b). This area is located approximately $10 \mathrm{~km}$ west-southwest (WSW) of Kalgoorlie and comprises float/subcrop of felsic volcaniclastic rocks (white polygons, Figure 10), alluvium/colluvium and lacustrine sediments [102]. The published regolith mapping [101] interpreted this area to be "transitional" between deeply weathered pediment to the north and transported materials in the south. Exploration drilling had intersected fresh rock at depths ranging from $>60 \mathrm{~m}$ to $<15 \mathrm{~m}$ below surface (Figure 10a). The bottom-of-hole fresh rock samples were assayed by the exploration company for gold and spectrally measured to capture information regards, for example, white mica $2200 \mathrm{~nm}$ absorption wavelength.

Without the assistance of the company's drill core information, a white mica $2200 \mathrm{~nm}$ absorption wavelength map was generated from the HyMap ${ }^{\mathrm{TM}}$ data (Figure 10b), which was masked to remove those pixels with any kaolin related $2160 \mathrm{~nm}$ absorption, i.e., any mixtures of white mica and kaolin were omitted (black areas). In spite of this heavy first pass masking, the resultant surface white mica image shows close similarity with the bottom of drill hole "fresh rock" spectral data points (colored dots). For example, areas of "transported" cover at localities "A" and "B" (Figure 10) show the same white mica information at the surface as that found $>60 \mathrm{~m}$ below in fresh rock.

This highlights the valuable potential of remote measurement and mapping of spectral-mineralogy and the difficultly in generating an accurate map of regolith cover using subjective interpretation 
of traditional data sets (e.g., visible imagery) and field mapping methods. Thus, explorers using traditional regolith maps are potentially designing inappropriate drilling programs at high cost financially and to the environment when a more accurate mapping of cover could be obtained from remote mineral mapping data (see Rocklea Inlier example in Section 2.12.2).
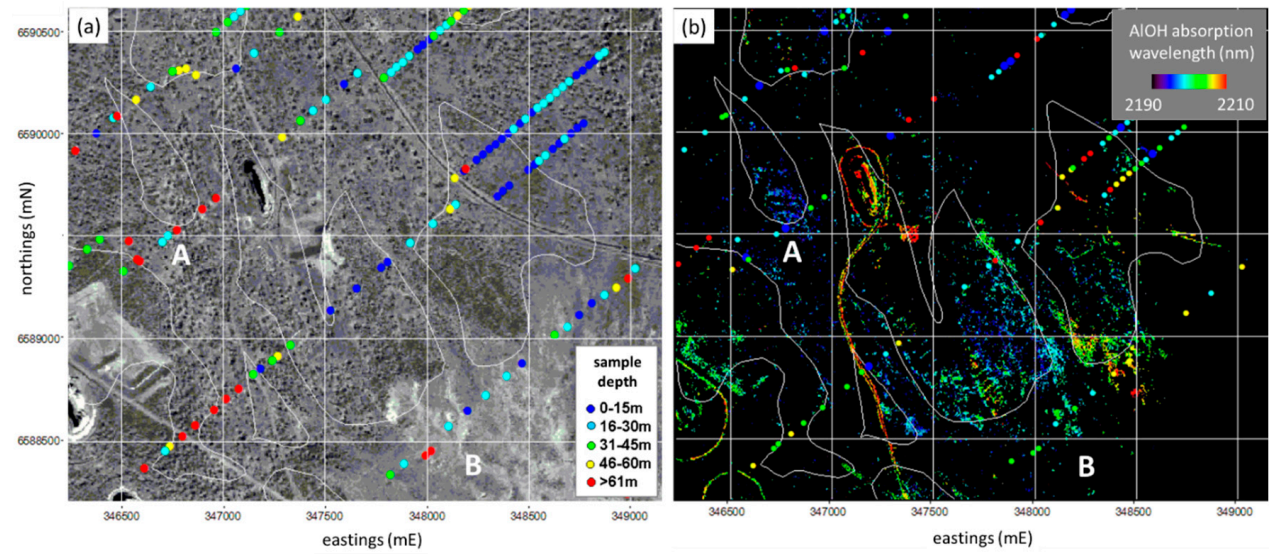

Figure 10. Regolith-alteration maps of the Binduli area, $15 \mathrm{~km}$ WSW of Kalgoorlie, Western Australia (see Figure 9). (a) Airborne HyMap ${ }^{\mathrm{TM}} \mathrm{B} \& W$ visible image together with drill-core locations that are color coded to show "depth to fresh rock" (Figure 1). White polygons show float/subcrop of felsic volcaniclastic rocks [102] -all other areas, except mine workings, are published as alluvium/colluvium and lacustrine sediments; (b) Airborne HyMap ${ }^{\mathrm{TM}}$ image of white mica composition, masked to remove all pixels with detectable $2160 \mathrm{~nm}$ kaolin absorption, together with similarly processed bottom-of-hole fresh rock spectral measurements.

\subsubsection{Scalable White Mica Alteration Patterns through Regolith Cover}

The HyMap ${ }^{\mathrm{TM}}$ survey over 1:100,000 scale Kalgoorlie-Kanowna map-sheet created the opportunity to test whether the apparent persistence of fresh rock white mica spectral-mineral information through the regolith at Binduli (Figure 10) can be extended across the entire 1:1000,000 scale map-sheet (Figure 11a). If so, then how does this pattern relate to the distribution of Archaean gold deposits and our understanding of the architecture and drivers to Archaean Au mineral systems?

The HyMap ${ }^{\mathrm{TM}}$ white mica $2200 \mathrm{~nm}$ absorption wavelength map (Figure 11a), which used a mask to only include those pixels with detectable $2200 \mathrm{~nm}$ absorption (i.e., no kaolin $2160 \mathrm{~nm}$ mask was applied) [100]. This shows two major zones ( $>25 \mathrm{~km}$ wide) which are demarked by an interpreted magenta dotted line Figure 11a). The short-wavelength white mica (low Tschermak substitution) is located in the east-center and is enveloped (accept in the east) by long-wavelength white mica (high Tschermak substitution). At this regional-scale, this pattern of white mica Tschermak substitution cuts across both the underlying fresh rock stratigraphy [102] and regolith units (Figure 9b). That is, it appears to be independent of parent rock type and weathering intensity.

Validation of this regionally crosscutting white mica composition pattern was made using XRD analyses of $\sim 250$ field surface $(<1 \mathrm{~cm})$ samples (color coded dots in Figure 11a) [100]. The XRD enables the mapping of two types of white mica, namely: muscovite-phengite with wider unit cell related to the dominance of $\mathrm{K}$ in the interlayers; and paragonite with a smaller unit cell related to the dominance of $\mathrm{Na}$ in the interlayers. Importantly, paragonite is typically short-wavelength $(<2195 \mathrm{~nm})[69,70,100]$. The XRD paragonite versus muscovite-phengite results are consistent with the HyMap ${ }^{\mathrm{TM}}$ white mica composition mapping, i.e., short-wavelength $2200 \mathrm{~nm}$ absorption (cooler colors) is associated with paragonite \pm muscovite (cyan and blue dots) while muscovite ( \pm phengite) only (red dots) is associated with longer wavelengths (Figure 11a).

This regional pattern of white mica composition cannot be explained by Archaean regional metamorphic pressure-temperature gradients [69] as petrographic studies [103] found that lower 
grades (greenschist facies) are associated with short wavelength white mica while higher grades (biotite facies) are associated with long wavelength white mica. This is contrary to the studies that show that increasing metamorphic grade is related to decreasing white mica Tschermak substitution [69].

Thermodynamic modelling [104] provided a more plausible explanation for the pattern of white mica composition. This found that REDOX/pH can drive changes in white mica composition, with increasing alkaline/oxidized conditions producing muscovite then phengite whereas paragonite is developed in acid/reduced conditions (Figure 11b). The thermodynamic modelling also predicted the development of pyrophyllite in the most acid/reduced conditions (Figure 11b). Even though pyrophyllite had not previously been recorded in the Kalgoorlie area, the HyMap ${ }^{\mathrm{TM}}$ survey data revealed clear pyrophyllite spectral signatures (Figure 11c). These include localities such as A and $B$ in Figure 11c, which were subsequently validated by laboratory spectral and XRD analyses of field samples [100]. As predicted by thermodynamic modelling, this spectrally mapped pyrophyllite is located close to (within) the paragonite-bearing zone (i.e., acid/reduced conditions) and not the muscovite-phengite zone (i.e., alkaline/oxidized conditions).

The implications from these results is that spectrally measured white mica composition can be used as a gauge for REDOX/pH gradients and that remote hyperspectral SWIR-2 data has mapped (for the first time and through cover) very large ( $>25 \mathrm{~km}$ wide, i.e., proportional to the thickness of the crust) hydrothermal cells with contrasting REDOX/pH characteristics. Importantly, gold deposits/camps in the Kalgoorlie region (white dots and includes the Superpit and Kanowna Belle ( $X$ and Y respectively) in Figure 11a) are located at the largest gradients in white mica $2200 \mathrm{~nm}$ wavelength, i.e., the reactive interface between reduced/acid fluids and alkaline/oxidized fluids/rocks [105]. How these cells relate to the 3D crustal architecture of structural-controlled plumbing systems [106] is currently unclear.

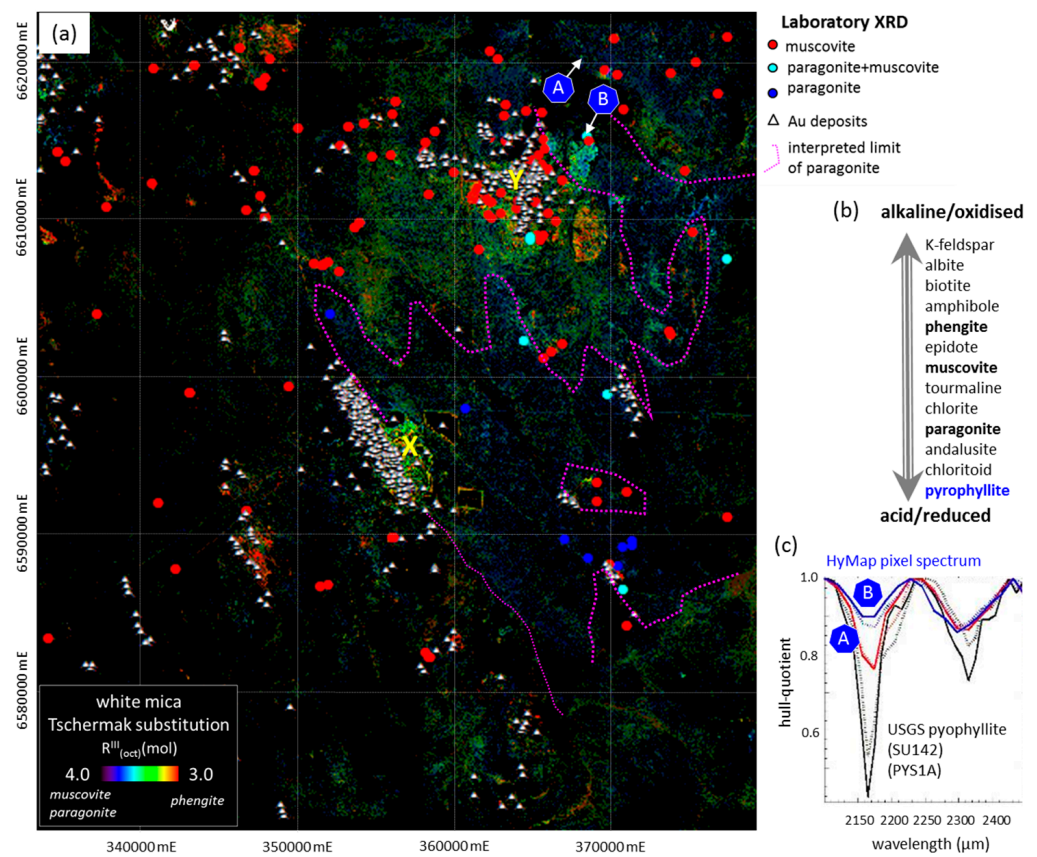

Figure 11. Alteration mineralogy of the Kalgoorlie region, Western Australia, spanning a $50 \times 50 \mathrm{~km}$ area (25 airborne HyMap ${ }^{\mathrm{TM}}$ flight-lines @ $5 \mathrm{~m}$ pixel resolution) centered over Kalgoorlie city. (a) Airborne HyMap ${ }^{\mathrm{TM}}$ ( 2005) derived image of white mica composition based on the wavelength minimum (first derivative of a fitted fourth-order polynomial) of the continuum-removed $2200 \mathrm{~nm}$ absorption between 2120 and $2250 \mathrm{~nm}$ and masked to only include pixels with a detectable $2200 \mathrm{~nm}$ absorption. X marks the Superpit and Y is Kanowna Belle gold mines; (b) Predicted mineral suite with changing $\mathrm{pH}$ and REDOX [104] at greenschist facies. Note prediction paragonite and pyrophyllite in more acid/reduced conditions; (c) Selected HyMap ${ }^{\mathrm{TM}}$ pixel spectra and USGS library spectra showing the diagnostic major absorption feature at $2160 \mathrm{~nm}$ and minor one at $2320 \mathrm{~nm}$ for pyrophyllite. 


\subsubsection{Project Postscript}

The success of the M370 Kalgoorlie mineral mapping project extended beyond regolith and alteration mapping including the mapping of talc-carbonate altered ultramafic units [107] not previously detected using conventional mapping methods, which relied heavily on airborne magnetics (serpentine-magnetite bearing ultramafic rocks) to see through thick regolith cover. The M370 project was also the catalyst for other government geosurveys in Australia to undertake either new public, precompetitive airborne hyperspectral surveys, such as the Geological Survey of Queensland's (GSQ) North Queensland campaigns in 2006-2007 (see Queensland airborne survey in Section 2.10) or for other geosurveys to reprocess their existing regional airborne hyperspectral surveys into similar (standardized) mineral maps, such as the New South Wales Geological Survey (NSWGS) and their 2002 Broken Hill Block HyMap Survey (see Broken Hill survey in Section 2.11).

\subsection{North Queensland Airborne Hyperspectral Mineral Mapping Project}

\subsubsection{Background}

Over 250 flight-lines of HyMap ${ }^{\mathrm{TM}}$ imagery spanning $>25,000 \mathrm{~km}^{2}$ at $4 \mathrm{~m}$ pixel resolution were acquired by HVC for the GSQ during two airborne campaigns in 2006 and 2007. These data were processed by CSIRO using the similar methods developed for the M370 project (Section 2.9) in order to generate comparable suites (standards) of mineral maps [108]. Here we focus on a mineral system analysis $[109,110]$ of the derived mineral maps for the Starra area in the Mount Isa Eastern Succession (Figure 12a) which hosts IOCG style deposits [111]. This mineral system approach examines the spatial and physicochemical relationships between mineralizing fluid source/s, pathway/s and trap/s.

The published geology of the Starra area (Figure 12b) shows two felsic intrusive bodies that could be the source of "oxidized", metal-bearing fluids, namely: the (i) Mount Dore Granite (MDG); and the Gin Creek Granite (GCG). These granites intruded meta-sediments, including graphitic shales which in theory could provide a strong reductant to trigger deposition of metals from oxidized fluids. Recognition of viable a fluid pathway/s that could have transported the oxidized fluids from their source to reduced traps is thus key for exploration targeting.

The published geology (Figure 12b) also shows two major structures, namely: (i) the Starra shear zone (SSZ; dashed line); and (ii) the Mount Dore shear zone (MDSZ; dotted line). Previous company exploration programs focused on the SSZ because of its pronounced magnetic character (Figure 12c) which was considered indicative of a REDOX gradient. The relatively high (compared to the GCG) magnetic and radiometric responses of the MDG (Figure 12c,d respectively) are evidence for it being the source of oxidized metal-bearing fluids. The magnetic data shows a broad high between the MDG and the SSZ (Figure 12c), though there is no comparable signature in the radiometric data (Figure 12d).

The question is whether the mineral mapping data provides more complete characterization and thus understanding of the Starra mineral system. To address this question, only three of the 25 published HyMap ${ }^{\mathrm{TM}}$ mineral maps [108] are considered here, namely: (i) opaque — a product for mapping "reduced" ( carbonaceous) rocks (Figure 12f); (ii) white mica content (Figure 12e)—a product for mapping K-rich hydrothermal pathways; and (iii) white mica composition (Figure 12g)—a product for mapping fluid physicochemical gradients, i.e., vector to mineralization. 

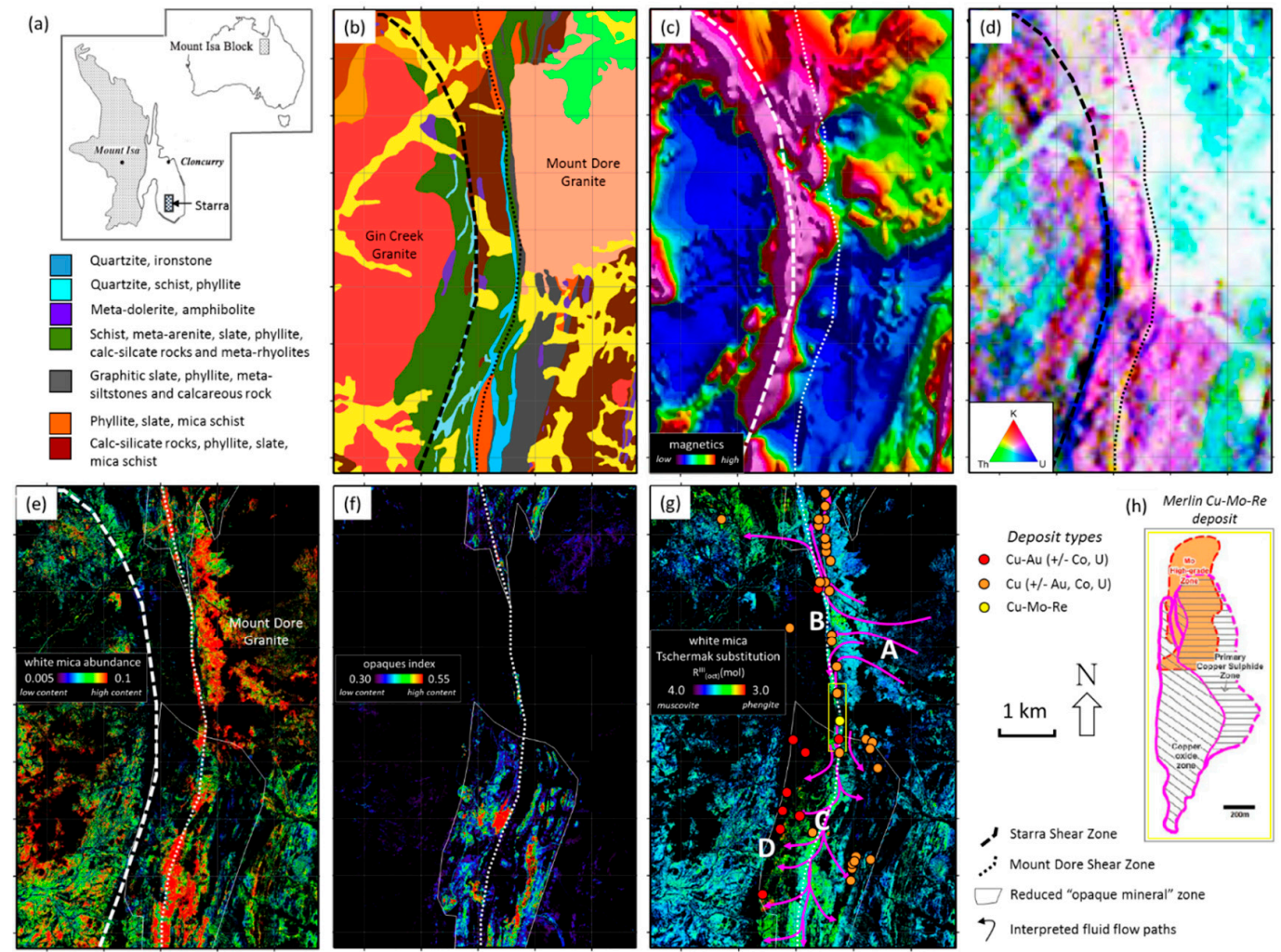

Figure 12. Airborne mineral mapping results for the Starra IOCG Cu-Au-Mo-Re-U mineral system, Mount Isa Bock, Queensland Australia. Approximate scene center -21.6555 latitude $140.4841^{\circ}$ longitude. (a) Location and geological legend; (b) Published geology map [112] including the potential sources of hydrothermal fluids (Gin Creek and Mount Dore granites) and possible fluid pathways (Starra and Mount Dore line Shear Zones, dashed and dotted lines respectively); (c) Published airborne magnetics image [113]. Shear zones are annotated; (d) Published airborne K-Th-U radiometrics image [113]; (e) Airborne HyMap ${ }^{\mathrm{TM}}$ white mica abundance map based on the continuum-depth (fitted fourth-order polynomial) of the $2200 \mathrm{~nm}$ absorption and masked to remove pixels with kaolin and Al-smectite; (f) Airborne HyMap ${ }^{\mathrm{TM}}$ opaque mineral map (includes carbon black) based on the index $R_{450} / R_{1650}$ (where $R_{X}$ is the reflectance of the spectral band at the indicated wavelength in $\mathrm{nm}$ ) and with a mask that includes only those pixels with $1650 \mathrm{~nm}$ reflectance $<30 \%$; (g) Airborne HyMap ${ }^{\mathrm{TM}}$ white mica composition map based on the wavelength of continuum-removed (fitted fourth-order polynomial) $2200 \mathrm{~nm}$ absorption and masked to remove pixels with kaolin (2160 nm feature) and Al-smectite (no $2350 \mathrm{~nm}$ feature). Also shown are the published mineral deposits/occurrences, extent of the reduced zone defined by the opaque product (f), interpreted fluid flow path and the location (yellow rectangle) of the Merlin Co-Mo-Re deposit (h).

\subsubsection{Mineral System Mapping and Analysis}

The HyMap ${ }^{\mathrm{TM}}$ opaque product (Figure 12f) reveals zones of apparent reduced rocks (white line polygon) that cross-cut the published meta-sediments (Figure 12b), with one zone in the north and the other in the south, both of which being intersected by the MDSZ (white dotted line). The white mica abundance product (Figure 12e) shows that the MDG is relatively rich (compared to the GCG) in white mica (warm tones). Within the MDG, this white mica is most abundant/exposed on the western and south-western margins where it then seamlessly traces across into the flanking meta-sediments as well as along the MDSZ (white dotted line). The MDSZ is abundant in white mica along most/all of its north-south length including into the opaque-rich meta-sediments (Figure 12f), where it disperses and decreases outward up to $1.5 \mathrm{~km}$ away on both sides of the MDSZ. In contrast, the SSZ (dashed white line) lacks white mica. The white mica $2200 \mathrm{~nm}$ wavelength product (Figure 12g) shows how 
the white mica evolves from their MDG source to their mineralization trap. Within the MDG (A in Figure 12g), the white mica $2200 \mathrm{~nm}$ wavelength is at its shortest (blue to cyan tones; 2197 nm), i.e., most Al-rich and Si poor. The white mica wavelength becomes progressively longer (greener tones; $2203 \mathrm{~nm}$ ) towards the western edge of the MDG (A to B to C in Figure 12g). A similar level of Tschermak substitution is also apparent in the neighboring MDSZ. This level is then maintained along much of the length MDSZ before increasing at an apparent faster rate as it progresses outward through the reduced metasedimentary rocks before an abrupt termination against short-wavelength white mica in "background" rocks. Note that this highest level of Tschermak substitution (yellow red tones, $2210 \mathrm{~nm}$, e.g., D in Figure 12g) also marks: (i) the margin of the opaque zone; (ii) where white mica content is at its least; and (iii) where many mineral deposits/occurrences are located.

This mineral mapping alteration pattern significantly extends the previous understanding of the alteration zonation. For example, at the western margin of the alteration system where there are a number of $\mathrm{Cu}-\mathrm{Au}$ deposits (red dots in Figure 12g), previous published work [114] recognized a $\sim 400 \mathrm{~m}$ wide zone of biotite and chlorite alteration positioned over the SSZ and flanked by massive stratiform magnetite $(\mathrm{FeO})$ on the western side (silicate alteration minerals do extend $>1 \mathrm{~m}$ beyond this magnetite zone) and stratiform hematite $\left(\mathrm{Fe}_{2} \mathrm{O}_{3}\right)$ on the east side. They also only recognized white mica as a minor silicate alteration phase, which presumably was not recognized as extending beyond the $400 \mathrm{~m}$ wide biotite-chlorite zone. Both of the iron rich zones contribute (at different levels) to the airborne magnetite signature in Figure 12c, with their contrasting mineralogy indicating a REDOX gradient, which is complex when factoring in the location of the fluid path. i.e., SSZ and not the MDSZ as proposed here based on the mineral mapping results. The fact that most of the known $\mathrm{Cu} / \mathrm{Au}$ deposits in the area are located at large gradients defined by the HyMap "TM "surface" mineral maps and not the published geology and airborne magnetics and gamma radiometrics (Figure 12b-g) is strong evidence of the value of remote sensing for improving the characterization and understanding of alteration zonation, mineral systems and thus exploration targeting.

\subsubsection{Project Postscript}

Following the public release of the Queensland HyMap ${ }^{\mathrm{TM}}$ mineral maps in 2008 and the Starra mineral system case history [115], the discovery of Merlin Cu-Mo-Re deposit (Figure 12h) was announced on the Australian Stock Exchange in 2009 [116]. Merlin is located along the white mica-rich MDSZ where it intersects the reduced meta-sediments (yellow dot in Figure 12g). Following the public web-release of the $25 \mathrm{HyMap}^{\mathrm{TM}}$ standard, GIS-compatible mineral products for each of 24 regions across north Queensland, users from around the world ( $>40$ countries) downloaded $>60,000$ maps within the next three months.

\subsection{Broken Hill Airborne Hyperspectral Mineral Mapping Project}

\subsubsection{Background}

The Broken Hill HyMap ${ }^{\mathrm{TM}}$ survey $\left(4000 \mathrm{~km}^{2}\right.$ at $3.5 \mathrm{~m}$ pixel resolution) was collected for the NSWGS in 2002 and then publicly released as radiance@sensor, surface reflectance and a selection of mineral-enhanced (e.g., MNF) products created by HVC. However, by 2008, only two copies of these HyMap ${ }^{\mathrm{TM}}$ survey data were taken up by industry despite geological case histories showing the potential of the dataset [117]. In 2009, CSIRO was contracted by NSWGS to generate the same types of mineral suites released for north Queensland [108] and Kalgoorlie [100]. Here we focus on the white mica and kaolin hyperspectral products for mapping retrograde hydrothermal alteration, which is potentially associated with vein-style base metal mineralization [118].

The Broken Hill Block is characterized by prograde granulite facies metamorphism (Figure 13a) that developed during the 1600 Ma Olarian Orogeny [119] and resulted in extensive dehydration mineral reactions, including for example, the transformation of muscovite (with availability of $\mathrm{H}^{+}$) into sillimanite plus water (Equation (1)). This was followed much later by retrograde, upper 
greenschist to amphibolite facies metamorphism [116] during the Delamerian Orogeny (515 to $500 \mathrm{Ma}$ ). The retrogression alteration was primarily in structurally controlled zones where white mica was often developed [120]. The source of the fluids responsible for this retrograde hydration alteration and mineralization event remains unclear though one theory [120-122] involves the rapid uplift and erosion of the Paleoproterozoic Broken Hill block during the 820-700 Ma breakup of Rodinia [123]. This uplifted block was exposed to near surface meteoric fluids that infiltrated down along fault networks before the whole Block was subsequently (re)buried by a thick (up the $15 \mathrm{~km}$ ) layer of sediments (including the 720-635 Ma Taroowangee Group).

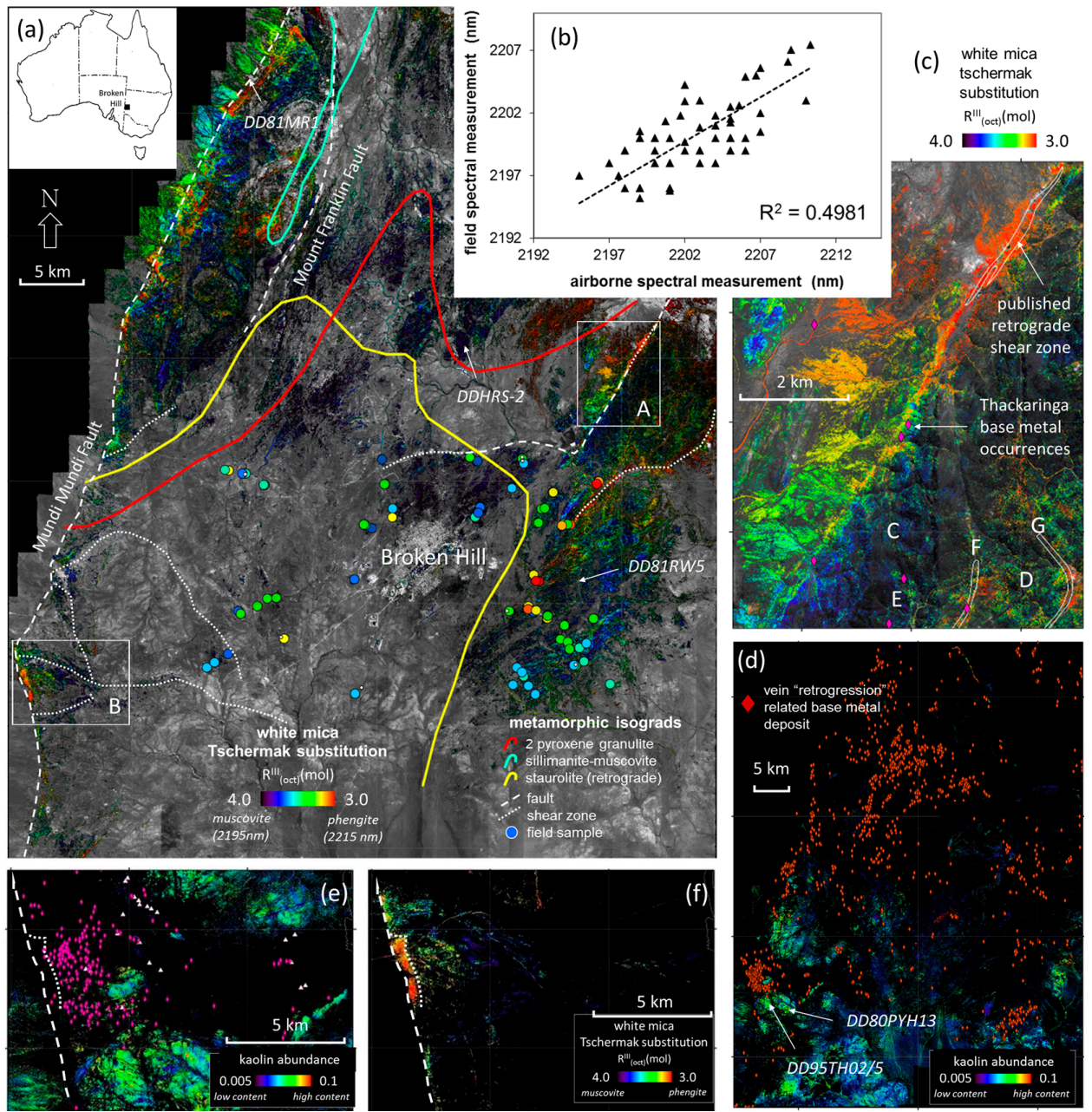

Figure 13. Airborne mineral mapping results for the Broken Hill block, Australia. Approximate scene center $-31.9669^{\circ}$ latitude $141.44134^{\circ}$ longitude. (a) Airborne HyMap white mica composition map based on the wavelength of continuum-removed (fitted fourth-order polynomial) $2200 \mathrm{~nm}$ absorption (masked to remove pixels with kaolin and Al-smectite) together with similarly processed field sample data (dots) and published prograde and retrograde metamorphic isograds and selected faults/shears [126]. A selection of National Virtual Core Library (NVCL) drill core locations referred to in the text are labelled as "DDxx" where $x x$ is diamond drill core number; (b) Scatter-gram of the wavelength of the $2200 \mathrm{~nm}$ absorption measured from field samples (dots in (a) versus their corresponding HyMap pixel spectra; (c) Zoom of the northeast white rectangle shown in (a) which covers a retrograde shear zone; (d) HyMap derived kaolin content product of the Broken Hill block together with location of retrogression-related base metal deposits (brown diamonds) and a selection of NVCL drill core locations referred to in the text; (e) HyMap derived kaolin content of the SW white rectangle in (a) together with retrogression base metal deposits (magenta diamonds); (f) HyMap derived white mica composition of the SW white rectangle in (a). 
One opportunity for remote hyperspectral SWIR sensing is mapping in more detail this retrograde white mica to better characterize the fluid pathways and related physicochemical gradients across the Broken Hill Block, especially as these may be useful for targeting related base metal mineralization.

\subsubsection{Regional-Scale Retrogression Related Alteration and Base Metal Mineralization}

The white mica composition map generated from 40 flight-lines of HyMap ${ }^{\mathrm{TM}}$ data (Figure 13a) was validated using similarly processed field ASD data (color coded dots in Figure 13a and scatter-gram in Figure 13b). This validated product shows that the most intense development of white mica is concentrated on the Paleoproterozoic block margins, especially in the northwest and east (Figure 13a). White mica development largely parallels the staurolite-in isograd (yellow line in Figure 13a) [124] but also appears to be constrained/linked to major north-northeast trending faults/shears, such as the Mundi Mundi and Mount Franklin Faults (Figure 13a). Interestingly, this pattern of white mica (Figure 13a) has an inverse relationship to the distribution of kaolin (Figure 13d), which is especially abundant in the southwest. Spectral measurements of drill-core from across the Broken Hill Block [125] show that kaolin is the dominant dioctahedral silicate mineral throughout the drill holes in the southwest, for example drill-holes DD95TH02 (200 m depth), DH95TH05 (189 m depth) and DD80PYH13 (77.5 m depth) (Figure 13d), whereas, white mica is the dominant mineral (kaolin is typically lacking) elsewhere, for example, DD81RW5 (421.7 m depth), DDHRS-2 (343.6 m depth) and DD81MR (171.7 $\mathrm{m}$ depth) (Figure 13a) [125].

The pervasive, three-dimensional (3D; >300 m depth to surface) development of kaolin in the southwest is theoretically positioned within the highest retrograde temperatures [124], i.e., above the staurolite isograd ( amphibolite facies, $\sim 450{ }^{\circ} \mathrm{C}$ ) [126], which is too high for kaolin to be stable $\left(<350^{\circ} \mathrm{C}\right)$ [127]. If kaolin is a retrograde product, then temperatures had to have cooled sufficiently ( greenschist facies) such that the activities of water and $\mathrm{K}$ (and availability of $\mathrm{H}^{+}$) could instead be key drivers to their apparent antithetic development according to Equation (2).

$$
\begin{aligned}
& 2 \mathrm{KAl}_{2} \mathrm{Si}_{3} \mathrm{AlO}_{10}(\mathrm{OH})_{2}+2 \mathrm{H}^{+} \leftrightarrow 3 \mathrm{Al}_{2} \mathrm{SiO}_{5}+3 \mathrm{SiO}_{2}+2 \mathrm{~K}^{+}+3 \mathrm{H}_{2} \mathrm{O} \\
& \text { (muscovite) (sillimanite) (quartz) } \\
& 2 \mathrm{KAl}_{2} \mathrm{Si}_{3} \mathrm{AlO}_{10}(\mathrm{OH})_{2}+2 \mathrm{H}^{+}+3 \mathrm{H}_{2} \mathrm{O} \leftrightarrow 3 \mathrm{Al}_{2} \mathrm{Si}_{2} \mathrm{O}_{5}(\mathrm{OH})_{4}+2 \mathrm{~K}^{+} \\
& \text {(muscovite) (kaolinite) }
\end{aligned}
$$

However, if kaolin is simply a recent weathering product of an original, earlier-formed, higher temperature plagioclase, which is consistent with the numerous commercial feldspar deposits in this area [124], then temperature (plus $\mathrm{K}, \mathrm{H}_{2} \mathrm{O}$ and $\mathrm{H}^{+}$activities) could be a key driver. Note that plagioclase and muscovite can be used in combination as a geobarometer [128]. At any rate, the spectral mapping of white versus kaolinite/plagioclase appears useful for locating hydrothermal pathways associated with retrograde base mineralization.

\subsubsection{Prospect-Scale Retrograde White Mica Composition}

Two contrasting retrograde faults/shears are examined here in more detail. The first occurs at "shallow" crustal depths within a few kilometers from the base of the overlying Taroowangee Group sediments (A in Figure 13a), where a NNW-SSE linear, "steeply-dipping" fault-shear dislocates five different Paleoproterozoic geological units along a 10-20 km length. The second is located in the southern, "deeper" kaolinite zone (B in Figure 13a) and comprises a broad, east-southeast trending ("flat-lying") shear zone that intersects the "steep" NNE-SWW trending Mundi Mundi Fault to the west (Figure 13a).

Figure 13c shows a major linear, north-northeast trending fault/shear characterized by a concentration of white mica that progressively changes its wavelength from $2210 \mathrm{~nm}$ near the contact with Taroowangee Group sediments ( 2 km to the north) to $2195 \mathrm{~nm}$ in the south-southwest, i.e., decreasing Tschermak substitution (Si content) with ( Delamerian) crustal depth. The wall-rock 
of this area (e.g., C and D, Figure 13c) is characterized by the pervasive development of white mica which typically has a shorter wavelength compared with the closest retrograde shears/faults (e.g., E, F and $\mathrm{G}$ in Figure 13c), which all show topographic low expression.

Importantly, all of the published occurrences of retrogression-related base metal occurrences (magenta diamonds) are located along zones of longer wavelength white mica, some of which have not been interpreted as faults/shears by previous mapping (e.g., E in Figure 13c). These mineral mapping results are interpreted as follows: (i) early white mica formation in near surface crustal wall rocks with little fluid movement/evolution and no association with mineralization; and (ii) later white mica development in zone/shears focusing significant fluids that progressively lost $\mathrm{Si}$ and with associated base metal mineralization (Figure 13d).

Figure $13 \mathrm{f}$ shows a $>5 \mathrm{~km}$ wide, triangular-shaped zone of white mica zone (B in Figure 13a) that cross-cuts kaolin-rich wallrock (Figure 13e) and intersects numerous retrogression base metal occurrences (magenta diamonds). This white mica decreases its level of Tschermak substitution eastward (Figure 13f) away from the Mundi Mundi Fault (dashed white line) which it abuts/intersects to the west and is interpreted as the source (originating pathway) of the mineralizing fluids. In detail, these base metal occurrences are located in a zone of moderate levels of white mica Tschermak substitution (green to yellow) but not within the highest levels as seen within the zone $\sim 1 \mathrm{~km}$ from the Mundi Mundi Fault (white dotted line in Figure 13d,e). This is also consistent with the results shown in Figure $13 \mathrm{c}$ and suggests that base metal precipitation required some change in fluid physicochemistry before metal precipitation, which was also reflected in the level of white mica Tschermak substitution. The precise mechanism for this process is unclear.

\subsubsection{Geological and Exploration Implications}

The pervasive nature, compositional uniformity and relatively low level of Tschermak-substitution of white mica developed in wall rocks in the upper parts of the block only is interpreted to have formed by the downward movement of near-surface waters into underlying rocks during the 820-700 Ma uplift/erosion and possibly into the 720-635 Ma period of Taroowangee Group sedimentation during rift basin formation. This water was relatively poor in Si but rich in alkalis. This was followed by Si-rich water, also from above, that moved along faults/shears that (re)activated during the 515 to 500 Ma Delamerian Orogeny, with some fluids penetrating along these to much greater depths where no early-formed white mica was developed in the wall-rocks. This later Si-rich fluid post-dated the staurolite-in isograd [126] and carried the potentially economic metal budget. The point of precipitation of these metals from solution is linked to a decrease in fluid Si activity.

From these results, the sites/zones of metal deposition can be targeted as follows: (i) eliminating areas where kaolinite (and abundant plagioclase) are develop from the viable search space; (ii) identifying zones of locally higher levels of Tschermak substitution compared to the neighboring wall rocks (if present); and (iii) eliminate areas of highest white mica Tschermak substitution (i.e., Si-rich) and instead focus on gradients associated with moderate levels of white mica Tschermak substitution.

\subsection{Western Australian Centre of Excellence for 3D Mineral Mapping (C3DMM)}

\subsubsection{Background}

C3DMM was a five-year collaborative project supported by State and Federal government agencies, industry and technology service organizations. The aim of C3DMM was to generate spectral-mineral mapping capabilities that deliver a web-accessible, scalable, seamless, digital 3D mineral map of (Western) Australia. This required new methods, including: (i) cross-calibration of drill core, field and remote sensing data [129,130]; (ii) unmixing the contribution of both green and dry vegetation from the target mineral information in remote sensing data [89]; and (iii) rigorous validation aimed at establishing national geoscience information product standards [131]. Here we focus on: previously unpublished aspects of (i) the "prospect-scale" Rocklea Inlier iron ore exploration 
case history from the Hamersley region of Western Australia at hyperspectral ( 18 nm SWIR-2) resolution [132-134]; (ii) the Australian ASTER geoscience map [135] and the challenge of unmixing vegetation cover; and (iii) the Mount Turner Queensland 3D epithermal-porphyry system mapped at multi-spectral ( 40 $\mathrm{nm}$ SWIR-2) resolution.

\subsubsection{Rocklea Inlier Iron Ore-Hyperspectral 3D Mineralogy}

Rocklea Inlier (Figure 14) was the focus of Tertiary channel iron ore deposit (CID) exploration by a company supporting C3DMM. The company however planned to use traditional methods (published geology, geophysics, high resolution visible imagery) to design their exploration drilling program. The exploration area comprised lowlands of Quaternary alluvium and colluvium (white dotted lines in Figure 14a) and exposures of Tertiary pisolitic limonite, i.e., (magenta polygon in Figure 14a), which the company subsequently focused its exploration drilling (vertical sticks in Figure 14a). This drilling also included a zone between two published areas of pisolitic limonite (C and D (Figure 14a) which the company believed was CID covered by Quaternary alluvium/colluvium.
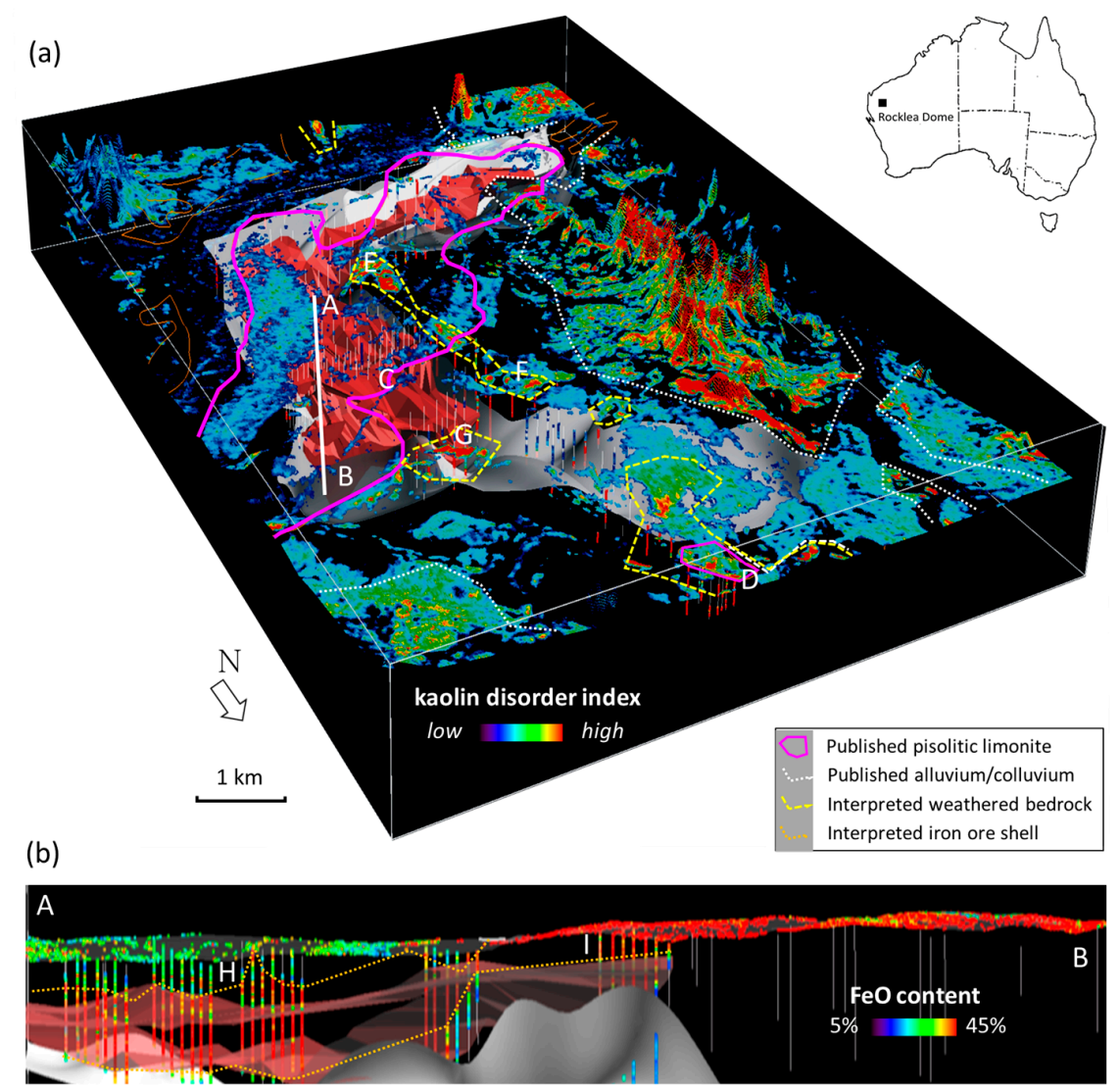

Figure 14. Rocklea Inlier, Pilbara WA three-dimensional (3D) mineral models. Scene center is approximately $-22.8216^{\circ}$ latitude $117.4652^{\circ}$ longitude. (a) A southwest oblique 3D view of the Rocklea study area showing kaolin disorder measured using airborne HyMap ${ }^{\mathrm{TM}}$ (surface) and drill core HyLogger $^{\mathrm{TM}}$ (colored vertical pegs) reflectance data. Warmer colors (well-ordered kaolin) relate to weathered, in situ bedrock, while cooler colors (poorly-ordered kaolin) relate to transported (alluvium/colluvium) materials. The interpolated model of the base of the channel iron system calculated using the 3D kaolin disorder map is shown by the shaded grey surface. The channel iron ore deposit, which was calculated using an estimate of $\% \mathrm{FeO}$ generated from the drill core spectral data [133], is shown by a shaded red volume. A white straight line shows the location of the cross-section (A-B) presented in (b); (b) Cross section A-B in (a) of the \%FeO measured from the drill core and airborne imagery, which was vegetation unmixed [134]. 
One of the aims of C3DMM was to determine if mineral mapping could provide a more efficient (accurate, faster, cheaper, sustainable) tool for designing an exploration drilling program targeting CID in "covered" terrain. Key to this is recognition of weathered in situ Archaean geology persisting through either the Tertiary or Quaternary cover sequences as these would constrain the architecture of any economically viable CID system and which may have been missed by conventional regolith mapping methods. Kaolin disorder (Figure 1) was selected as a key mineral mapping product for this task. Airborne AMS (hyperspectral) imagery was acquired (from the De Beers archive) to deliver this information (ASTER being of insufficient spectral resolution) which was later supplemented by over 100 company drill cores that were spectrally (VNIR-SWIR) scanned using a HyLogger ${ }^{\mathrm{TM}}$. This enabled the generation of a suite of 3D mineral products of the CID and its surrounds. The same MFEM information extraction methods were applied to both the AMS and HyLogger ${ }^{\mathrm{TM}}$ data.

The resultant 3D map of kaolin disorder (Figure 14a) shows well-ordered kaolin (i.e., weathered in situ bedrock) as warmer colors and poorly-ordered kaolin (i.e., transported Tertiary CID or Quaternary alluvium/colluvium) as cooler colors. Note how the red tops to drill core strings near D and E intersect warmer colors in the surface AMS results for areas shown (incorrectly) in the published mapping as being "transported" pisolitic limonite. That is, these areas are weathered in situ basement and not transported Tertiary or Quaternary cover. There are also areas within the published Quaternary alluvium/colluvium cover that the mineral mapping data reveal as being weathered in situ basement, such as F and G (Figure 14a). The regolith pattern that emerges from the kaolin disorder map is a linear chain of previously unmapped weathered basement rocks exposed at the surface (yellow dashed polygons). This basement high would have restricted the development of any Tertiary channel ore development and thus critical in designing an exploration drilling program. Unfortunately, the company's exploration drilling program did not take advantage of these mineral mapping information, such that $\sim 30 \%$ of their drill holes were sunk into weathered basement that was close to/at the surface. Note that the visual appearance of the surface is indistinguishable between these weathered in situ and transported areas [134].

The potential value of the remote sensing mineral mapping data to a company's exploration program can also be extended to quantitative delineation of the deposit, including its ore quality. This requires unmixing complicating surface effects such as green and dry vegetation [89,134]. Figure $14 \mathrm{~b}$ presents a cross-section (A-B, Figure 14a) of the spectrally estimated \%FeO content generated from the drill core and airborne hyperspectral data. This mineral mapping estimate of $\% \mathrm{FeO}$ was generated/validated against geochemical data $[132,133]$. The results show that the shell of iron ore (orange, dotted polygon in Figure 14b) can be extended from under a cover of $\sim 20 \mathrm{~m}$ of alluvium near " $\mathrm{H}$ " to where it is exposed at the surface zone near " $\mathrm{I}$ " where both the remote sensing and drill core spectral results show the same estimates of \% FeO. Other attributes of iron ore quality, such as the amount and composition of clay minerals, can similarly be measured spectrally and modelled in 3D enabling the opportunity for more comprehensive 3D characterization of the ore body. The message being that current 3D modelling of the ore can be improved through use of remote sensing data. This opportunity to seamlessly map target geology in 3D despite variable vegetation and regolith cover is also demonstrated for a porphyry hydrothermal alteration system in Section 2.12.4.

\subsubsection{ASTER Geoscience Maps-Vegetation Cover Challenge}

Fifteen ASTER "Version 1" (V1) geoscience map products of Australia were publicly released in 2012 [135]. A number of these ASTER mineral products appeared to be independent of vegetation cover, for example, "Ferric Oxide Composition" (Figure 15a), which is essentially a measure of the visible color (ASTER bands $B_{2} / B_{1}$ ) with the abundance of "red" hematite being the driver. This vegetation-independence is shown by its apparent high correlation with $>1000$ ASD measurements of the National Geochemical Survey of Australia (NGSA) surface (0-10 cm depth) sample suite [136], which were convolved to ASTER band pass responses in order derive a comparable $\mathrm{B}_{2} / \mathrm{B}_{1}$ product (colored dots in Figure 15a). 

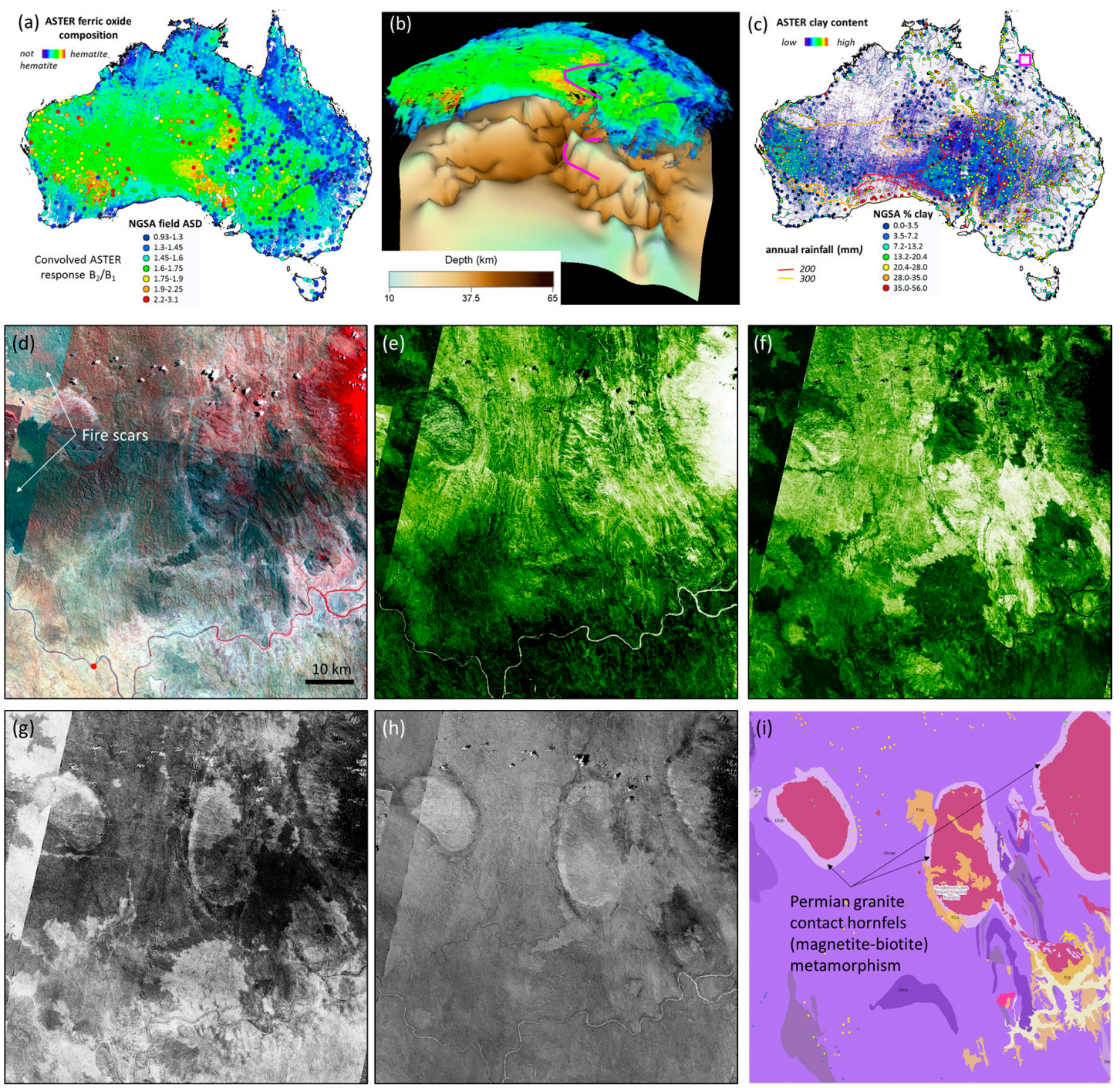

Figure 15. (a) ASTER V1 Ferric Oxide Composition map of Australia [135] with similarly processed field validation ASD measurements of the field NGSA surface samples (0-10 cm depth) [136] (colored dots); (b) Oblique view from south of the Australian ASTER ferric composition and Mohorovičić Discontinuity (MOHO) maps [137]. The edge of a high in the MOHO is marked by a magenta line which mirrors a change in the surface iron oxide information; (c) ASTER V1 Al-clay content map of Australia together with rainfall and field validation NGSA \%clay data; (d) ASTER false color image of the Mt Carbine area, NE Queensland. Scene center is approximately $-16.4104^{\circ}$ latitude $144.6905^{\circ}$ longitude; (e) ASTER green vegetation index $\mathrm{B}_{3} / \mathrm{B}_{2}$; (f) ASTER dry vegetation index; (g) ASTER Al-clay content before vegetation unmixing; (h) ASTER Al-clay content after vegetation unmixing; (i) Published geology, which shows granites rimmed by contact metamorphic hornfels aureoles where minerals such as muscovite were replaced by biotite.

Other ASTER V1 products, such as the clay content (called "AlOH Group content", Figure 15c), are strongly influenced by variable green and dry vegetation cover and thus required heavy masking [135] to leave as residual only the vegetation-free pixels, such as across semiarid regions where annual rainfall is $<300 \mathrm{~mm}$. Because of this heavy masking, outside of these dry areas, the ASTER V1 processing yielded much less geologic information, such as Mt Carbine area in NE Queensland (magenta box in Figure 15c) where $<10 \%$ of the pixels delivered Al-clay information. This lack of mineral information was seen by users as detracting from the value of the ASTER V1 products, even 
though it was recognized that recording "null" information was better than providing "erroneous" information, as follow-up fieldwork is costly.

Theoretically, it is better to unmix rather than mask the effects of variable vegetation cover from the target mineral information as it should deliver many more pixels with more accurate mineral information. For multi-spectral data such as ASTER data, it is relatively easy to unmix the contribution of green vegetation $[138,139]$ given: (i) the availability of diagnostic green vegetation spectral ASTER bands $B_{2}$ (chlorophyll absorption) and $B_{3}$ (photosynthetically-active, near infrared reflectance plateau); and (ii) suitable mixing relationships. For the Mt Carbine area, this $B_{3} / B_{2}$ ratio (Figure 15e) shows close similarity with green vegetation's "redness" in the standard false color product (Figure 15d). Dark areas of recent fire scars, where there is no green (or dry) vegetation, are highlighted. However, dry vegetation, which is a much greater cover problem compared to green vegetation for a dryland environment such as Australia, is not well suited for measurement using a system such as ASTER. ASTER like most Earth imaging satellites, was not specifically designed to measure the diagnostic spectral components of dry vegetation, such as absorptions associated with cellulose $(\sim 2080 \mathrm{~nm})$ and lignin $(\sim 2300 \mathrm{~nm})$. Nevertheless, approximations have been developed including one shown in Figure 15f (developed by the author) which uses a weighted combination of NIR and SWIR ASTER bands and was validated using airborne hyperspectral measurements of the continuum-depth of the cellulose $2080 \mathrm{~nm}$ absorption.

The effects of the variable green and dry vegetation cover on the Mount Carbine ASTER V1 Al-clay content $\left[\left(B_{5}+B_{7}\right) / B_{6}\right]$ without masking are pronounced (Figure $15 \mathrm{~g}$ ) when compared with the corresponding green and dry vegetation products (Figure 15e,f, respectively). However, after unmixing (Figure 15h), the Al-clay content information shows string similarity to the published geological map (Figure 15i), including the definition of granite plutons and their contact metamorphic aureoles. These aureoles mark zones of high temperature where Al clay minerals in the sedimentary wall rocks were converted to biotite, thus causing a low Al-clay content response.

The success of this green and dry vegetation unmixing is the basis for the Version 2 (V2) Australian ASTER geoscience maps. Like the Rocklea Inlier example (Section 2.12.2), it also enables the generation of 3D mineral maps, albeit at ASTER spectral resolution, using similarly processed drill core, field and remote VNIR-SWIR-TIR sensing data (see Section 2.12.4).

\subsubsection{Mount Turner Queensland-3D Multi-Spectral Mineral Products from Hyperspectral Data}

Published mapping [140] identified a porphyry-epithermal alteration system at Mt Turner near Georgetown Queensland with associated phyllic and (advanced) argillic alteration. Both the published airborne HyMap mineral mapping [108] and the ASTER V1 geoscience maps [135] had not shown much useful alteration information because of variable vegetation cover. These spectral data were re-processed in 2016 using vegetation unmixing methods [89]. Here we focus on only an ASTER spectral resolution Al-clay composition product ("AlOH Group Composition"; ASTER B 5 / $B_{7}$ masked by Al-clay content) where lower values (cooler colors) relate to kaolin (= advanced argillic) and higher values (warmer colors) are white mica (= phyllic). The spectral data sets used to generate the resultant 3D product for Mt Turner (Figure 16 include: (i) four NVCL drill-holes (NS1-4-Figure 16a,b) that were sampled from a starting depth of $300 \mathrm{~m}$ below the surface, i.e., base of weathering; and (ii) airborne HyMap $^{\mathrm{TM}}$ which was unmixed for vegetation (Figure 16). 


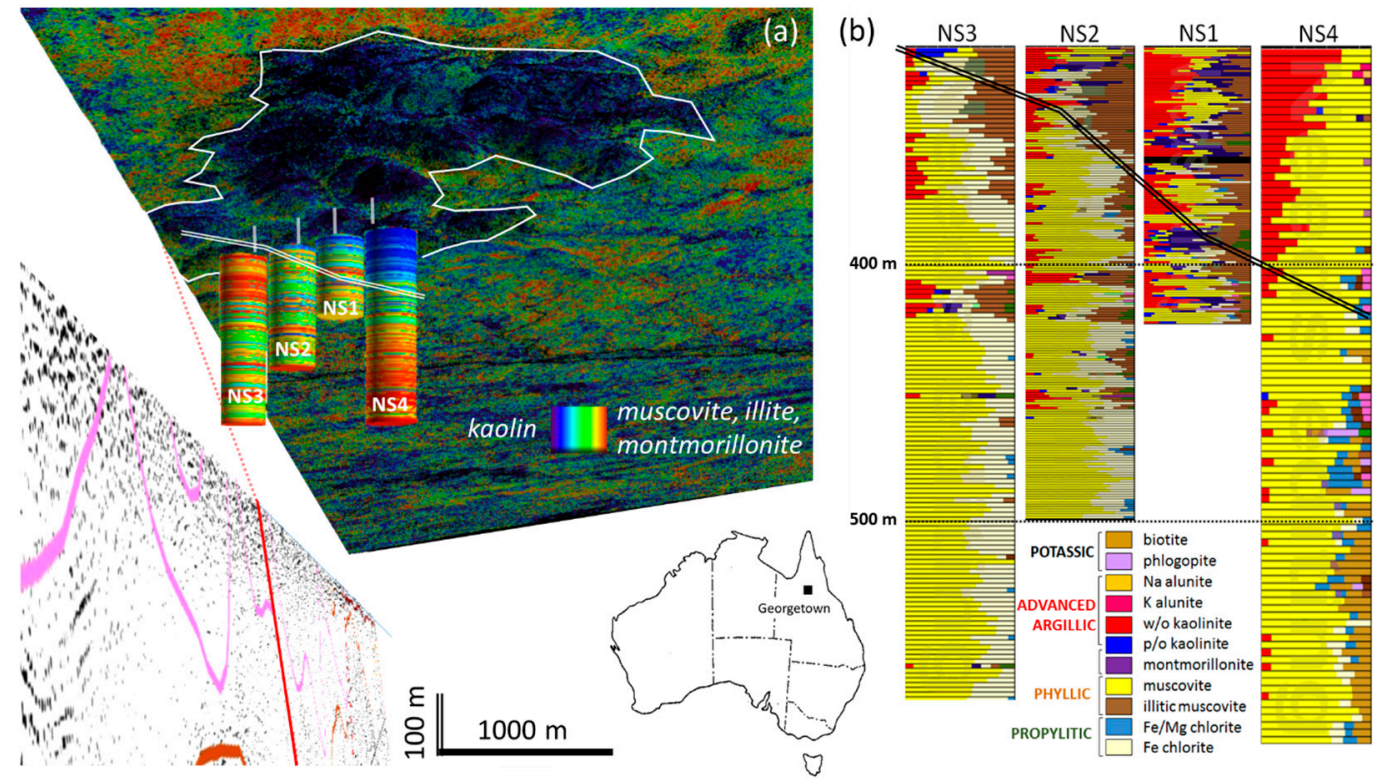

Figure 16. (a) Three-dimensional oblique view (up from the NE) of the Mt Turner porphyry-epithermal system near Georgetown. Area center is approximately $-18.2479^{\circ}$ latitude $143.4473^{\circ}$ longitude. Surface map is airborne HyMap ${ }^{\mathrm{TM}}$ convolved to ASTER bandpass configuration and then processed to generate a vegetation-unmixed Al-clay composition map before draping over a digital elevation model. The similarly color-coded vertical pillars are drill-core HyLogger ${ }^{\mathrm{TM}}$ data which also have been convolved to ASTER bandpass configuration and then processed to generate the same Al-clay composition product. The interpreted boundary between advanced argillic and phyllic alteration zonation is shown on both the HyMap ${ }^{\mathrm{TM}}$ (single line) and HyLogger ${ }^{\mathrm{TM}}$ (double line) results. Also shown is the vertical cross-section of a seismic line with pink lines showing granite contacts and red lines showing major faults; (b) Detailed mineralogy of the four HyLogger ${ }^{\mathrm{TM}}$ drill cores shown in (a) and generated using "The Spectral Assistant" in TSG ${ }^{\mathrm{TM}}$ software. The interpreted boundary between advanced argillic (comprises well-ordered kaolinite \pm alunite) and phyllic (comprises muscovite/illite) alteration is shown by a double black line. Note that the NVCL drill cores start at fresh rock $\sim 300 \mathrm{~m}$ below surface.

The 3D simulated ASTER Al-clay composition drill core and HyMap ${ }^{\mathrm{TM}}$ results (Figure 16a) show a coherent pattern comprising a central, upper (proximal) zone rich in kaolin (advanced argillic alteration) and a distal outer zone relatively rich in which mica (phyllic alteration?). The detailed spectral mineralogy interpreted from the full spectral resolution NVCL/HyLogger ${ }^{\mathrm{TM}}$ drill core data (Figure 16b) shows the alteration zonation. For example, drill core NS4 shows at its upper levels well-ordered kaolinite and alunite which are diagnostic of advanced argillic alteration, together with white mica. This changes down the drill core into dominantly white mica (phyllic alteration). There is also increasing biotite towards the bottom of this drill core, indicating possible potassic alteration. Biotite and alunite are not detected in the other drill-holes. The fact that information about advanced argillic versus phyllic alteration is captured at ASTER spectral resolution despite variable vegetation and regolith cover is significant for exploration (See Discussion, Section 3).

\section{Discussion}

The journey for mineral mapping technologies has come a long way since the launch of ERTS-1 in 1972. There is now an expanding array of both government-science and private-commercial sensors operating on drill-core, field, laboratory, airborne and satellite systems operating worldwide. Global-scale maps of emissivity [141], continental-scale maps of multi-spectral mineralogy [135] and country-scale maps of hyperspectral mineralogy [142] have been generated. Country-scale proximal sensing spectral data are also now being assembled for public field [136] and drill core [125] programs. 
Across Australia, Federal, State and Territory government geoscience organizations now provide as part of their standard suite of digital pre-competitive geoscience data/information [125], spectral-mineral products generated from satellite ASTER and drill core HyLogger ${ }^{\mathrm{TM}}$ data [143]. At the same time, commercial drill core (e.g., Corescan ${ }^{\mathrm{TM}}$ and Terracore ${ }^{\mathrm{TM}}$ ), airborne (e.g., systems from HVC, SpecTIR and ITRES) and space-borne (e.g., DigitalGlobe ${ }^{\mathrm{TM}}$ and its WV-3 sensor) companies are delivering tailored spectral-mineral information services/products to the resources industry [144-147].

During the last 20 years, at least four global resource companies adopted airborne hyperspectral imaging capabilities as a frontline tool in their global exploration programs. This resulted in faster delineation, more comprehensive characterization and thus improved prioritization of targets compared with conventional methods based on photointerpretation of geophysical and visible (e.g., Google Earth ${ }^{\mathrm{TM}}$ ) data [148,149]. Unfortunately, these exploration companies have since ceased using remote hyperspectral sensing largely because of changes in their management structures. Nonetheless, other companies are using field and drill core hyperspectral technologies for their operational requirements in exploration (e.g., epithermal and porphyry exploration in Australia and Chile) and mining (e.g., iron ore characterization in the Pilbara Western Australia).

The key question is whether this evolution of mineral mapping technologies has translated into the discovery of significant new mineral deposits. Examples where remote sensing appears to have provided valuable information to a company's successful targeting leading to a significant new discovery include: Ujina-Collahuasi [30] and Gaby porphyry Cu deposits in Chile; Alturas high sulfidation epithermal Au in Chile; and Hadleigh Castle low sulfidation Au in Australia. Interestingly, these examples used multispectral remote sensing data, such as Landsat TM, ASTER and Geoscan, but not hyperspectral data.

This apparent success of multispectral over hyperspectral remote systems is a testament to the valuable design of sensors such as ASTER and Geoscan to include specific spectral bands sensitive to key alteration types, such as: advanced argillic (alunite, pyrophyllite and/or well/ordered kaolinite which absorb $2165 \mathrm{~nm}$ ), argillic (kaolinite, montmorillonite and/or white mica which absorb 2165 to $2200 \mathrm{~nm}$ ), phyllic (white mica which absorbs $\sim 2200 \mathrm{~nm}$ ), propylitic (chlorite, amphibole carbonate which absorb 2260 to $2330 \mathrm{~nm}$ ) and silicic (quartz/silica which reflects 8300 to $9200 \mathrm{~nm}$ ) alteration. ASTER's ability to map alteration mineral groups, combined with the fact that it is inexpensive (now free) and provides global coverage, has resulted in it becoming the first choice for many exploration companies using SWIR/TIR remote sensing data. This despite ASTER's technical/data limitations (e.g., SWIR cross talk [150]) and the need for the "as-received" Level 1B radiance at sensor or Level 2 reflectance and/or emissivity data to be subsequently processed (potentially incorrectly) by 3rd parties to deliver the geoscience information sought by explorers.

The decision by the commercial satellite company DigitalGlobe to model its WV-3 SWIR-2 bands on ASTER's bands 5-8 is testament to the success of ASTER's design for alteration mapping. WV-3, which has been operating since 2014, opens up new opportunities for exploration especially in more heavily vegetated environments where its small pixel resolution (i.e., $\sim 4 \mathrm{~m}$ ) can more easily map between the trees, including any networks of unsealed tracks/roads.

There are several possible reasons for the relative lack of deposit discoveries using especially remote hyperspectral systems. The first is the limited spatial coverage to date of quality datasets. Currently the choice is between: (i) inexpensive (free) but inferior (low SNR) Hyperion satellite imagery, which was only designed to be a 6 month science-technical demonstrator but was subsequently pressed into longer-term service (now over 15 years) because of the lack of a suitable/expected imaging satellite replacement; or (ii) relatively high cost and logistically risky commercial airborne data (accept for example the $<1 \%$ area of Australia covered by government-funded surveys described in Sections 2.9-2.11).

A second issue is the inherent complexity of hyperspectral data (for both proximal and remote sensors), where successful explorers must translate their exploration targets into diagnostic minerals not measurable at multi-spectral resolution. This is non-trivial which is why CSIRO's research has 
focused much of its effort in this area. This has shown for example, that quality hyperspectral data can deliver unique exploration information such as: (i) white mica Tschermak substitution (wavelength of $2200 \mathrm{~nm}$ absorption) for mapping alteration footprints in Archaean Au and VMS systems; (ii) kaolin crystallinity for mapping transported regolith cover (relative depth of 2160 and $2205 \mathrm{~nm}$ features); (iii) Fe-substitution in kaolin (combination of 2240 and $2205 \mathrm{~nm}$ features) for mapping weathered bedrock composition; and (iv) a combination of Fe-kaolin mixed with white mica (broadening of the $2205 \mathrm{~nm}>18 \mathrm{~nm}$ FWHH) as an indicator for gold related K-altered ferromagnesian host rocks in deeply weathered rocks. Other possibilities not covered in this paper include: rare earth minerals and their many diagnostic sharp absorption features in the VNIR [151]; alunite K-Na composition in epithermal systems [152]; epidote-clinozoisite composition in Archean Au systems [153] and chlorite Mg number in propylitic systems [154]. Framing exploration targets in the context of specific spectral-mineral criteria [155] will drive better selection of sensors/data and processing methods and will reduce the current wholesale use of "free" ASTER data to solve unrealistic needs when hyperspectral data would be more appropriate.

This leads to the issue of floccinaucinihilipilification [156]. From a study of the published processes used in the discovery of 154 gold deposits from around the world from 1995 to 2013 [157] the following conclusions were made: (i) "gold has no direct recognizable geophysical signature but geophysics is used as an indirect tool to model the geology, alteration and weathering", furthermore "geophysical methods, be they magnetic or electrical methods maintain a similar level of interest through programs success"; (ii) "all types of gold deposit (except placers) have significant recognizable alteration" but the geophysical data is used to try and map it; (iii) the low levels of reporting by companies of other more appropriate mineral alteration mapping technologies, e.g., hyperspectral, suggests they are either "under-reported or under-utilised". "If under-reported, then are senior managers and directors who wrote these papers aware of the intellectual effort of their teams?" Alternatively, if "under-used, alteration [and structure] may represent a significant opportunity for the next generation of exploration".

The Starra example (Section 2.10.1) reflects this problem when geophysics and visible information are relied on to map, arguably incorrectly, a mineral system. The solution is integration of the strengths (and recognition of weaknesses) of different sensors/data/methods. Ultimately specific mineral mapping technologies should provide much of the critical mineral (alteration, geology and regolith) information, especially given the ease at which it can collect/deliver spatially comprehensive, detailed survey data for which there is no equal.

The mineral resource industry's perception of value of remote hyperspectral technologies would be ignited by a related discovery of a Tier 1 deposit. Unfortunately, the current status is making this outcome more difficult to achieve given the likelihood that emerging government-funded hyperspectral satellite missions, such as Germany's EnMap and Japans' Hisui are unlikely to provide much, if any access of their hyperspectral satellite data to the global resources sector. This reflects the history of government funded satellite missions not supporting the interests of the minerals community. Even ASTER was not meant to be an operational tool for the global resources industry. Thus, the commercial sector is really the only prospect for delivering operational systems suitable for this sector. There have already been attempts to develop commercial hyperspectral mineral mapping satellites, such as the Australian ARIES in the late 1990s and more recently one by Boeing, though these were unable to garner sufficient funding support. Nevertheless, there remain other live initiatives, including Canada's Northstar which has plans to launch and commercially operate a constellation of $750 \mathrm{~kg}$ hyperspectral imaging satellites from 2020 [158].

A possible threat to these high cost, heavy hyperspectral imaging systems, with their on-board calibration and large data storage, is the emerging generation of low-cost, lightweight CubeSats $(10 \mathrm{~cm}$ cube and a mass of no more than 1.33 kilograms), Nanosats (masses between $1 \mathrm{~kg}$ and $10 \mathrm{~kg}$ ) and microsats (mass between $10 \mathrm{~kg}$ and $500 \mathrm{~kg}$ ). These much smaller and low cost imaging satellites are expected to have fewer spectral bands that target niche geoinformation opportunities [159] and 
have little (if any) on-board image calibration (i.e., reliance on vicarious and/or other forms of cross-calibration) and limited data storage capacity (i.e., continuous data download). Key challenges for generating valuable geoinformation from these small imaging systems will be: (i) reducing the uncalibrated sensor signal into accurate surface compositional information; and (ii) spatially integrating data/information from one sensor with that from other sensors to deliver integrated geoscience information of value to users.

Given that one of the consistent issues in CSIRO's research over the last 30 years has been the importance of high quality data calibration, without which the derived information is reduced to just pretty pictures, then large volumes of uncalibrated, disparate data from these small satellites is a concern. The emerging paradigm of artificial intelligence, such as International Business Machines Corporation's Watson [160], may provide the solutions though these two frontiers have yet to coalesce effectively/operationally for resource applications.

Today there is a plethora of non-standard (not comparable) geoscience information products being generated from the many different sensor types and information service providers. These products all too often lack related documentation of their methods, let alone independent validation assessments. Even though this may help preserve the commercial viability of providers, it arguably has confused the resources community, reduced the size of marketplace and limited the opportunity for building integrated datasets. The solution is setting traceable standards, which to date has been problematic for this community. Ideally, explorers should be able to insert their local field or drill core data into a regional mineral mapping framework that was generated from other public drill core, field airborne and satellite data. This would for example, enable explorers to determine if the alteration recognized in their data extends beyond their exploration leases.

A first-step mineral mapping framework could be based on the global ASTER data archive, which is now free and available as an ortho-rectified radiance@sensor product [161,162]. Any/all other drill core, field, airborne and space-borne VNIR-SWIR-TIR spectral data could thus be convolved into ASTER's 14 spectral bands and then processed and integrated with other similarly processed ASTER mineral products [135]. This vision is currently being pursued by CSIRO and the GSQ for all publicly available spectral data (NVCL, NGSA, HyMap, Hyperion and ASTER) across Queensland. The aim is to generate a suite of consistent (standard), transferrable, public, digital geologically-valuable mineral products that are readily visualized in 3D using off-the-shelf software. To achieve a similar opportunity globally, requires understanding and preserving the interests of different government-science and private-commercial organizations. Such an opportunity can potentially be pursued through the inter-governmental Group on Earth Observation's (GEO), especially its newly established Societal Benefit Area (SBA) on "Minerals and Energy Management" (CA06) [163] or via an industry R\&D broker such as AMIRA.

Given that accurate, seamless 3D mineral mapping is now within reach, then future $R \& D$ could develop opportunities around using the "measured" mineral information to model "hybrid" geological information. For example: (i) transported versus in situ materials based on kaolin physicochemistry (and other diagnostic spectral-mineral indicators) from surface and if available sub-surface hyperspectral data; (ii) lithology cross-cutting alteration zonation/footprints based on, for example, a combination of white mica plus amphibole, chlorite or talc as an indicator for $\mathrm{K}$ and Si metasomatized ferromagnesian rocks; and (iii) a complete mineral system using spectral-mineral indicators sensitive to REDOX (e.g., opaque phases such as graphite) and Si (white mica Tschermak substitution) and K (white mica content) activities. Such hybrid geological models could also be useful in the inversion of geophysical data. For example, a mineral mapping derived hybrid map of transported versus in situ regolith materials could assist in the first-pass inversion of airborne electromagnetic data for modelling depth to bedrock through complex unconsolidated cover [164].

There also remain fundamental questions regards what geologic conditions drive the spectrally measurable physicochemistry of specific minerals. For example, white mica Tschermak substitution has shown apparently conflicting patterns for different mineral deposits at similar pressure-temperature 
conditions [165]. Thermodynamic modelling research is now helping to resolve this complexity [166,167], which may ultimately explain even larger patterns, such as whether the apparent relationship between the thickness of the Australian crust ( depth to MOHO) [137] and the surface (top $100 \mu \mathrm{m}$ ) mineralogy (e.g., Figure 16b) is related to the vertical migration of reduced, alkaline mantle fluids [168,169].

Finally, even though this paper has focused on mineral resource exploration, the spectral sensing technologies examined here have particular relevance to the theme of this special issue, namely "lithological and structural mapping using earth observation technologies" (as well as many other applications, such as mining environment, soils, agricultural fertility, ground and surface water, natural heritage sites, desertification, vegetation communities and ecosystems). That is, our ability to measure and map mineralogy will enable better characterization of lithological and structural architecture as well as provide valuable new insights into any superimposed metasomatic and weathering alteration imprints/processes.

\section{Conclusions}

This paper summarizes results from 30 years of many unpublished CSIRO collaborative industry projects that tested emerging proximal and remote sensing systems for mapping mineral information potentially valuable for mineral exploration. These sensors operated at specific optical wavelengths (within the 400 and 14,000 $\mathrm{nm}$ range), spectral resolutions (multi-spectral to hyperspectral), radiometric resolutions, spatial footprints and/or measurement conditions (platforms, calibration, timing, access, cost) and included: (i) airborne Geoscan Mk II, MIRACO 2 LAS, HyMap ${ }^{\mathrm{TM}}$, SEBASS and TIPS imaging and/or profiling systems, (ii) satellite Hyperion and ASTER imaging satellites; (iii) PIMA field spectrometer; and (iv) HyLogger ${ }^{\mathrm{TM}}$ drill core logger. The mineral exploration challenges tackled by the various CSIRO projects included: (i) characterization of the regolith and transported cover using kaolinite crystallinity and/or degree of Fe-substitution; (ii) persistence of Archaean orogenic gold related white mica alteration through deep lateritic regolith cover at Kalgoorlie, Eastern Goldfields with PIMA-II, HyMap ${ }^{\mathrm{TM}}$ and ASTER; (iii) extent and chemistry of white mica alteration associated with volcanic massive sulfide alteration at Panorama in the Pilbara using HyMap ${ }^{\text {TM }}$, Hyperion and ASTER; (iv) patterns of garnet and feldspar mineral-chemistry related to skarn-porphyry alteration at Yerington, Nevada with SEBASS and TASI-600; (v) mapping the mineral system framework for an iron oxide copper-gold system at Starra, Mount Isa with HyMap ${ }^{\mathrm{TM}}$; (vi) pyroxene compositions associated with platinum-group element mineralization in a differentiated ultramafic intrusive complex at Munni Munni in the Pilbara with TIPS; (vii) prograde garnet and retrograde white mica alteration associated with base metal systems at Broken Hill with MIRACO $\mathrm{CAS}_{2}$ and HyMap ${ }^{\mathrm{TM}}$; and (viii) 3D geometry of iron oxide and clay compositions/contents for the Rocklea Inlier channel iron ore deposit, Hamersley Basin with HyLogger ${ }^{\mathrm{TM}}$ and AMS. These studies show that spectral sensing technologies can deliver specific mineral information of value to explorers, whether it be for more accurate and efficient mapping/characterizing of the regolith or detection of alteration footprints to economic mineralization. The most recent CSIRO projects have demonstrated that it is now possible to generate accurate mineral products that seamlessly mesh across different sensor types (multi-spectral to hyperspectral) and sensor platforms (drill core to satellite) enabling the generation of 3D mineralogy from "fresh rock to space". This has required solutions for example, to sensor data (re) calibration and vegetation unmixing, such that the vision of a global, scalable, web-accessible world of 3D mineralogy is now within reach for the benefit of the exploration community.

Supplementary Materials: The following is available online at http://www.mdpi.com/2076-3263/6/4/52/s1: An evaluation of airborne TASI-600 imagery for mineral mapping of the Yerington skarn-porphyry system, Nevada.

Acknowledgments: This 30-year journey has relied on the support of many people and organizations. These include from: (i) CSIRO-John Creasey, Peter Wilson, Jon Huntington, Andy Green, Andy Gabell, Ian Tapley, Peter Hick, Steve Fraser, Chris Horsfall, Maurice Craig, Peter Mason, Lew Whitbourn, Phil Conner, Dick Phillips, Rob Hewson, Dave Gray, Ravi Anand, Cindy Ong, Mike Caccetta, Andrew Rodger, Erick Ramanaidou, Rui Wang, John Walshe, Keith Scott, Kai Yang, Melissa Quigley, Maarten Haest, Carsten Laukamp, Martin Wells, Mike Verrell, Amanda Cornelius, Rob Woodcock, Ryan Fraser, Peter Warren, Mark Berman, Peter Caccetta, Simon Collings, 
Joanne Chia, Norm Campbell, Jeremy Wallace and many others; (ii) NASA/JPL-Mike Abrams, Anne Kahle and Simon Hook and others; (iii) Geoscience Australia-Matilda Thomas, Patrice De Caritat, Lesley Wyborn, Pauline English and others; (iv) Geological Survey of Western Australia-Marian Skwarnecki, Ian Tyler, Paul Morris, Bob Gozzard, Nadine de Souza Kovacs and others; (v) Geological Survey of South Australia-Alan Mauger and others; (vi) Queensland Geological Survey-Mal Jones, Dave Mason and Vladimir Lisitsin and others; (vii) USGS-Dave Meyer, Chris Doescher, Jim Crowley and others; (viii) CRC-LEME-Dennis Gee; (ix) MERIWA-Pam Smith; (x) AMIRA—Joe Cucuzza and Adele Seymon; (xi) ERSDAC/JSS—Osamu Kashimura, Yuichi Maruyama and others; (xii) Geological Survey of Japan-Yoshiki Ninomiya and others; (xiii) ASTER Science Team-Yasushi Yamaguchi, Larry Rowan, Jack Salisbury, Allan Gillespie and others; (xiv) Hyperion Science Team-David Jupp, Pamela Barry, Jay Pearlman; (xv) Aerospace Corporation-John Hackwell, Dean Riley and others; (xvi) HyVista/ISPL-Terry Cocks, Peter Cocks and others; (xvii) ITRES (Canada)—Stephen Achal; (xviii) SpecTIR-Mark Landers; (xix) World Geoscience (Fugro Airborne Services)—Peter Hausknecht, Pavel Jurza, Guy Roberts and others; (xx) International Training Centre (ITC Netherlands)—Frank van Ruitenbeek, Freek van der Meer and others; (xxi) University of Alberta-Benoit Rivard; (xxii) University of Campinas-Carlos Roberto de Souza Filho and others; (xxiii) Sumitomo Metal Mining-Kazuya Okada, Koji Ueda and others; (xxiv) JOGMEC (Japan) - Taro Yajima and others; (xxv) Anglo American (South Africa)—Michael Sears, Paul Linton, Phil Harris, Neil Pendock, Ronell Carey and others; (xxvi) DeBeers-Mike Hussey, Brian Bennett and others; (xxvii) Anglogold-Andrew Jenkins and others; (xxviii) Geoscan-Frank Honey, Bob Agar and others; (xxix) post graduate students whom I have supervised including Adrian Brown, Louise Luong, Iwan Vitins, Rebecca Smythe, Kombada Mhopjeni, Ivor Kahimise, Fitri Augustine and Julia Novikova; and (xxx) others such as (but not restricted to) Roger Bateman, Scott Halley, Carl Brauhart, Joe Boardman, Fred Kruse, Brigette Martini, Greg Swayze, Phoebe Hauff, Sasha Pontual, Gavin Hunt, Stuart Marsh, Stephen Chevrel, Eyal Ben Dor, Andreas Mueller, Charlie Kauffman, Sabine Chabrillat, Andi Eiseler, Pamela Blake, Saeid Asadzadeh, Florian de Boissieu, Rodrigo dos Reis Salles, Shi Pilong, Fu Bihong, and Chris McCauley Powell. To all of you thanks for making the journey all the more enjoyable and worthwhile. I also thank the three reviewers of the draft manuscript who provided useful comments which I trust have now been addressed.

Conflicts of Interest: The author declares no conflict of interest.

\section{References}

1. Buckingham, W.F.; Sommer, S.E. Mineralogical characterisation of rock surfaces formed by hydrothermal alteration and weathering-Application to Remote Sensing. Econ. Geol. 1983, 78, 664-674. [CrossRef]

2. Huntington, J.F.; Cudahy, T.J.; Yang, K.; Scott, K.M.; Mason, P.; Gray, D.J.; Berman, M.; Bischoff, L.; Reston, M.S.; Mauger, A.J.; et al. Mineral Mapping with Field Spectroscopy for Exploration; AMIRA Project P435-CSIRO Exploration and Mining Report 419R; Commonwealth Scientific and Industrial Research Organisation (CSIRO): Canberra, Australia, 1999. Available online: ftp://ftp.csiro.au/arrc/AMIRA\% 20P435\%20Project\%20Reports/Emr419r\%20Final.pdf (accessed on 13 September 2016).

3. Henry, R.L. The transmission of powdered films in the infrared. J. Opt. Soc. Am. 1948, 38, 775-789. [CrossRef]

4. Launer, P.J. Regularities in the infrared absorption spectra of silicate minerals. Am. Mineral. 1952, 37, 764-784.

5. Hapke, B.W. A theoretical photometric function for the lunar surface. J. Geophys. Res. 1963, 68, 4571-4585. [CrossRef]

6. Lyon, R.J.P.; Burns, E.A. Analysis of rocks and minerals by reflected infrared radiation. Econ. Geol. 1963, 58, 274-284. [CrossRef]

7. Lyon, R.J.P. Analysis of rocks by spectral infrared emission (8 to 25 microns). Econ. Geol. 1965, 60, 715-736. [CrossRef]

8. Conel, J.E. Infrared emissivities of silicates: Experimental results and a cloudy atmosphere model of spectra emission from condensed particulate mediums. J. Geophys. Res. 1969, 74, 1614-1634. [CrossRef]

9. Hunt, G.R.; Vincent, R.K. The behaviour of spectral features in the infrared emission from particulate surfaces of various grain sizes. J. Geophys. Res. 1968, 73, 6039-6046. [CrossRef]

10. Vincent, R.K.; Hunt, G.R. Infrared reflectance from mat surfaces. Appl. Opt. 1968, 7, 53-59. [CrossRef] [PubMed]

11. Hunt, G.R.; Salisbury, J.W.; Lenhoff, C.J. Visible and near-infrared spectra of minerals and rocks. III. Oxides and hydroxides. Mod. Geol. 1971, 2, 195-205.

12. Hunt, G.R.; Salisbury, J.W.; Lenhoff, C.J. Visible and near-infrared spectra of minerals and rocks. VI. Additional silicates. Mod. Geol. 1973, 4, 85-106.

13. Hunt, G.R.; Salisbury, J.W. Visible and near-infrared spectra of minerals and rocks. I. Silicate minerals. Mod. Geol. 1970, 1, 283-300.

14. Hunt, G.R.; Salisbury, J.W. Visible and near infrared spectra of minerals and rocks: III. Silicates. Mod. Geol. 1971, 1, 283-300.

15. Hunt, G.R.; Salisbury, J.W. Visible and near-infrared spectra of minerals and rocks. WI. Sedimentary rocks. Mod. Geol. 1976, 5, 211-217. 
16. Clark, R.N. Spectral properties of mixtures of montmorillonite and dark carbon grains: Implications for remote sensing minerals containing chemically and physically absorbed water. J. Geophys. Res. 1983, 88, 10635-10644. [CrossRef]

17. Clark, R.N. Chapter 1: Spectroscopy of Rocks and Minerals, and Principles of Spectroscopy. In Manual of Remote Sensing; Rencz, A.N., Ed.; John Wiley and Sons: New York, NY, USA, 1999; Volume 3, pp. 3-58.

18. Salisbury, J.W.; Walter, L.S. Thermal infrared $(2.5-13.5 \mu \mathrm{m})$ spectroscopic remote sensing of igneous rock types on particulate planetary surfaces. J. Geophys. Res. 1989, 94, 9192-9202. [CrossRef]

19. Rivard, B.; Arvidson, R.E.; Duncan, I.J.; Sultan, M.; Kaliouby, B.E. Varnish, sediment and rock controls on spectral reflectance of outcrops in arid regions. Geology 1992, 20, 295-298. [CrossRef]

20. Ninomiya, Y. Quantitative estimation of $\mathrm{SiO}_{2}$ content in igneous rocks using thermal infrared spectra with a neural network approach. IEEE Trans. Geosci. Remote Sens. 1995, 33, 684-691. [CrossRef]

21. Rowan, L.C.; Wetlaufer, P.H.; Goetz, A.F.H.; Billingsley, F.C.; Stewart, J.H. Discrimination of Rock Types and Altered Areas in Nevada by Use of ERTS Images; U.S. Geological Survey Professional Paper 883; U.S. Geological Survey: Washington, DC, USA, 1974.

22. Rowan, L.C.; Goetz, A.F.H.; Ashely, R.P. Discrimination of hydrothermally altered rocks in visible and near infrared multispectral images. Geophysics 1977, 42, 522-535. [CrossRef]

23. Goetz, A.F.H.; Rowan, L.C.; Kingston, M.J. Mineral identification from orbit: Initial results from the Shuttle Multispectral Infrared Radiometer. Science 1982, 218, 1020-1024. [CrossRef] [PubMed]

24. Abrams, M.J.; Brown, D.; Lepley, L.; Sadowski, R. Remote sensing for porphyry copper deposits in southern Arizona. Econ. Geol. 1983, 78, 591-604. [CrossRef]

25. Kahle, A.B.; Goetz, A.F.H. Mineralogic information from a new airborne thermal infrared multispectral scanner. Science 1983, 222, 24-27. [CrossRef] [PubMed]

26. Townsend, T.E. Discrimination of iron alteration minerals in visible and near infrared reflectance data. J. Geophys. Res. 1987, 92, 1441-1454. [CrossRef]

27. Drury, S.A. Image Interpretation in Geology; Allen and Unwin: London, UK, 1987.

28. Kruse, F.A. Use of airborne imaging spectrometer data to map minerals associated with hydrothermal altered rocks in the Northern Grapevine Mountains, Nevada and California. Remote Sens. Environ. 1988, 24, 31-51. [CrossRef]

29. Vane, G.; Green, R.O.; Chrien, T.G.; Enmark, H.T.; Hansen, E.G.; Porter, W.M. The airborne visible/infrared imaging spectrometer (AVIRIS). Remote Sens. Environ. 1993, 44, 127-143. [CrossRef]

30. Sabins, F.F. Remote sensing for mineral exploration. Ore Geol. Rev. 1999, 14, 157-183. [CrossRef]

31. Ninomiya, Y.; Fu, B.; Cudahy, T.J. Detecting lithology with Advanced Space-borne Thermal Emission and Reflectance Radiometer (ASTER) multispectral thermal infrared "radiance-at-sensor" data. Remote Sens. Environ. 2005, 99, 127-139. [CrossRef]

32. Hewson, R.D.; Cudahy, T.J. Chapter 13: Issues affecting geological mapping with ASTER data: A case study of the Mount Fitton area, South Australia. In Land Remote Sensing and Global Environmental Change: NASA's Earth Observing System and the Science of ASTER and MODIS; Ramachandran, B., Justice, C., Abrams, M., Eds.; Springer: New York, NY, USA, 2010; pp. 273-300.

33. AMIRA. Available online: http:/ / www.amira.com.au (accessed on 29 September 2016).

34. MRIWA. Available online: http://www.mriwa.wa.gov.au (accessed on 29 September 2016).

35. Auscope. Available online: http://www.auscope.org.au/ncris (accessed on 29 September 2016).

36. Anand, R.R.; Paine, M. Regolith geology of the Yilgarn Craton, Western Australia: implications for exploration. Aust. J. Earth Sci. 2002, 49, 3-162. [CrossRef]

37. UNCOVER. Searching the Deep Earth: A Vision for Exploration Geoscience in Australia. Available online: http://www.uncoverminerals.org.au (accessed on 20 September 2016).

38. Gabell, A.R.; Cudahy, T.J.; Gozzard, J.R.; Hunter, W.M.; Munday, T.J.; Tapley, I.J. Remote sensing for Gold Exploration in Western Australia-Final Report; AMIRA Project P243-Remote Sensing for Gold Exploration Geoscience Restricted Report 329R; Commonwealth Scientific and Industrial Research Organisation (CSIRO): Canberra, Australia, 1992.

39. Green, A.A.; Craig, M.D. Analysis of aircraft spectrometer data with logarithmic residuals. In Proceedings of the Airborne Imaging Spectrometer Data Analysis Workshop, 8-10 April 1985; JPL Publication: Pasadena, CA, USA, 1985; pp. 85-41, 111-119. 
40. Green, A.A.; Berman, M.; Switzer, P.; Craig, M.D. A transformation for ordering multispectral data in terms of image quality with implications for noise removal. IEEE Trans. Geosci. Remote Sens. 1988, 26, 65-74. [CrossRef]

41. Gillespie, A.R.; Kahle, A.B.; Walker, R.E. Color enhancement of highly correlated images. I. Decorrelation and HIS contrast stretch. Remote Sens. Environ. 1986, 20, 209-235. [CrossRef]

42. Cudahy, T.J. Improved Lithological and Structural Mapping Using Landsat Thematic Mapper and NS001 Remotely Sensed Data in the Laverton Region, Western Australia; AMIRA Project P243-Exploration Geoscience Restricted Investigation Report 61R; Commonwealth Scientific and Industrial Research Organisation (CSIRO): Canberra, Australia, 1989.

43. Cudahy, T.J. The Spectral Characteristics over the 0.4 to 2.5 Micrometre Wavelength Region of Rocks and Soils from the Lawlers Area, Western Australia; AMIRA P243 Project-CSIRO Division of Minerals and Geochemistry, Restricted Investigation Report MG61R; Commonwealth Scientific and Industrial Research Organisation (CSIRO): Canberra, Australia, 1988.

44. Cudahy, T.J. A Model for the Development of the Regolith of the Yilgarn Craton Incorporating Selected Spectral Information; CSIRO Exploration Geoscience Restricted Investigation Report 243R; Commonwealth Scientific and Industrial Research Organisation (CSIRO): Canberra, Australia, 1992.

45. Tardy, Y.; Nahon, D. Geochemistry of laterites stability of Al-goethite, Al-hematite and Fe-kaolinite in bauxites and ferricrete: An approach to the mechanism of concretion formation. Am. J. Sci. 1985, 285, 865-903. [CrossRef]

46. Clout, J.M.F.; Cleghorn, J.H.; Eaton, P.C. Geology of the Kalgoorlie Goldfield. In Geology of the Mineral Deposits of Australia and Papua New Guinea; Hughes, F.E., Ed.; Australian Institute of Mining and Metallurgy: Carlton South, Australia, 1990; pp. 411-431.

47. Cudahy, T.J. PIMA-II Spectral Characteristics of Natural Kaolins; CSIRO Exploration and Mining Report 420R; Commonwealth Scientific and Industrial Research Organisation (CSIRO): Canberra, Australia, 1997.

48. Petit, S.; Decarreau, A. Hydrothermal $\left(200{ }^{\circ} \mathrm{C}\right)$ synthesis and crystal chemistry of iron-rich kaolinites. Clay Miner. 1990, 25, 181-196. [CrossRef]

49. Mestdagh, M.M.; Vielvoye, L.; Herbillon, A.J. Iron in kaolinite: II. The relationship between kaolinite crystallinity and iron content. Clay Miner. 1991, 15, 1-12. [CrossRef]

50. Cudahy, T.J.; Gray, D.J.; Phillips, R.N.; Wildman, J. Pilot Spectral Study of the Bronzewing Gold Deposit, Western Australia; CSIRO Exploration and Mining Restricted Investigation Report 124R; Commonwealth Scientific and Industrial Research Organisation (CSIRO): Canberra, Australia, 1995.

51. Honey, F.R.; Daniels, J.L. Rock discrimination and alteration mapping for mineral exploration using the Carr Boyd Geoscan airborne multi-spectral scanner. In Proceedings of the 5th Thematic Conference on Geologic Remote Sensing, ERIM, Reno, NV, USA, 29 September-2 October 1986; pp. 267-278.

52. Lyon, R.J.P.; Honey, F.R. Direct mineral identification (DMI) with Geoscan MKII advanced multi-spectral scanner (AMSS). In Proceedings of the Imaging Spectroscopy of the Terrestrial Environment, Orlando, FL, USA, 16-17 April 1990; Volume 1298, pp. 50-61.

53. Huntington, J.F.; Cudahy, T.J.; Craig, M.D.; Mason, P. Mineral Mapping with Spectrally Processed Geoscan Mk II Scanner Data, Olary District, South Australia; CSIRO/AMIRA Project P382—CSIRO Exploration and Mining Report 45R; Commonwealth Scientific and Industrial Research Organisation (CSIRO): Canberra, Australia, 1994.

54. Cudahy, T.J.; Huntington, J.F.; Boardman, J. Mineral Mapping with Spectrally Processed Geoscan Mk II Scanner Data. Final Report; AMIRA Project P382-CSIRO Exploration and Mining Restricted Investigation Report 170R; Commonwealth Scientific and Industrial Research Organisation (CSIRO): Canberra, Australia, 1995.

55. Yamaguchi, Y.; Kahle, A.B.; Tsu, H.; Kawakami, T.; Pniel, M. Overview of Advanced Space-borne Thermal Emission and Reflection Radiometer (ASTER). IEEE Trans. Geosci. Remote Sens. 1998, 36, 1062-1071. [CrossRef]

56. Whitbourn, L.B.; Phillips, R.N.; James, G.; O'Brien, M.T. An airborne multiline $\mathrm{CO}_{2}$ laser system for remote sensing of minerals. J. Mod. Opt. 1990, 37, 1865-1872. [CrossRef]

57. Cudahy, T.J.; Whitbourn, L.B.; Connor, P.; Mason, P.; Phillips, R.N. Mapping surface mineralogy and scattering behaviour using backscattered reflectance from a hyperspectral mid-infrared airborne $\mathrm{CO}_{2}$ laser system (MIRACO 2 LAS). IEEE Trans. Geosci. Remote Sens. 1999, 37, 2019-2034. [CrossRef]

58. Willis, I.L. Plate 1: Stratigraphic Interpretation (distribution of metamorphic suites) in the Broken Hill Block, Willyama Complex, N.S.W. In Rocks of the Broken Hill Block: Their Classification, Nature, Stratigraphic Distribution and Origin; Stevens, B.P.J., Stroud, W.J., Eds.; Department of Mineral Resources, Geological Survey of New South Wales: Maitland, Australia, 1983; Volume 21, Part 1. 
59. Boardman, J.W. Automatic spectral unmixing of AVIRIS data using convex geometry concepts. In Proceedings of the 4th Annual Airborne Geoscience Workshop, Washington, DC, USA, 25-29 October 1993; p. 11.

60. Solomon, M.; Walshe, J.L.; Eastoe, C.J. Experiments on convection and their relevance to the genesis of massive sulphide deposits. Aust. J. Earth Sci. 1987, 34, 311-323. [CrossRef]

61. Binns, R.A.; Barriga, F.J.A.S.; Miller, D.J. Leg 193 synthesis: anatomy of an active felsic-hosted hydrothermal system, eastern Manus Basin, Papua New Guinea. Proc. ODP Sci. Results 2007, 193, 1-17.

62. Hewson, R.; Hausknecht, P.; Cudahy, T.; Batty, S.; Stamoulis, V.; Mauger, A. Geophysically integrated profiling airborne mineral mapping-Mount Fitton. MESA J. 2001, 23, 16-19.

63. Hausknecht, P.; Cudahy, T.J.; Jurza, P.; Yajima, T. The airborne ARGUS line-profiling system: Integrated hyperspectral VNIR-SWIR-TIR spectrometry with magnetics and radiometrics-Geological case history, Panorama, Pilbara, Western Australia. In Proceedings of the 12th Australasian Remote Sensing and Photogrammetry Conference, Fremantle, Australia, 18-22 October 2004.

64. Hoatson, D.M.; Keays, R.R. Formation of Platiniferous Sulfide Horizons by Crystal Fractionation and Magma Mixing in the Munni Munni Layered Intrusion West Pilbara Block Western Australia. Econ. Geol. 1989, 84, 1775-1804. [CrossRef]

65. Rivard, B. (CSIRO Visiting Scientist from University of Alberta, Edmonton, AB, Canada). Personal communication, 2002.

66. Hausknecht, P. (Fugro Airborne Services, Perth, Australia). Personal communication, 2002.

67. Huntington, J.F.; Whitbourn, L.B.; Laukamp, C.; Schodlock, M.; Yang, K.; Haest, M.; Quigley, M.; Mason, P.; Green, A.A. Probing Australia's Subsurface with New 1, 2 and 3D Hyperspectral Logging Technologies for "Whole-of-Mine-Life" Mineralogical Characterisation; Australian Institute of Geoscientists, Exploration Technologies: Perth, Australia, 2011; pp. 40-47.

68. Cudahy, T.J. Geometry of the Spectral-Mineralogical Alteration Halo at Birthday South, Fimiston Gold Deposit, Western Australia; CSIRO Exploration and Mining Report 421R; Commonwealth Scientific and Industrial Research Organisation (CSIRO): Canberra, Australia, 1997.

69. Duke, E.F. Near infrared spectra of muscovite, Tschermak substitution and metamorphic reaction progress: Implications for remote sensing. Geology 1994, 22, 621-624. [CrossRef]

70. Scott, K.; Yang, K. Spectral Reflectance Studies of White Micas; CSIRO Exploration and Mining Restricted Investigation Report 439R; Commonwealth Scientific and Industrial Research Organisation (CSIRO): Canberra, Australia, 1997.

71. Hussey, M. (De Beers, Perth, Australia). Personal communication, 1998.

72. Bateman, R. (KCGM, Kalgoorlie, Australia). Personal communication, 1998.

73. Cocks, T.; Jenssen, R.; Stewart, A.; Wilson, I.; Shields, T. The HyMap ${ }^{\mathrm{TM}}$ airborne hyperspectral sensor: The system, calibration and performance. In Proceedings of the 1st EARSEL Workshop on Imaging Spectrometry, Zurich, Switzerland, 6-8 October 1998; pp. 37-42.

74. Cudahy, T.J.; Okada, K.; Ueda, K.; Brauhart, C.; Morant, P.; Huston, D.; Cocks, T.; Wilson, J.; Mason, P.; Huntington, J.F. Mapping the Panorama VMS-Style Alteration and Host Rock Mineralogy, Pilbara Block, Using Airborne Hyperspectral VNIR-SWIR Data; MERIWA Report No. 205-CSIRO Exploration and Mining Report 661R; Commonwealth Scientific and Industrial Research Organisation (CSIRO): Canberra, Australia, 1999.

75. Brauhart, C.W.; Groves, D.I.; Morant, P. Regional alteration systems associated with volcanogenic massive sulphide mineralization at Panorama, Pilbara, Western Australia. Econ. Geol. 1998, 93, 292-302. [CrossRef]

76. Huston, D.L.; Kamprad, J.; Brauhart, C. Definition of High Temperature Alteration Zones with PIMA: An Example from the Panorama VHMS District, Central Pilbara Block; AGSO Research Newsletter 30; Australian Geological Survey Organisation (AGSO): Canberra, Australia, 1999.

77. Young, C. Footwall Alteration at the Sulphur Springs Zn-Cu Volcanic-Hosted Massive Sulphide (VMS) Prospect, East Pilbara, Western Australia. Honours Thesis, University of Western Australia, Crawley, Australia, 1997.

78. Laukamp, C.; Caccetta, M.; Chia, J.; Cudahy, T.J.; Gessner, K.; Haest, M.; Liu, Y.C.; Ong, C.; Rodger, A. Uses, abuses and opportunities for hyperspectral technologies and derived geoscience information. In Proceedings of the Geo-Computing 2010, Australian Institute of Geoscientists, Brisbane, Australia, 29 September-1 October 2010; pp. 73-76.

79. Rouse, J.W.; Haas, R.H.; Scheel, J.A.; Deering, D.W. Monitoring Vegetation Systems in the Great Plains with ERTS. In Proceedings of the 3rd Earth Resource Technology Satellite (ERTS) Symposium, Washington, DC, USA, 10-14 December 1973; Volume 1, pp. 48-62. 
80. Drieberg, S.L.; Hagemann, S.G.; Huston, D.L.; Landis, G.; Ryan, C.G.; Van Achterbergh, E.; Vennemann, T. The interplay of evolved seawater and magmatic-hydrothermal fluids in the 3.24 Ga panorama volcanic-hosted massive sulfide hydrothermal system, North Pilbara Craton, Western Australia. Econ. Geol. 2012, 108, 79-110. [CrossRef]

81. Cudahy, T.J.; Hewson, R.D.; Huntington, J.F.; Quigley, M.A.; Barry, P.S. The performance of the satellite-borne Hyperion Hyperspectral VNIR-SWIR imaging system for mineral mapping at Mount Fitton, South Australia. In Proceedings of the IEEE 2001 International Conference on Geoscience and Remote Sensing, Sydney, Australia, 9-13 July 2001.

82. Cudahy, T.J.; Rodger, A.R.; Barry, P.S.; Mason, P.; Quigley, M.A.; Folkman, M.A.; Pearlman, J. Assessment of the stability of the Hyperion SWIR module for hyperspectral mineral mapping using multi-date images from Mount Fitton, Australia. In Proceedings of the IEEE 2002 International Conference on Geoscience and Remote Sensing, Toronto, ON, Canada, 24-28 June 2002.

83. Cudahy, T.J.; Okada, K.; Brauhart, C. Targeting VMS-style Zn mineralisation at Panorama, Australia, using airborne hyperspectral VNIR-SWIR HYMAP ${ }^{\mathrm{TM}}$ data. In Proceedings of the 14th International Conference on Applied Geologic Remote Sensing, Las Vegas, NV, USA, 6-8 November 2000; pp. 395-402.

84. Ruitenbeek, F.J.A.; van Cudahy, T.J.; Hale, M.; van der Meer, F.D. Tracing fluid pathways in fossil hydrothermal systems with near infrared spectroscopy. Geology 2005, 33, 587-600. [CrossRef]

85. Ruitenbeek, F.J.A.; van Debba, P.; van der Meer, F.D.; Cudahy, T.J.; van der Meijde, M.; Hale, M. Mapping white micas and their absorption wavelengths using hyperspectral band ratios. Remote Sens. Environ. 2006, 102, 211-222. [CrossRef]

86. Luong, L.; Cudahy, T.J.; Hausknecht, P. A comparison of HyMap ${ }^{\mathrm{TM}}$ and ARGUS hyperspectral airborne systems, using white mica mineral mapping at the Panorama VMS deposits, Western Australia. In Proceedings of the 12th Australasian Remote Sensing and Photogrammetry Conference, Fremantle, Australia, 18-22 October 2004.

87. Cudahy, T.J.; Barry, P.S. Earth magmatic-seawater hydrothermal alteration revealed through satellite-borne Hyperion imagery at Panorama, Western Australia. In Proceedings of the 2002 IEEE International Conference on Geoscience and Remote Sensing, Toronto, ON, Canada, 24-28 June 2002.

88. Cudahy, T.J.; Quigley, M. Panorama. In Evaluation of the EO-1 Hyperion hyperSpectral Instrument and Its Applications at Australian Validation Sites 2001-2003; Jupp, D.L.B., Datt, B., Eds.; CSIRO Earth Observation Report No. 2004/6; Commonwealth Scientific and Industrial Research Organisation (CSIRO): Canberra, Australia, 2004; pp. 150-160.

89. Rodger, A.R.; Cudahy, T.J. Vegetation Corrected Continuum Depths at $2.20 \mu \mathrm{m}$ : An Approach for Hyperspectral Sensors. Remote Sens. Environ. 2009, 113, 2243-2257. [CrossRef]

90. Hackwell, J.A.; Warren, D.W.; Bongiovi, R.P.; Hansel, S.J.; Hayhurst, T.L.; Mabry, D.J.; Sivjee, M.G.; Skinner, J.W. LWIR/MWIR Imaging Hyperspectral sensor for airborne and ground-based remote sensing. Proc. SPIE 1996, 2819, 102-107.

91. Einaudi, M.T. Petrogenesis of the copper-bearing skarn at the Mason Valley Mine, Yerington district, Nevada. Econ. Geol. 1977, 72, 769-795. [CrossRef]

92. Dilles, J.H.; Einaudi, M.T. Wall-rock alteration and hydrothermal flow paths about the Ann-Mason porphyry copper deposit, Nevada-A 6-km vertical reconstruction. Econ. Geol. 1992, 87, 1963-2001. [CrossRef]

93. Windeler, D.S. Garnet-pyroxene alteration mapping in the Ludwig skarn (Yerington, Nevada) with Geoscan airborne multispectral data. Photogramm. Eng. Remote Sens. 1993, 59, 1277-1286.

94. Windeler, D.S.; Lyon, R.J.P. Discriminating dolomitization of marble in the Ludwig skarn near Yerington, Nevada using high-resolution airborne infrared imagery. Photogramm. Eng. Remote Sens. 1991, 57, 1171-1177.

95. Cudahy, T.J.; Wilson, J.; Hewson, R.D.; Okada, K.; Linton, P.; Harris, P.; Sears, M.; Hackwell, J.A. Mapping variations in plagioclase feldspar mineralogy using airborne hyperspectral VNIR-SWIR-TIR imaging data. In Proceedings of the IEEE 2001 International Conference on Geoscience and Remote Sensing, Sydney, Australia, 9-13 July 2001.

96. Cudahy, T.J.; Okada, K.; Yamato, Y.; Maekawa, M.; Hackwell, J.A.; Huntington, J.F. Mapping Skarn and Porphyry Alteration Mineralogy at Yerington, Nevada, Using Airborne Hyperspectral TIR SEBASS Data; CSIRO Exploration and Mining Report 734R; Commonwealth Scientific and Industrial Research Organisation (CSIRO): Canberra, Australia, 2000. 
97. Cudahy, T.J.; Okada, K.; Yamato, Y.; Huntington, J.F.; Hackwell, J.A. Mapping skarn alteration mineralogy at Yerington, Nevada, using airborne hyperspectral TIR SEBASS imaging data. In Proceedings of the 14th International Conference on Applied Geologic Remote Sensing, Las Vegas, NV, USA, 6-8 November 2000; pp. 70-79.

98. Dilles, J.D.; Einaudi, M.T.; Profett, J.R.; Barton, M.D. Overview of the Yerington Porphyry Copper District: Magmatic to non-magmatic sources of fluids: Their flow paths and alteration effects on rocks and Cu-Mo-Fe-Au ores. Econ. Geol. 2000, 32, 55-66.

99. Cudahy, T.J.; Okada, K.; Megasu, K.; Hewson, R.D. VNIR-SWIR-TIR Spectral-Mineral Characterization and Assessment of Satellite-Borne ASTER and Hyperion Data from the Candelaria, Iron Oxide Cu-Au Deposit, Chile; CSIRO Exploration and Mining Report 1123R; Commonwealth Scientific and Industrial Research Organisation (CSIRO): Canberra, Australia, 2003.

100. Cudahy, T.J.; Caccetta, M.; Cornelius, A.; Hewson, R.D.; Wells, M.; Skwarnecki, M.; Halley, S.; Hausknecht, P.; Mason, P.; Quigley, M. Regolith Geology and Alteration Mineral Maps from New Generation Airborne and Satellite Remote Sensing Technologies and Explanatory Notes for the Kalgoorlie-Kanowna 1:100,000 Scale Map Sheet, Remote Sensing Mineral Maps; MERIWA Report No. 252; Commonwealth Scientific and Industrial Research Organisation (CSIRO): Canberra, Australia, 2005; pp. 1-114.

101. Skwarnecki, M. Regolith-Landform Mapping and Hyperspectral Data for the Kalgoorlie-Kanowna Area; Geological Survey of Western Australia Record 2005/7; Commonwealth Scientific and Industrial Research Organisation (CSIRO): Canberra, Australia, 2005.

102. GeoView. 1:100,000 Scale Geology. Available online: http://warims.dmp.wa.gov.au/GeoView/Viewer.html? Viewer=GeoVIEW (accessed on 6 October 2016).

103. Mikucki, E.J.; Roberts, F.I. Metamorphic Petrography of the Kalgoorlie Region Eastern Goldfields Granite-Greenstone Terrane METPET Database; Geological Survey of Western Australia: Perth, Australiia, 2003.

104. Walshe, J. (CSIRO Mineral Resources, Perth, Australia). Personal communication, 2005.

105. Neumayr, P.; Walshe, J.; Hagemann, S.; Petersen, K.; Roache, A.; Frikken, P.; Horn, L.; Halley, S. Oxidized and reduced mineral assemblages in greenstone belt rocks of the St. Ives gold camp, Western Australia: Vectors to high-grade ore bodies in Archaean gold deposits. Min. Depos. 2008, 43, 363-371. [CrossRef]

106. Blewett, R. Archaean Gold Mineral Systems in the Western Yilgran Craton. AUSGEO News, December 2010. Available online: http:/ /www.ga.gov.au/webtemp/image_cache/GA18909.pdf (accessed on 6 October 2016).

107. Cudahy, T.J.; Hewson, R.D.; Barnes, S.; Groenewald, B. Mapping non-magnetic talc-bearing ultramafic rocks in the Kalgoorlie region using airborne hyperspectral data. In Proceedings of the Australian Earth Science Convention, Melbourne, Australia, 2-8 July 2006.

108. Cudahy, T.J.; Jones, M.; Thomas, M.; Laukamp, C.; Caccetta, M.; Hewson, R.D.; Rodger, A.R.; Verrall, M. Next Generation Mineral Mapping: Queensland Airborne HyMap ${ }^{\mathrm{TM}}$ and Satellite ASTER Surveys 2006-2008; CSIRO Exploration and Mining Open File Report P2007/364; Commonwealth Scientific and Industrial Research Organisation (CSIRO): Canberra, Australia, 2008.

109. Wyborn, L.A.; Heinrich, C.A.; Jacques, A.L. Australian Proterozoic Mineral Systems: Essential ingredients and mappable criteria. In Proceedings of the AUSIMM Annual Conference, Darwin, Australia, 5-9 August 1994. Available online: https://www.researchgate.net/profile/Lai_Wyborn/publication/263884864_Australian_ Proterozoic_mineral_systems_essential_ingredients_and_mappable_criteria/links/54b48ef00cf28ebe92e47fe9. pdf (accessed on 27 September 2016).

110. McCuaig, T.C.; Hronsky, J. The Mineral System Concept: The Key to Exploration Targeting; Special Publication 18; Society of Economic Geologists, Inc.: Littleton, CO, USA, 2014; pp. 153-175.

111. Foster, D.R.W.; Austin, J.R. The 1800-1610 Ma stratigraphic and magmatic history of the Eastern Succession, Mount Isa Inlier, and correlations with adjacent Paleoproterozoic terranes. Precambrian Res. 2008, 163, 7-30. [CrossRef]

112. MinesOnlineMaps, Queensland Government. 1:100,000 Scale Geology. Available online: https://www.business. qld.gov.au/industry/mining/mining-online-services/minesonlinemaps (accessed on 7 October 2016).

113. Geophysical Archive Data Delivery System. Geoscience Australia. Available online: http://www.geoscience.gov.au/ cgi-bin/mapserv?map=/nas/web/ops/prod/apps/mapserver/gadds/wms_map/gadds.map\&mode=browse (accessed on 27 September 2016).

114. Rotherham, J.F. A metasomatic origin for the iron-oxide Au-Cu Starr ore bodies. Eastern Fold Belt, Mount Isa Inlier. Miner. Depos. 1997, 32, 205-218. [CrossRef] 
115. Cudahy, T.J.; Jones, M.; Thomas, M.; Laukamp, C.; Caccetta, M.; Hewson, R.D.; Verrall, M.; Hackett, A.; Rodger, A. Mineral Mapping Queensland: IOCG Mineral System Case History, Starra, Mount Isa Inlier. In Proceedings of the PACRIM Conference, Jupiters Casino, Australia, 24-26 November 2008. Available online: https:/ / www.ausimm.com.au/publications/epublication.aspx?ID=4787 (accessed on 21 September 2016).

116. Ivanhoe Australia's Merlin Project. Australian Stock Exchange Market Release 21 April 2009. Available online: http:/ / www.asx.com.au/asxpdf/20090421/pdf/31h4x7hqwh7v5g.pdf (accessed on 7 October 2016).

117. Taylor, G.R.; Hansford, P.; Stevens, B.P.J.; Robson, D. HyMap ${ }^{\mathrm{TM}}$ of Broken Hill-Imaging spectrometry for rock and mineral abundance mapping. Explor. Geophys. 2005, 36, 397-400. [CrossRef]

118. Barnes, R.G. Types of mineralization in the Broken Hill Block and their relationship to stratigraphy. In A Guide to the Stratigraphy and Mineralization of the Broken Hill Block, New South Wales-Record 20; Stevens, B.P.J., Ed.; Geological Survey of New South Wales: Maitland, Australia, 1980; pp. 33-70.

119. Binns, R.A. Zones of progressive regional metamorphism in the Willyama Complex, Broken Hill district, New South Wales. J. Geol. Soc. Aust. 1964, 11, 283-330. [CrossRef]

120. Fitzherbert, J.A.; Downes, P.M. A concise geological history of the Broken Hill region. Geol. Surv. N. S. W. Q. Notes 2015, 143, 29-43.

121. Raimondo, T.; Clark, C.; Hand, M.; Cliff, J.; Anczkiewicz, R. A. simple mechanism for mid-crustal shear zones to record surface-derived fluid signatures. Geology 2013, 41, 711-714. [CrossRef]

122. Clark, C.; Hand, M.; Faure, K.; Schmidt Mumm, A. Up-temperature flow of surface-derived fluids in mid-crust: The role of pre-orogenic burial of hydrated rocks. J. Metamorph. Petrol. 2006, 24, 367-387. [CrossRef]

123. Li, Z.X.; Bogdanova, S.V.; Collins, A.S.; Davidson, A.; De Waele, B.; Ernst, R.E.; Fitzsimons, I.C.W.; Fuck, R.A.; Gladkochub, D.P.; Jacobs, J.; et al. Assembly, configuration, and Break-up history of Rodinia: A Synthesis. Precambrian Res. 2008, 160, 179-210. [CrossRef]

124. Fitzherbert, J.A.; Downes, P.M.; Colquhoun, G.P.; Blevin, P.L.; Forster, D.B. Broken Hill Special 1:250,000 Metallogenic Map, 1st ed.; Geological Survey of New South Wales: Maitland, Australia, 2015.

125. Australian Geoscience Information Network-Geoscience Portal. Layer: Boreholes/NVCL. Drill Hole ID: DD95TH05. Available online: http:/ / portal.geoscience.gov.au/gmap.html (accessed on 23 September 2016).

126. Fitzherbert, J.A. Refined peak and retrograde metamorphic isograds for Broken Hill and Eurowie blocks, NSW. Geol. Surv. N. S. W. Q. Notes 2015, 143, 1-27.

127. De Segonzac, G.D. The transformation of clay minerals during diagenesis and low grade metamorphism: A review. Sedimentology 1970, 15, 281-346. [CrossRef]

128. Green, N.L.; Usdansky, S.I. Towards a practical plagioclase-muscovite thermometer. Am. Mineral. 1986, 71, 1109-1117.

129. Rodger, A. SODA: A new method of in-scene atmospheric water vapor estimation and post-flight spectral recalibration for hyperspectral sensors-Application to the HyMap sensor at two locations. Remote Sens. Environ. 2010, 115, 536-547. [CrossRef]

130. Caccetta, M.; Collings, S.; Cudahy, T.J. A calibration method for continental scale mapping using ASTER imagery. Remote Sens. Environ. 2012, 139, 306-317. [CrossRef]

131. Cudahy, T.; Caccetta, M.; Thomas, M.; Hewson, R.D.; Abrams, M.; Kato, M.; Kashimura, O.; Ninomiya, Y.; Yamaguchi, Y.; Collings, S.; et al. Satellite-derived mineral mapping and monitoring of weathering, deposition and erosion. Nat. Sci. Rep. 2016, 6, 23702. [CrossRef] [PubMed]

132. Haest, M.; Cudahy, T.; Laukamp, C.; Gregory, S. Quantitative mineralogy from visible to shortwave infrared spectroscopic data-I. Validation of mineral abundance and composition products of the Rocklea Dome channel iron deposit in Western Australia. Econ. Geol. 2012, 107, 209-228. [CrossRef]

133. Haest, M.; Cudahy, T.; Laukamp, C.; Gregory, S. Quantitative mineralogy from visible to shortwave infrared spectroscopic data-II. 3D mineralogical characterisation of the Rocklea Dome channel iron deposit, Western Australia. Econ. Geol. 2012, 107, 229-249. [CrossRef]

134. Haest, M.; Cudahy, T.J.; Rodger, A.; Laukamp, C.; Martens, C.; Caccetta, M. Unmixing vegetation from airborne visible-near to shortwave infrared spectroscopy-based mineral maps over the Rocklea Dome (Western Australia), with a focus on iron rich palaeochannels. Remote Sens. Environ. 2013, 129, 17-31. [CrossRef]

135. Cudahy, T.J. Australian ASTER Geoscience Product Notes; CSIRO Report, EP-30-07-12-44; Commonwealth Scientific and Industrial Research Organisation (CSIRO): Canberra, Australia, 2012. Available online: https:/ / data.csiro.au/dap/landingpage?pid=csiro\%3A6182 (accessed on 28 September 2016). 
136. De Caritat, P.; Cooper, M. National Geochemical Survey of Australia: The Geochemical Atlas of Australia; Geoscience Australia Record 2011/20; Geoscience Australia: Symonston, Australia, 2011. Available online: http://www.ga.gov.au/metadata-gateway/metadata/record/gcat_71973 (accessed on 17 November 2016).

137. Kennett, B.L.N.; Blewett, R.S. Lithospheric framework of Australia. Episodes 2012, 35, 9-22.

138. Smith, M.O.; Ustin, S.L.; Adams, J.B.; Gillespie, G.R. Vegetation in deserts: I. A regional measure of abundance from multispectral images. Remote Sens. Environ. 1990, 31, 1-26. [CrossRef]

139. Guerschman, J.P.; Scarth, P.F.; McVicar, T.R.; Renzullo, L.J.; Malthus, T.J.; Stewart, J.B.; Rickards, J.E.; Trevithick, R. Assessing the effects of site heterogeneity and soil properties when unmixing photosynthetic vegetation, non-photosynthetic vegetation and bare soil fractions from Landsat and MODIS data. Remote Sens. Environ. 2015, 161, 12-26. [CrossRef]

140. Rossiter, A.G. Stream-sediment sampling near two porphyry copper prospects, Georgetown, Queensland. BMR J. Aust. Geol. Geophys. 1979, 4, 163-165.

141. Hulley, G.C.; Hook, S.J.; Abbott, E.; Malakar, N.; Islam, T.; Abrams, M. The ASTER Global Emissivity Dataset (ASTER GED): Mapping Earth's emissivity at 100 meter spatial scale. Geophys. Res. Lett. 2015, 42. [CrossRef]

142. Kokaly, R.F.; King, T.V.V.; Hoefen, T.M.; Dudek, K.B.; Livo, K.E. Surface Materials Map of Afghanistan: Carbonates, Phyllosilicates, Sulfates, Altered Minerals and Other Materials: U.S. Geological Survey Scientific Investigations Map 3152-A, One Sheet, Scale 1:1,100,000. 2011. Available online: http://pubs.usgs.gov/ sim/3152/A/ (accessed on 9 October 2016).

143. Auscope National Virtual Core Library (NVCL). Available online: http://www.auscope.org.au/nvcl/ (accessed on 9 October 2016).

144. Robert, F.; Brommecker, R.; Bourne, B.T.; Dobak, P.J.; McEwan, C.J.; Rowe, R.R.; Zhou, X. Models and exploration methods for major gold deposit types. In Proceedings of the Exploration 07: Fifth Decennial International Conference on Mineral Exploration, Toronto, ON, Canada, 9-12 September 2007; pp. 691-711. Available online: https://www.911metallurgist.com/blog/wp-content/uploads/2015/10/Models-andExploration-Methods-for-Major-Gold-Deposit-Type.pdf (accessed on 8 November 2016).

145. Holliday, J.R.; Cook, D.R. Advances in geological models and exploration methods for copper \pm gold porphyry deposits. In Proceedings of the Exploration 07: Fifth Decennial International Conference on Mineral Exploration, Toronto, ON, Canada, 9-12 September 2007; pp. 791-809. Available online: https://www.911metallurgist.com/blog/wp-content/uploads/2015/10/Advances-in-Geological-Modelsand-Exploration-Methods-for-Copper-Gold-Porphyry-Deposits.pdf(accessedon8November2016).

146. Harris, A.C.; Carey, R.; Holliday, J.R.; MacCorquodale, F. High-resolution VNIR-SWIR core logging: A revolutionary new tool for exploration, mining and research. In Proceedings of the Society of Exploration Geology (SEG) 2015 Conference, Hobart, Australia, 27-30 September 2015. Available online: https://www.segweb.org/SEG/_Events/Conference_Website_Archives/2015/Conference_Proceedings / files/topics /..\%5Cpdf\%5COral-Presentations\%5CAbstracts\%5CHarris.pdf (accessed on 8 November 2016).

147. Halley, S.; Dilles, J.H.; Tosdal, R.M. Footprints: Hydrothermal alteration and geochemical dispersion around porphyry copper deposits. SEG Newslett. 2015, 100, 1-29.

148. Gingerich, J.; Peshko, M.; Ross, D. Enhancing the effectiveness and success rate of exploration. In Proceedings of the AMIRA 4th Biennial Exploration Managers' Conference “Globalisation of Exploration R\&D”, Melbourne, Australia, 27 March 2001.

149. Hussey, M. (De Beers, Perth, Australia). Personal communication, 2008.

150. Iwasaki, A.; Oyama, E. Correction of stray light and filter scratch blurring for ASTER imagery. IEEE Trans. Geosci. Remote. Sens. 2005, 43, 2763-2768. [CrossRef]

151. Rowan, L.C.; Mars, J.C. Lithological mapping in the Mountain Pass, California area using Advanced Spaceborne Thermal Emission and Reflectance Radiometer (ASTER) data. Remote Sens. Environ. 2003, 84, 350-366. [CrossRef]

152. Hauff, P. An Overview of VIS-NIR-SWIR Field Spectroscopy as Applied to Precious Metals Exploration; Spectral International Inc.: Arvada, CO, USA. Available online: http://www.spectral-international.com/files/ 50329239.pdf (accessed on 8 November 2016).

153. Roache, T.J.; Walshe, J.L.; Huntngton, J.F.; Quigley, M.A.; Yang, K.; Bil, B.W.; Blake, K.L.; Hyvärinen, T. Epidote-clinozoisite as a hyperspectral toll in exploration for Archaea gold. Aust. J. Earth Sci. 2011, 58, 813-822. [CrossRef] 
154. Wilkinson, J.J.; Chang, Z.; Cooke, D.R.; Baker, M.J.; Wilkinson, C.C.; Inglis, S.; Chen, H.; Gemmell, J.B. The chlorite proximitor: A new tool for detecting porphyry ore deposits. J. Geochem. Explor. 2015, 152, 10-26. [CrossRef]

155. Guides for Mineral Exploration (GMEX). AusSpec International. Available online: http://www.ausspec. com/GMEX.htm (accessed on 8 November 2016).

156. Vearncombe, J. Value in Exploration: A Geologists' Perspective on (Gold) Data, Perceptions and Messages; Australian Institute of Mining and Metallurgy and Australian Institute of Geoscientists: Perth, Australia, 2013. Available online: https://www.aig.org.au/wp-content/uploads/2013/05/Vearncombe-AusIMM_ AIG-talk.pdf (accessed on 11 November 2016).

157. Brown, L.; Vearncombe, J.R. Critical analysis of successful gold exploration methods. Appl. Earth Sci. Trans. Inst. Min. Miner. Metall. B 2014, 123, 18-24. [CrossRef]

158. Werner, D. Hyperspectral Harbingers. Space Daily News. 15 August 2016. Available online: https://www. spacenewsmag.com/feature/hyperspectral-harbingers/ (accessed on 10 November 2016).

159. Mandi, D.; Huemmerich, K.; Crum, G.; Ly, V.; Handy, M.; Ong, L. Hyperspectral Cubesat Constalletion for Rapid Natural Hazard Response. Available online: https://ntrs.nasa.gov/archive/nasa/casi.ntrs.nasa.gov/ 20150023589.pdf (accessed on 10 November 2016).

160. IBM Watson. Available online: http://www.ibm.com/watson/ (accessed on 12 November 2016).

161. ASTER Level 1 Precision Terrain Corrected Registered At-Sensor Radiance Download. Land Processes Distributed Active Archive Centre (LPDAAC). Available online: https://lpdaac.usgs.gov/dataset_ discovery/aster/aster_products_table/ast_11t (accessed on 12 November 2016).

162. ASTER Data Download, METI AIST Data Archive System (MASDAS). Available online: https://gbank.gsj. $\mathrm{jp} / \mathrm{madas} / \mathrm{map} /$ (accessed on 12 November 2016).

163. Group on Earth Observations (GEO) Strategic Plan 2016-2025: Community Activity CA-06: EO Data and Mineral Resources. Available online: http:/ / www.earthobservations.org/activity.php?id=6 (accessed on 9 October 2016).

164. Wilford, J.R. New Regolith Mapping Approaches for Old Australian Landscapes. Ph.D. Thesis, The University of Adelaide, Adelaide, Australia, 2013. Available online: https:/ /digital.library.adelaide.edu.au/dspace/ bitstream/2440/85930/9/01front.pdf (accessed on 12 November 2016).

165. Herrmann, W.; Blake, M.; Doyle, M.; Huston, D.; Kamprad, J. Application of PIMA and FTIR spectrometry to VHMS alteration studies. In AMIRA P439 Project Final Report, Studies of VHMS-Related Alteration: Geochemical and Mineralogical Vectors to Ore; University of Tasmania: Hobart, Australia, 1998; pp. 13-88. Available online: http://www.codes.utas.edu.au/reports/AMIRA_Reports/P439/P439_06_Vol_3_May_1998.pdf (accessed on 12 November 2016).

166. Wang, R.; Cudahy, T.J.; Laukamp, C.; Walshe, J.L.; Bath, A.; Mei, Y.; Young, C.; Roache, T.J.; Jenkins, A.; Roberts, M.; et al. White mica as a hyperspectral tool in exploration for Sunrise Dam and Kanowna Belle gold deposits, Western Australia. Econ. Geol. 2016, in press.

167. Abweny, M.S.; van Ruitenbeek, F.J.A.; de Smeth, J.B.; Woldai, T.; van der Meer, F.D.; Cudahy, T.; Zegers, T.; Blom, J.K.; Thuss, B. Short-wavelength infrared (SWIR) spectroscopy of low-grade metamorphic volcanic rocks of the Pilbara Craton. J. Afr. Earth Sci. 2016, 117, 124-134. [CrossRef]

168. Wickam, S.M.; Janardhan, A.S.; Stern, R.J. Regional carbonate alteration of the crust by mantle-derived magmatic fluids, Tamil Nadu, South India. J. Geol. 1994, 102, 379-398. [CrossRef]

169. Frezzotti, M.; Touret, J.L.R. $\mathrm{CO}_{2}$, carbonate-rich melt, and brines in the mantle. Geosci. Front. 2014, 5, 697-710. [CrossRef]

(C) 2016 by the author; licensee MDPI, Basel, Switzerland. This article is an open access article distributed under the terms and conditions of the Creative Commons Attribution (CC-BY) license (http://creativecommons.org/licenses/by/4.0/). 